\title{
Honeywell
}

\section{MESERAN Test Results for Elimination of Flammable Solvents in Wipe Applications at Pantex}

Federal Manufacturing \& Technologies

M. G. Benkovich

Department 833

KCP-613-7015

Distributed March 2005

Final Report on W7609000

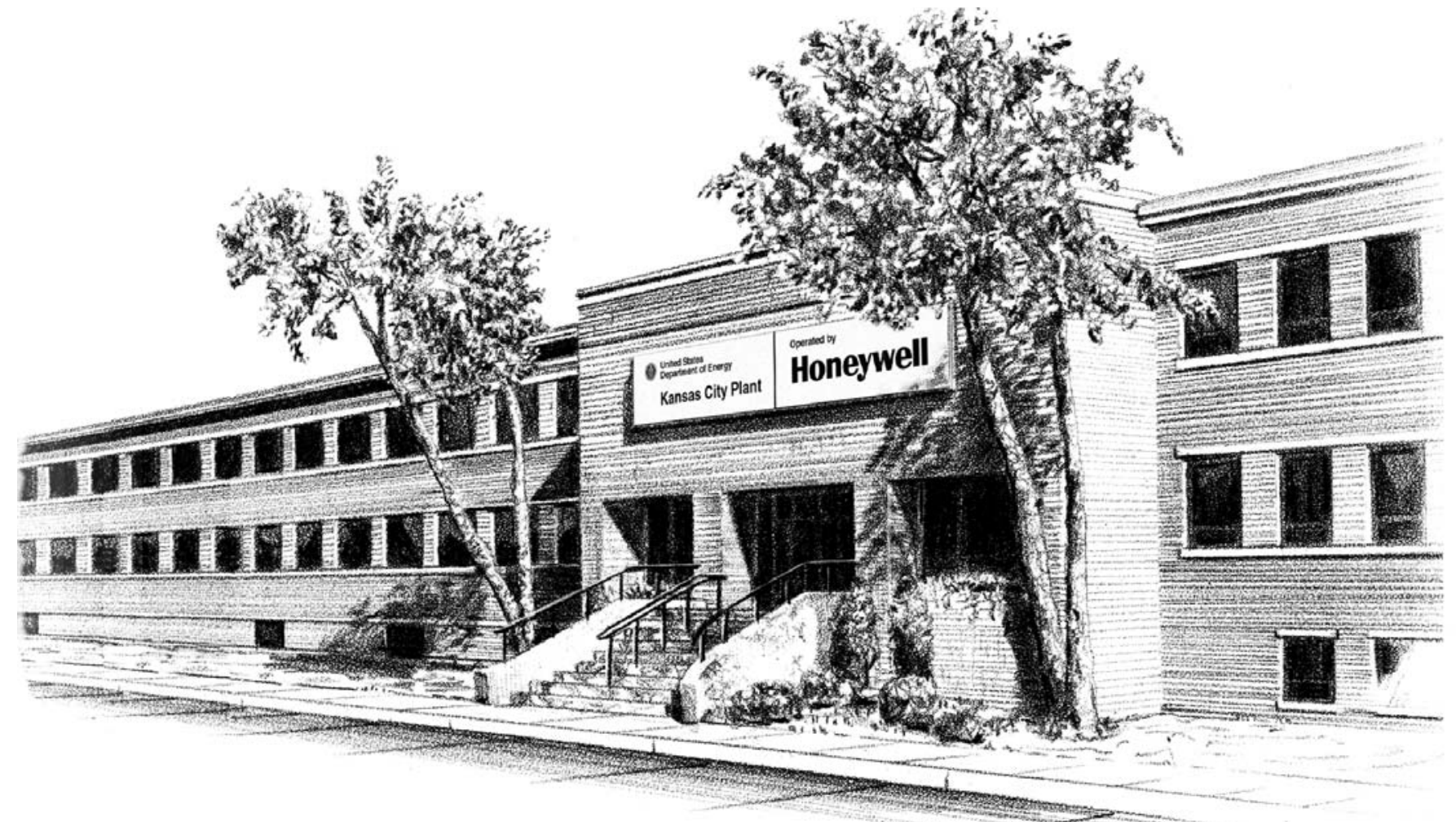




\section{DISCLAIMER}

This report was prepared as an account of work sponsored by an agency of the United States Government. Neither the United States Government nor any agency thereof, nor any of their employees, makes any warranty, express or implied, or assumes any legal liability or responsibility for the accuracy, completeness, or usefulness of any information, apparatus, product, or process disclosed, or represents that its use would not infringe privately owned rights. Reference herein to any specific commercial product, process or service by trade names, trademark, manufacturer, or otherwise, does not necessarily constitute or imply its endorsement, recommendation or favoring by the United States Government or any agency thereof. The views and opinions of authors expressed herein do not necessarily state or reflect those of the United States Government or any agency thereof.

All data prepared, analyzed and presented has been developed in a specific context of work and was prepared for internal evaluation and use pursuant to that work authorized under the reference contract. Reference herein to any specific commercial product, process or service by trade name, trademark, manufacturer, or otherwise, does not necessarily constitute or imply its endorsement, recommendation or favoring by the United States Government, any agency thereof or Honeywell Federal Manufacturing \& Technologies, LLC.

Printed in the United States of America.

This report has been reproduced from the best available copy.

Available to DOE and DOE contractors from the Office of Scientific and Technical Information, P.O. Box 62, Oak Ridge, Tennessee 37831; prices available from (865) 576-8401, FTS 626-8401.

Available to the public from the National Technical Information Service, U.S. Department of Commerce, 5285 Port Royal, Rd., Springfield, Virginia 22161, (703) 487-4650.

A prime contractor with the United States Department of Energy under Contract Number DE-AC04-O1AL66850

\author{
Honeywell Federal Manufacturing \& Technologies \\ P.O. Box 419159 \\ Kansas City, Missouri, 64141-6159
}




\title{
Honeywell
}

KCP-613-7015

Distribution Category UC-42

Approved for public release; distribution is unlimited.

\section{MESERAN TEST RESULTS FOR ELIMINATION OF FLAMMABLE SOLVENTS IN WIPE APPLICATIONS AT PANTEX}

\author{
M. G. Benkovich \\ Department 833 \\ KCP-613-7015 \\ Distributed March 2005 \\ Final Report on W7609000 \\ M. G. Benkovich, Project Leader
}





\section{Contents}

Section Page

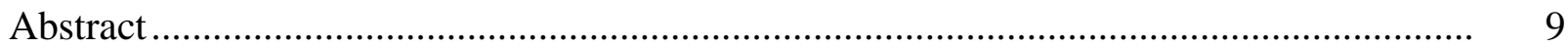

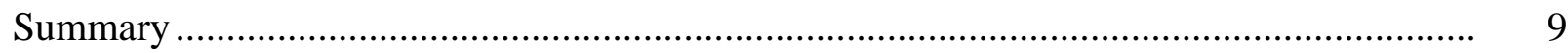

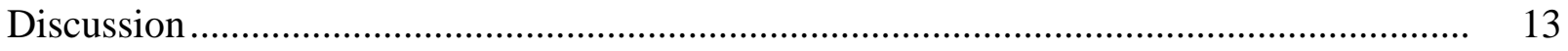

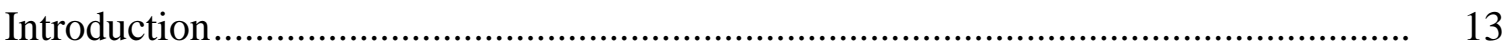

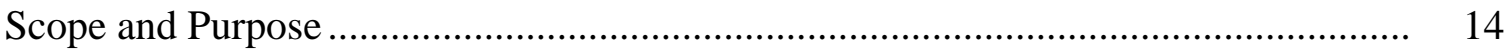

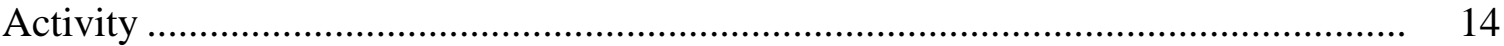

Solvents Evaluated........................................................................... 14

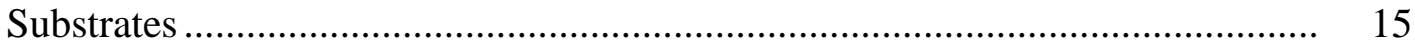

Precleaning of Substrates .................................................................... 15

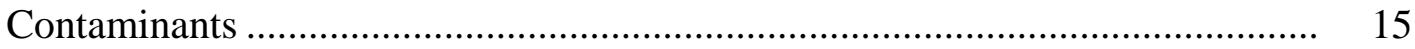

Wipe Cleaning Process ....................................................................... 16

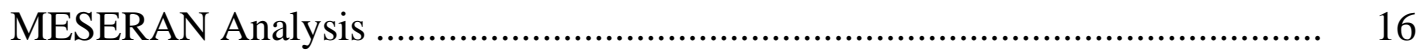

Cleanliness Levels .............................................................................. 18

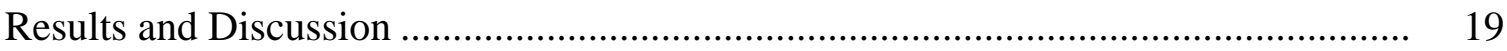

Krytox 240-AD Fluorinated Grease Cleaning Evaluations ............................. 19

Dow Corning 4 (DC-4) Silicone Insulating Compound Cleaning Evaluations ... 28

Dust Sebum Emulsion Cleaning Evaluations ............................................. 40

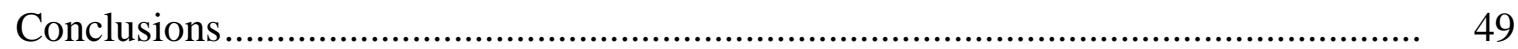

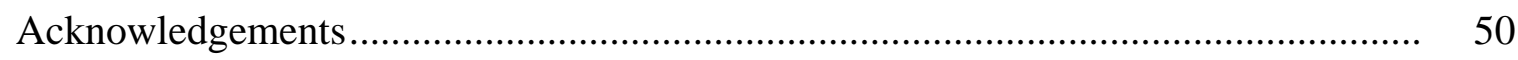




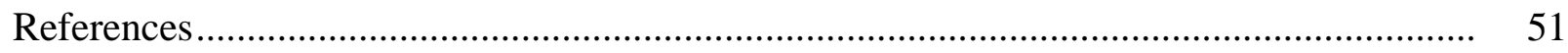

Appendix. Detailed Information on MESERAN Analysis for Organic Contamination

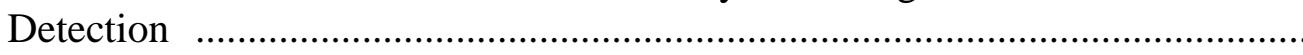




\section{Illustrations}

Figure Page

1 Volumetric Dilution Process for Formulating Calibration Solutions ........................... 17

2 Calibration of Krytox 240-AD Fluorinated Grease on 2024 Aluminum Disks............ 19

3 Calibration of Krytox 240-AD Fluorinated Grease on 304L Stainless Steel Disks ..... 21

4 Calibration of Krytox 240-AD Fluorinated Grease on Passivated304L Stainless

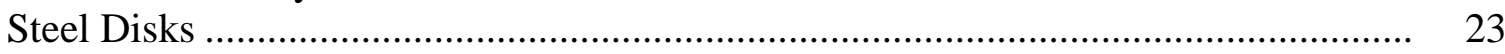

5 Calibration of Krytox 240-AD Fluorinated Grease on 303 Stainless Steel Disks........ 25

6 MESERAN Slope Data for Krytox 240-AD Fluorinated Grease Cleaning

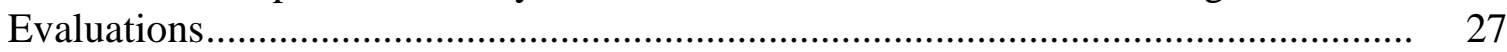

7 Equivalent Contamination Amounts Determined by MESERAN Analysis for Krytox 240-AD Fluorinated Grease Cleaning Evaluations..................................... 27

8 Calibration of DC-4 Silicone Insulating Compound on 2024 Aluminum Disks.......... 28

9 Calibration of DC-4 Silicone Insulating Compound on 304L Stainless Steel Disks.... 31

10 Calibration of DC-4 Silicone Insulating Compound on Passivated 304L Stainless Steel Disks ...................................................................................................... 33

11 Calibration of DC-4 Silicone Insulating Compound on 303 Stainless Steel Disks ...... 35

12 MESERAN Slope Data for DC-4 Silicone Insulating Compound Cleaning Evaluations

13 Equivalent Contamination Amounts Determined by MESERAN Analysis for DC-4 Silicone Insulating Compound Cleaning Evaluations

14 Calibration of Dust Sebum Emulsion on 2024 Aluminum Disks................................. 40

15 Calibration of Dust Sebum Emulsion on 304L Stainless Steel Disks .......................... 42

16 Calibration of Dust Sebum Emulsion on Passivated 304L Stainless Steel Disks......... 44 
17 Calibration of Dust Sebum Emulsion on 303 Stainless Steel Disks............................. 46

18 MESERAN Slope Data for Dust Sebum Emulsion Cleaning Evaluations.................... 48

19 Equivalent Contamination Amounts Determined by MESERAN Analysis

for Dust Sebum Emulsion Cleaning Evaluations........................................................... 49

\section{Tables}

Number

Page

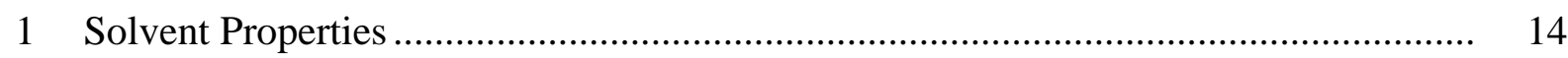

2 IEST-STD-CC1246D Cleanliness Levels............................................................... 18

3 MESERAN Results and Equivalent Contamination Amounts for Krytox 240-AD Fluorinated Grease on 2024 Aluminum Disks............................................................ 20

4 MESERAN Results and Equivalent Contamination Amounts for Krytox 240-AD Fluorinated Grease on 304L Stainless Steel Disks

5 MESERAN Results and Equivalent Contamination Amounts for Krytox 240-AD Fluorinated Grease on Passivated 304L Stainless Steel Disks .................................... 24

6 MESERAN Results and Equivalent Contamination Amounts for Krytox 240-AD Fluorinated Grease on303 Stainless Steel Disks......................................................... 26

7 MESERAN Results and Equivalent Contamination Amounts for DC-4 Silicone Insulating Compound on 2024 Aluminum Disks .......................................................... 29

8 MESERAN Results and Equivalent Contamination Amounts for DC-4 Silicone Insulating Compound on 304L Stainless Steel Disks ................................................... 32

9 MESERAN Results and Equivalent Contamination Amounts for DC-4 Silicone Insulating Compound on Passivated 304L Stainless Steel Disks .................................. 34

10 MESERAN Results and Equivalent Contamination Amounts for DC-4 Silicone Insulating Compound on 303 Stainless Steel Disks 
11 MESERAN Results and Equivalent Contamination Amounts for Dust Sebum

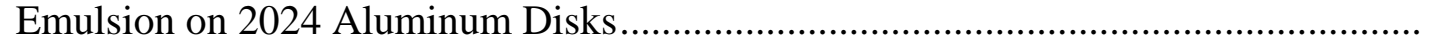

12 MESERAN Results and Equivalent Contamination Amounts for Dust Sebum Emulsion on 304L Stainless Steel Disks

13 MESERAN Results and Equivalent Contamination Amounts for Dust Sebum Emulsion on Passivated 304L Stainless Steel Disks.

14 MESERAN Results and Equivalent Contamination Amounts for Dust Sebum Emulsion on 303 Stainless Steel Disks 


\begin{abstract}
In recent years, efforts have been made within the nuclear weapons complex (National Nuclear Security Administration) of the Department of Energy (DOE) to replace Resource Conservation and Recovery Act (RCRA) regulated solvents (i.e., flammable, toxic, corrosive, and reactive) and ozone-depleting chemicals $(O D C)$ with more benign alternatives. Within the National Nuclear Security Administration (NNSA) and the Department of Defense (DoD) sectors, these solvents are used for cleaning hardware during routine maintenance operations. A primary goal of this study is to replace flammable solvents for wiping applications. Two cleaners, including a hydrofluoroether (HFE) and an azeotrope of the HFE and isopropyl alcohol (IPA), have been studied as potential replacements for flammable solvents. Cleaning efficacy, short-term and longterm materials compatibility, corrosion, drying times, flammability, environment, safety and health $(E S \& H)$ issues and accelerated aging studies are among the tests that are being conducted and that are used to screen candidate solvents by the interagency team performing this work. The results are compared to the traditionally used isopropyl alcohol, which serves as the baseline cleaner. This report details the results of MESERAN (Measurement and Evaluation of Surfaces by Evaporative Rate ANalysis) testing performed at the Kansas City Plant (KCP) to quantify the cleaning efficacy on samples contaminated with the various contaminants and cleaned by wiping with the various solvents being evaluated.
\end{abstract}

\title{
Summary
}

Cleaning hardware during routine maintenance operations has historically been accomplished with RCRA-regulated or ODC solvents within the National Nuclear Security Administration (NNSA). In an effort to curtail the use of these toxic and flammable solvents for wipe applications, a study has been conducted to identify and qualify a more benign alternative or alternatives. The primary goal is to systematically reduce flammable and combustible solvents used in proximity to and in nuclear explosive operations through solvent elimination, minimization or substitution.

Two solvents, HFE-7100 hydrofluoroether and HFE-7100/IPA azeotrope, were evaluated and compared to IPA for their abilities to remove contamination from metal substrates using a wipe cleaning application. The four metal alloys evaluated in this portion of the study were 2024aluminum, 304L stainless steel, passivated 304L stainless steel, and 303 stainless steel. The following three contaminants were selected because they were a representative cross section of those found on weapon surfaces: Krytox 240-AD fluorinated grease, Dow Corning 4 (DC-4) silicone insulating compound and dust sebum emulsion (a simulated fingerprint oil).

MESERAN (Measurement and Evaluation of Surfaces by Evaporative Rate ANalysis) Analysis was performed at the Kansas City Plant (KCP) to quantify the cleaning efficacy on samples contaminated with the various contaminants and cleaned by wiping with the various solvents 
being evaluated. MESERAN testing was performed both before applying the contaminants and then again after wiping with IPA, HFE-7100, or HFE-7100/IPA azeotrope. The substrates included 2024 aluminum, 304L stainless steel, passivated 304L stainless steel, and 303 stainless steel. Based on calibration curves developed for these specific contaminants on these specific substrates, the MESERAN slopes could be converted to equivalent contamination levels.

For the two alternative solvents evaluated, the HFE-7100/IPA azeotrope is much more effective than HFE-7100 for removing the three contaminants from the four substrates evaluated.

MESERAN data indicates that the HFE-7100/IPA azeotrope was able to remove all three of the contaminants from all of the substrates to a level below $1 \mu \mathrm{g} / \mathrm{cm}^{2}$ (the cleanliness level called out by most aerospace companies for metal cleaning operations). In some cases, the HFE-7100/IPA azeotrope was even able to remove the contaminants below $100 \mathrm{ng} / \mathrm{cm}^{2}$ (the cleanliness level LLNL calls out for some of their NIF cleaning operations). However, no defined cleanliness levels are called out for the product being wipe cleaned at BWXT Pantex Plant. Therefore, these evaluations centered on determining if either HFE-7100 or HFE-7100/IPA azeotrope could clean as well as or better than the baseline solvent (IPA).

Generally, for Krytox 240-AD and dust sebum emulsion, wiping six times with HFE-7100/IPA azeotrope approached the same cleanliness achieved with wiping three times with IPA. For some substrates, wiping three times with HFE-7100/IPA azeotrope was roughly equivalent to wiping three times with IPA. However, for other substrates, wiping six times was necessary.

For Krytox 240-AD, three wipes with HFE-7100/IPA azeotrope was equivalent to three wipes with IPA.

For dust sebum emulsion, wiping six times with HFE-7100/IPA azeotrope approaches the same cleanliness achieved with wiping three times with IPA.

IPA is the most effective solvent evaluated for removing DC-4 silicone. In initial evaluations, wiping six times with HFE-7100 approaches the same cleanliness achieved with wiping three times with IPA; however, the results could not be repeated when the HFE-7100 evaluations were performed again. The HFE-7100/IPA azeotrope was not as effective as IPA, even when six wipes were used.

DC-4 silicone was the hardest contaminant for the HFE-7100/IPA azeotrope to remove. Wiping six times with HFE-7100/IPA azeotrope did not remove the DC-4 silicone as well as IPA. Wiping six times with HFE-7100/IPA azeotrope was able to clean the DC-4 silicone from all of the substrates to a level below $1 \mu \mathrm{g} / \mathrm{cm}^{2}$. However, it was unable to clean it to submonolayer levels. It must be determined whether the cleanliness level achieved is good enough or if additional wipes are necessary.

HFE-7100 Premoistened Wipers were not effective in removing contamination. In addition, they appeared to leave large amounts of contamination on the samples. Either the HFE-7100 in the premoistened wipers is not very clean or the HFE-7100 is extracting something from the wipers or the bags they are stored in. 
Wipe cleaning is an operator-dependent process and can lead to variability in cleaning results. Even when the same operator cleans all of the samples, significant variability will exist.

Generally, wipe cleaning is good for removing gross amounts of contamination, but will not consistently remove low levels of contamination unless the contaminants being cleaned are soluble in the solvent used for wiping. 


\section{Discussion}

\section{Introduction}

Kansas City Plant, Sandia National Laboratories, BWXT Pantex Plant, and other National Nuclear Security Administration (NNSA) sites have teamed to identify suitable replacements for Resource Conservation and Recovery Act (RCRA) solvents and ozone-depleting chemicals (ODC) used in nuclear maintenance operations. The primary goal is to systematically reduce the usage of flammable solvents (principally isopropyl alcohol) used in proximity to and in nuclear explosive operations through a risk-cost benefit assessment of solvent and combustible material elimination, minimization or substitution. The cost benefits to all programs at BWXT Pantex Plant by removing a flammable solvent, such as isopropyl alcohol (IPA), would include (1) the savings of significant process time if the requirements for task exhaust, bonding and dry times were lifted due to the use of nonflammable solvents; (2) other operational efficiencies, such as the use of facilities that are not currently available for weapons work due to the absence of task exhaust, could be optimized if the requirement was removed; (3) waste disposal costs could be reduced for both the NNSA/BWXT Pantex Plant and the Department of Defense (DoD) since the waste generated has the potential of not being categorized as hazardous or mixed; and, most importantly, (4) safety would be greatly enhanced, i.e., the elimination of flammable solvents would remove the fuel component necessary to support a fire.

As mandated by NNSA [ref. 1], the BWXT Pantex Plant is currently in the process of implementing a two-stage approach that will eliminate the use of RCRA (especially flammable) and ODC solvents in one pilot program. The first stage is to reduce the number of cleaning steps where these solvents are used, and the second stage is to substitute a nonflammable/ noncombustible solvent, where it is not possible to eliminate solvent use, or implement an alternative cleaning process. To date, most of the Freon TF (CFC-113), methyl ethyl ketone and 1,1,1 trichloroethane in the pilot program have been eliminated, primarily by replacement with IPA. Although BWXT Pantex Plant is in the process of eliminating several cleaning steps where IPA is used, complete elimination is impossible. Therefore, a nonflammable alternate solvent(s) must be found.

Initially, one candidate solvent, HFE-7100 hydrofluoroether, [ref. 2], was extensively studied as a potential replacement. Additional testing occurred on HFE-7100/IPA azeotrope, [ref. 3].

HFE-7100 is an inseparable mixture of methoxynanofluorobutane and methoxynanofluoroisobutane. The HFE-7100/IPA azeotrope evaluated consisted of 95.5 wt.\% HFE and 4.5 wt.\% IPA. Isopropyl alcohol was the principal baseline solvent in this study.

The solvents were evaluated not only for their inability to support combustion, but on other criteria that include: ES\&H issues, e.g., toxicity, ozone depletion potential, global warming potential etc.; cleaning efficacy; corrosion of metal alloys; materials compatibility of polymers; nonvolatile residue; high explosive compatibility; cure inhibition of polymers; and shortterm/long-term compatibility concerns. 
Three contaminants were evaluated on several metal substrates. The three contaminants included Krytox 240-AD [ref. 4] fluorinated grease, Dow Corning 4 (DC-4) silicone insulating compound [ref. 5] and dust sebum emulsion (a simulated fingerprint oil) [ref. 6]. The contaminants selected were a representative cross section of those found on weapon surfaces.

\section{Scope and Purpose}

The purpose of the work detailed in this report was to perform MESERAN (Measurement and Evaluation of Surfaces by Evaporative Rate ANalysis) Analysis to quantify the cleaning efficacy on samples contaminated with the three contaminants discussed above and cleaned by wiping with the various solvents being evaluated.

\section{Activity}

\section{Solvents Evaluated}

Isopropyl alcohol was the principal baseline solvent evaluated in this study. The other two solvents evaluated as potential replacements for IPA were HFE-7100 hydrofluoroether and HFE7100/IPA azeotrope. A comparison of some of the physical properties of IPA, HFE-7100, and HFE-7100/IPA azeotrope are shown in Table 1.

Table 1. Solvent Properties

\begin{tabular}{|c|c|c|c|}
\hline Solvent Properties & IPA & HFE-7100 & HFE-IPA Azeotrope \\
\hline $\begin{array}{c}\text { Boiling Point @ } 760 \\
\text { mmHg }\end{array}$ & $82^{\circ} \mathrm{C}$ & $61^{\circ} \mathrm{C}$ & $54.8^{\circ} \mathrm{C}$ \\
\hline Vapor Pressure & $96 \mathrm{~mm} \mathrm{Hg} \mathrm{@} 25^{\circ} \mathrm{C}$ & $202 \mathrm{~mm} \mathrm{Hg}$ at $25^{\circ} \mathrm{C}$ & $207 \mathrm{~mm} \mathrm{Hg}$ at $25^{\circ} \mathrm{C}$ \\
\hline Flash Point & $12^{\circ} \mathrm{C}$ & None & None \\
\hline $\begin{array}{c}\text { Time Weighted } \\
\text { Average (8hr.) }\end{array}$ & $400 \mathrm{ppm}$ & $750 \mathrm{ppm}$ & $750 / 400 \mathrm{ppm}$ \\
\hline $\begin{array}{c}\text { Global Warming } \\
\text { Potential }\end{array}$ & & $\begin{array}{c}320(\mathrm{lb} \text { equivalent } \\
\left.\mathrm{CO}_{2}\right)\end{array}$ & $\begin{array}{c}310(\mathrm{lb} \text { equivalent } \\
\left.\mathrm{CO}_{2}\right)\end{array}$ \\
\hline $\begin{array}{c}\text { Ozone Depletion } \\
\text { Potential }\end{array}$ & 0 & 0 & 0 \\
\hline
\end{tabular}

The IPA used was Fisher Scientific 2-Propanol, Optima Grade, Lot number 023388, with a stated residue after evaporation of 1 ppm. The HFE-7100/IPA azeotrope was made up by mixing 95.5 wt.\% of HFE-7100 and 4.5 wt.\% IPA. The original bottle of HFE-7100 used was 3M Novec TM HFE-7100, Lot number 24205, Mfg. Date: 7/03. This bottle was used for all of the HFE-7100 wiping evaluations and the majority of the HFE-7100/IPA azeotrope evaluations. After the original bottle of HFE-7100 was depleted, another bottle was ordered. This material was labeled 3M Novec TM HFE-7100DL, Lot number 20154, Mfg. Date: 12/04. This is a higher purity version of Novec TM HFE-7100. Novec TM HFE-7100DL is tightly-controlled for ions, metals, and non-volatile residue. Additional azeotrope evaluations (all azeotrope evaluations for wiping six times to remove DC-4 silicone) were performed by mixing the HFE-7100DL with IPA. 


\section{$\underline{\text { Substrates }}$}

Substrates were 1.5" diameter metal disks that were $1 / 4$ " thick and machined to a $16 \mathrm{rms}$ finish. The four metal alloys evaluated using MESERAN Analysis were 2024-aluminum, 304L stainless steel, passivated 304L stainless steel, and 303 stainless steel. Initial evaluations were attempted on anodized 2024-aluminum and alodined-2024 aluminum, but MESERAN Analysis was not suitable for directly testing these substrates. Their increased surface condition due to the porosity of the anodized and alodined surfaces makes direct testing using MESERAN Analysis impractical.

\section{Precleaning of Substrates}

All of the disks were precleaned prior to contamination to create a uniform initial substrate surface. The disks were spray cleaned, ultrasonic cleaned, and vapor degreased under vacuum in trichloroethylene (TCE) using the F-1 Near Zero Emission Cleaner. This process involves warm $\left(50^{\circ} \mathrm{C}\right)$ TCE spray cleaning for 5 minutes, warm $\left(50^{\circ} \mathrm{C}\right)$ TCE ultrasonic cleaning for 5 minutes, cold $\left(25^{\circ} \mathrm{C}\right)$ TCE spray cleaning for 5 minutes, cold $\left(25^{\circ} \mathrm{C}\right)$ TCE ultrasonic cleaning for 5 minutes (this 4-stage cycle is repeated three times), vapor degreasing for 5 minutes, and vacuum drying.

The stainless steel disks were then additionally cleaned using the following process: (1) ultrasonic cleaned in Dirl Lum 603 (30g per liter concentration) for 5 minutes at $140^{\circ} \mathrm{F}$, (2) rinsed in flowing DI water for 15 - 30 seconds, (3) DI water rinsed in ultrasonic cascade rinse station with 3 tanks (30 seconds in each tank) at $110-115^{\circ} \mathrm{F}$, (4) blown dry with filtered nitrogen, (5) baked for 30 minutes minimum at $220^{\circ} \mathrm{F}$ in a HEPA filtered convection oven with nitrogen flowing into the oven. The disks were then packaged in nylon bags and heat sealed. Aqueous cleaning was not performed on the aluminum disks due to the possibility of microetching the aluminum with the aqueous alkaline ultrasonic cleaning process.

\section{Contaminants}

The contaminants selected were a representative cross section of those found on weapon surfaces. The three contaminants included Krytox 240-AD fluorinated grease, Dow Corning 4 (DC-4) silicone insulating compound, and dust sebum emulsion (a simulated fingerprint oil).

The contaminants were applied as follows. For the dust sebum, approximately 4 microliters $(\mu / \mathrm{L})$ [i.e., 4 milligrams (mg), assuming a density of 1 gram/milliliter $(\mathrm{g} / \mathrm{mL})$ ] of the simulated fingerprint oil were deposited and spread over the center of each disk using a toothpick. The dust sebum emulsion consists primarily of organic acids, paraffin, and oils. Since a fingerprint weighs ca. 0.1 milligrams, each deposit corresponds to 40 superimposed fingerprints. The Krytox 240-AD fluorinated grease and the DC-4 silicone insulating compound were each deposited by squirting a 0.05 grams (g) [or 50 milligrams] on a disk and then lightly spreading the contaminant across the entire surface of the disk using a tongue depressor. After the 
contaminant was applied to the disk, the samples were allowed to dry for 30 minutes before being wiped clean and evaluated with the MESERAN Analyzer. All of the samples were contaminated by Eddie Lopez, Sandia National Laboratories/New Mexico (SNL/NM).

\section{Wipe Cleaning Process}

The contaminants were removed by wiping with either IPA, HFE-7100, or HFE-7100/IPA azeotrope using a Kaydry impregnated with roughly $5 \mathrm{~mL}$ of solvent. One wipe consists of applying a light pressure with the middle and forefingers on the wiper and dragging it across the surface of the metal disk. A second wipe consists of using a fresh Kaydry impregnated also with ca. $5 \mathrm{~mL}$ of solvent, etc. In some cases, up to six wipes were necessary to remove the contaminant from the surface, regardless of the type of solvent used. Removal of the three contaminants from the four metal substrates was evaluated by the MESERAN Analyzer. Replicates of five samples per condition were performed. All of the samples were cleaned by Eddie Lopez, SNL/NM.

Some evaluations were performed on Millimoist ${ }^{\circledR}$ Anticon Gold premoistened polyester wipers saturated with HFE-7100. These wipers were packaged three to a bag (vapor barrier bag) with ca. $90 \mathrm{~mL}$ of HFE-7100 in each bag. The wiping process was performed as above except the wipers were already saturated with the HFE-7100. A fresh wipe was used each time.

\section{MESERAN Analysis}

\section{General MESERAN Analysis Information [ref. 7-22]}

The MESERAN (Measurement and Evaluation of Surfaces by Evaporative Rate ANalysis) Analyzer was used at KCP for determining cleanliness. The precision analytical technique known as MESERAN Analysis permits quantitative measurement of the level of preexisting organic residue on a substrate from $<1$ nanogram $/$ centimeter $^{2}\left(\mathrm{ng} / \mathrm{cm}^{2}\right)$ to $>100$ micrograms/centimeter ${ }^{2}\left(\mu \mathrm{g} / \mathrm{cm}^{2}\right)$ in 2 minutes. The characterization is performed by depositing a radiochemical solution onto the test surface and then observing the rate at which the radiochemical disappears. The radiochemical solution covers approximately $1 \mathrm{~cm}^{2}$ on the surface being tested. The rate at which the radiochemical evaporates is a function of the amount of residue on the surface. The quicker the radiochemical evaporates (higher slope), the cleaner the surface and the slower it evaporates (lower slope), the greater the contamination amount. Further details of the MESERAN Analysis method are shown in the Appendix.

\section{Formulation of Calibration Solutions}

Extensive solubility evaluations were conducted to determine the appropriate solvent to use in dissolving the contaminants so that calibration solutions of these contaminants could be made. Methylene chloride proved to be the best solvent for dissolving DC-4 silicone insulating compound. CFC-113 proved to be the best solvent for dissolving Krytox 240-AD fluorinated grease. Methylene chloride proved to be the best solvent for dissolving dust sebum (a true solution could not be made with the dust sebum, but we achieved a thoroughly mixed 
suspension). Calibration solutions of these contaminants were made so that calibration curves for the contaminants could be developed on the various substrates. MESERAN results obtained on the samples tested can then be compared to the calibration curves to determine quantitative amounts of contamination detected.

Volumetric dilutions were used to make contamination solutions for depositing known amounts of the organic contaminant on the substrates. These calibrations were performed in the following manner. A master calibration solution was prepared in a 10-mL volumetric flask by dissolving $100 \mathrm{mg}$ of the organic contaminant in $10 \mathrm{~mL}$ of solvent (e.g., methylene chloride or CFC-113 that has been double distilled in an all-glass still with no grease in the joints - NVOR of these solvents are approximately $10 \mathrm{ppb}$ ). The master calibration solution was thoroughly mixed and $1 \mathrm{~mL}$ of this solution was placed in another $10-\mathrm{mL}$ volumetric flask. The second volumetric flask was then diluted with the double distilled solvent until the solution level was at $10 \mathrm{~mL}$ and this solution was thoroughly mixed. Subsequent dilutions were carried out in a similar fashion. Ten microliters $(\mu \mathrm{L})$ of each calibration solution were deposited on the precleaned substrates and allowed to evaporate. This resulted in the following amounts of contamination on the substrates: $1 \mathrm{ng}, 10 \mathrm{ng}, 100 \mathrm{ng}, 1 \mu \mathrm{g}, 10 \mu \mathrm{g}$, and $100 \mu \mathrm{g}$. In some cases, intermediate levels were obtained by depositing $3 \mu \mathrm{L}$ and $5 \mu \mathrm{L}$ of the calibration solutions. The volumetric dilution process for making calibration solutions is shown in Figure 1.

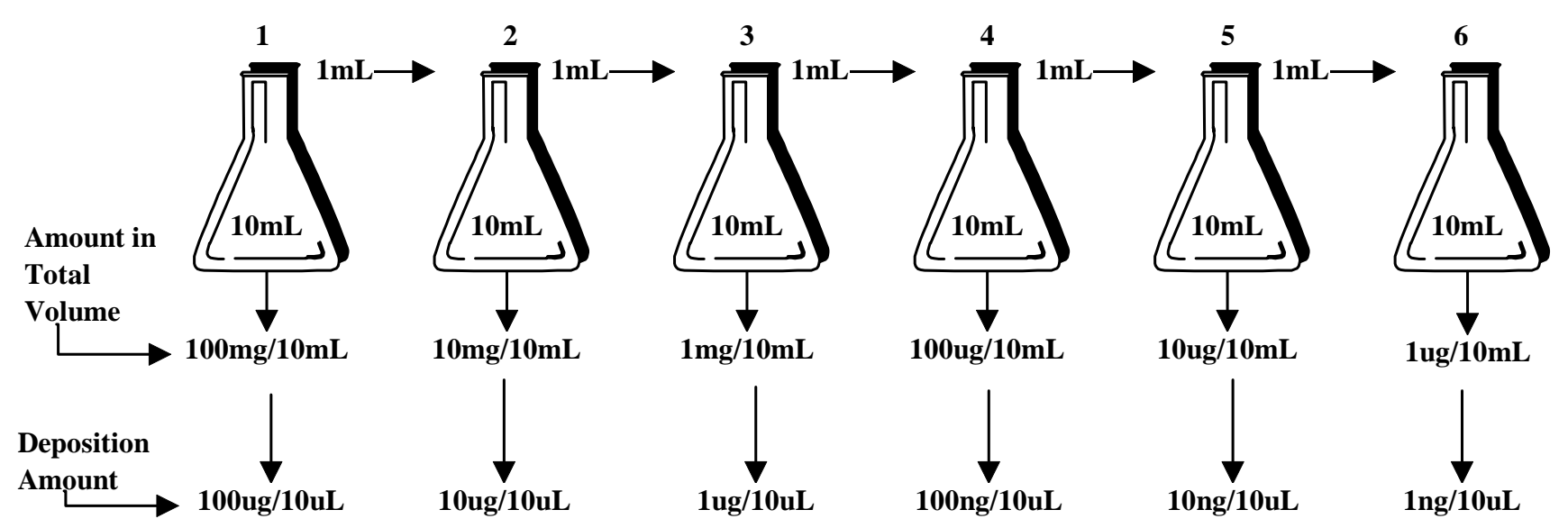

Figure 1. Volumetric Dilution Process for Formulating Calibration Solutions 


\section{Radiochemicals Chosen for Evaluations}

When testing samples that were contaminated with DC-4 silicone insulating compound, the radiochemical solution consisted of tridecane $\mathrm{C}-14$ radiochemical dissolved in methylene chloride. When testing samples that were contaminated with Krytox 240-AD fluorinated grease, the radiochemical solution consisted of tridecane C-14 radiochemical dissolved in CFC-113. When testing samples that were contaminated with dust sebum emulsion, the radiochemical solution consisted of tridecane C-14 radiochemical dissolved in cyclopentane.

\section{Cleanliness Levels}

No defined cleanliness levels are called out for the product being cleaned. Therefore, these evaluations centered on determining if either HFE-7100 or HFE-7100/IPA azeotrope could clean as well as or better than the baseline solvent (IPA). It is important to remember that the cleanliness analysis method used at KCP (MESERAN Analysis) is extremely sensitive for detecting organic contamination. MESERAN Analysis can detect levels of contamination in the nanogram range, which is up to 100 - 1000 times lower than many other standard cleanliness detection methods. Most companies in the aerospace industry use gravimetric analysis for quantifying cleanliness. Gravimetric analysis is not very accurate below microgram levels of contamination.

IEST-STD-CC1246D (Product Cleanliness Levels and Contamination Control Program) [ref. 23] allows users of this document to define desired cleanliness levels. The cleanliness levels called out in this document are shown in Table 2.

Table 2. IEST-STD-CC1246D Cleanliness Levels

\begin{tabular}{|c|c|c|}
\hline $\mathrm{A} A 5=10 \mathrm{pg} / \mathrm{cm}^{2}$ & $\mathrm{AA} 3=1 \mathrm{ng} / \mathrm{cm}^{2}$ & $\mathrm{~A}=1 \mu \mathrm{g} / \mathrm{cm}^{2}$ \\
\hline $\mathrm{AA} 4.7=20 \mathrm{pg} / \mathrm{cm}^{2}$ & $\mathrm{AA} 2.7=2 \mathrm{ng} / \mathrm{cm}^{2}$ & $\mathrm{~B}=2 \mu \mathrm{g} / \mathrm{cm}^{2}$ \\
\hline $\mathrm{AA} 4.3=50 \mathrm{pg} / \mathrm{cm}^{2}$ & $\mathrm{AA} 4.3=5 \mathrm{ng} / \mathrm{cm}^{2}$ & $\mathrm{C}=3 \mu \mathrm{g} / \mathrm{cm}^{2}$ \\
\hline $\mathrm{A} A 4=100 \mathrm{pg} / \mathrm{cm}^{2}$ & $\mathrm{~A} / 100=10 \mathrm{ng} / \mathrm{cm}^{2}$ & $\mathrm{D}=4 \mu \mathrm{g} / \mathrm{cm}^{2}$ \\
\hline $\mathrm{A} 3.7=200 \mathrm{pg} / \mathrm{cm}^{2}$ & $\mathrm{~A} / 50=20 \mathrm{ng} / \mathrm{cm}^{2}$ & $\mathrm{E}=5 \mu \mathrm{g} / \mathrm{cm}^{2}$ \\
\hline $\mathrm{A} 44.3=500 \mathrm{pg} / \mathrm{cm}^{2}$ & $\mathrm{~A} / 20=50 \mathrm{ng} / \mathrm{cm}^{2}$ & $\mathrm{~F}=7 \mu \mathrm{g} / \mathrm{cm}^{2}$ \\
\hline & $\mathrm{A} / 10=100 \mathrm{ng} / \mathrm{cm}^{2}$ & $\mathrm{G}=10 \mu \mathrm{g} / \mathrm{cm}^{2}$ \\
\hline & $\mathrm{A} / 5=200 \mathrm{ng} / \mathrm{cm}^{2}$ & $\mathrm{H}=15 \mu \mathrm{g} / \mathrm{cm}^{2}$ \\
\hline & $\mathrm{A} / 2=500 \mathrm{ng} / \mathrm{cm}^{2}$ & $\mathrm{~J}=25 \mu \mathrm{g} / \mathrm{cm}^{2}$ \\
\hline
\end{tabular}

Note: $\mathrm{pg}=$ picograms $\left(10^{-12}\right.$ grams $)$,

$\mathrm{ng}=$ nanograms $\left(10^{-9}\right.$ grams $)$, and

$\mu \mathrm{g}=\operatorname{micrograms}\left(10^{-6}\right.$ grams $)$

Many aerospace companies call out a cleanliness level of A $\left(1 \mu \mathrm{g} / \mathrm{cm}^{2}\right)$ for their metal cleaning applications. However, there are some applications where they call out lower levels. Lawrence Livermore National Laboratory (LLNL) calls out A/10 $\left(100 \mathrm{ng} / \mathrm{cm}^{2}\right)$ for some of their National Ignition Facility (NIF) cleaning processes. Depending upon the contaminant and the surface roughness of the substrate, one monolayer of organic contamination is approximately 100 - 300 $\mathrm{ng} / \mathrm{cm}^{2}$. 


\section{Results and Discussion}

MESERAN testing was performed both before applying the contaminants and then again after wiping with IPA, HFE-7100, or HFE-7100/IPA azeotrope. The substrates included 2024 aluminum, 304L stainless steel, passivated 304L stainless steel, and 303 stainless steel. Based on calibration curves developed for these specific contaminants on these specific substrates, the MESERAN slopes could be converted to equivalent contamination levels.

\section{$\underline{\text { Krytox 240-AD Fluorinated Grease Cleaning Evaluations }}$}

\section{Krytox 240-AD Fluorinated Grease on 2024 Aluminum Disks}

The calibration of Krytox 240-AD fluorinated grease on 2024 aluminum disks is shown in Figure 2.

MESERAN Low Variance Slope Calibration of Krytox 240-AD on Original MetaSpec Bare AL (2024 T-351) Disks with 16 RMS Finish Tested with BJ 0309092

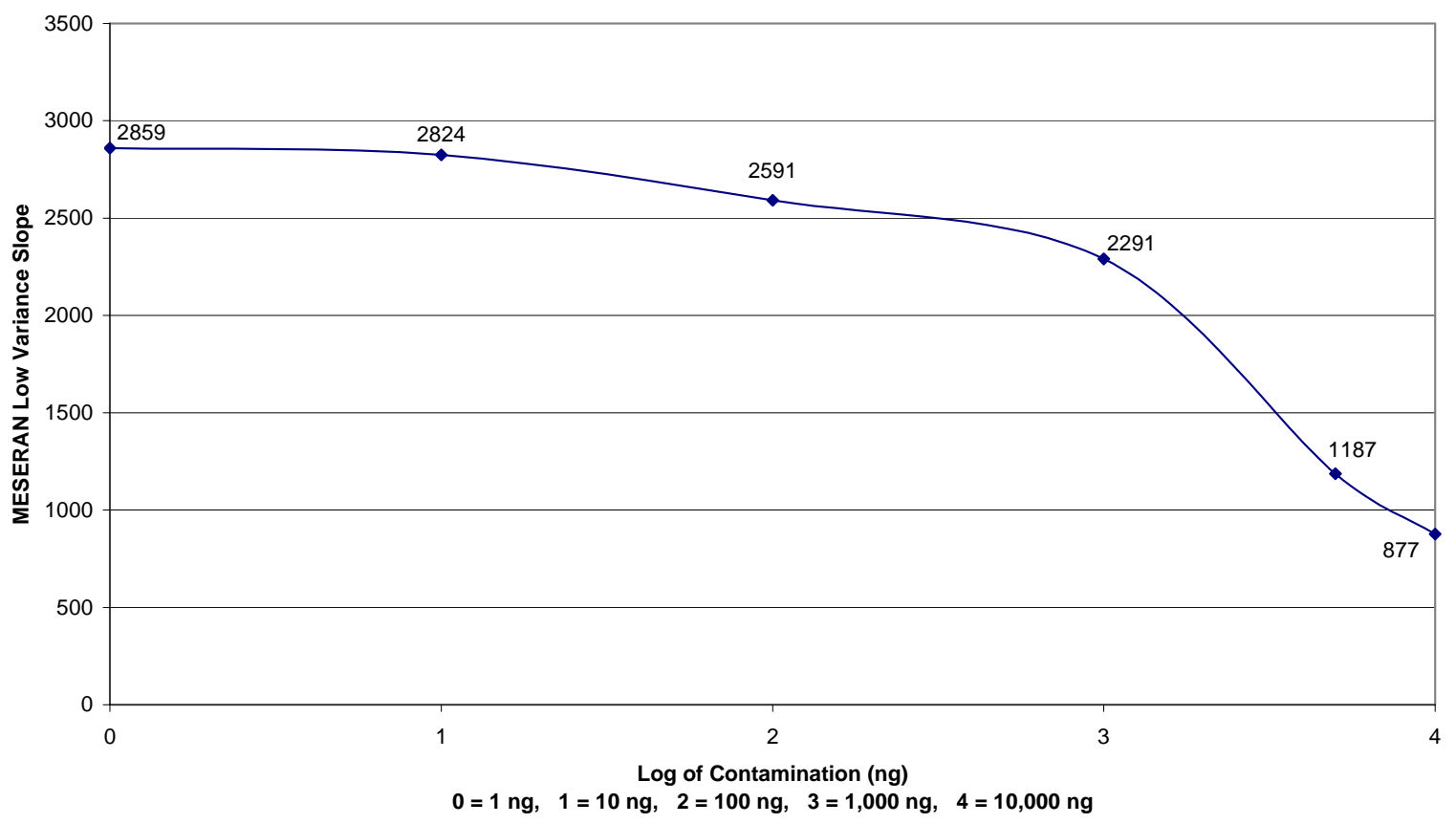

Figure 2. Calibration of Krytox 240-AD Fluorinated Grease on 2024 Aluminum Disks 
The results of the cleaning evaluations performed to remove the Krytox 240-AD fluorinated grease from 2024 aluminum disks are shown in Table 3.

Table 3. MESERAN Results and Equivalent Contamination Amounts for Krytox 240AD Fluorinated Grease on 2024 Aluminum Disks

\begin{tabular}{|c|c|c|c|c|c|c|}
\hline & \multicolumn{2}{|c|}{$\begin{array}{l}\text { Gross Contamination } \\
\text { (Not Cleaned) }\end{array}$} & \multicolumn{2}{|c|}{$\begin{array}{c}\text { Cleaned by Wiping } \\
\text { with IPA } \\
\text { (5 mL/Kaydry) }-3 \text { Times }\end{array}$} & \multicolumn{2}{|c|}{$\begin{array}{c}\text { Cleaned by Wiping } \\
\text { With HFE-7100 } \\
\text { (5 mL/Kaydry) - } 3 \text { Times }\end{array}$} \\
\hline Test & $\begin{array}{l}\text { Low } \\
\text { Variance } \\
\text { Slope }\end{array}$ & $\begin{array}{c}\text { Equivalent } \\
\text { Contamination } \\
\left(\mathrm{ng} / \mathrm{cm}^{2}\right)\end{array}$ & $\begin{array}{l}\text { Low } \\
\text { Variance } \\
\text { Slope }\end{array}$ & $\begin{array}{c}\text { Equivalent } \\
\text { Contamination } \\
\left(\mathrm{ng} / \mathrm{cm}^{2}\right)\end{array}$ & $\begin{array}{l}\text { Low } \\
\text { Variance } \\
\text { Slope }\end{array}$ & $\begin{array}{c}\text { Equivalent } \\
\text { Contamination } \\
\left(\mathrm{ng} / \mathrm{cm}^{2}\right)\end{array}$ \\
\hline 1 & 233 & Est. $>100,000$ & 2271 & 1030 & 1314 & 4155 \\
\hline 2 & 297 & Est. $>100,000$ & 2433 & 336 & 1293 & 4284 \\
\hline 3 & 400 & Est. $>100,000$ & 3032 & $<1$ & 1148 & 5456 \\
\hline 4 & 179 & Est. $>100,000$ & 3545 & $<1$ & 898 & 9541 \\
\hline 5 & 164 & Est. $>100,000$ & 2171 & 1191 & 972 & 8086 \\
\hline Avg. & 255 & Est. $>100,000$ & 2690 & 511 & 1125 & 6304 \\
\hline Std. Dev. & 96.6 & & 582.9 & 566.7 & 186.7 & 2401.6 \\
\hline$\% \mathrm{CV}$ & 37.9 & & 21.7 & 110.8 & 16.6 & 38.1 \\
\hline
\end{tabular}

Est. $=$ Values estimated outside of calibration curve

\begin{tabular}{|c|c|c|c|c|}
\hline & \multicolumn{2}{|c|}{$\begin{array}{c}\text { Cleaned by Wiping } \\
\text { With HFE-7100 } \\
(5 \mathrm{~mL} / \text { Kaydry) }-6 \text { Times }\end{array}$} & \multicolumn{2}{c|}{$\begin{array}{c}\text { Cleaned by Wiping With } \\
\text { HFE-7100/IPA Azeotrope } \\
(5 \mathrm{~mL} / \text { Kaydry }-3 \text { Times }\end{array}$} \\
\hline Test & $\begin{array}{c}\text { Low } \\
\text { Variance } \\
\text { Slope } \\
\text { Contamination } \\
\left(\mathrm{ng} / \mathrm{cm}^{2}\right)\end{array}$ & $\begin{array}{c}\text { Low } \\
\text { Variance } \\
\text { Slope }\end{array}$ & $\begin{array}{c}\text { Equivalent } \\
\text { Contamination } \\
\left(\mathrm{ng} / \mathrm{cm}^{2}\right)\end{array}$ \\
\hline 1 & 1652 & 2538 & 2704 & 33 \\
\hline 2 & 1160 & 5311 & 2779 & 16 \\
\hline 3 & 1074 & 6437 & 2620 & 75 \\
\hline 4 & 1371 & 3824 & 2275 & 1024 \\
\hline 5 & 1367 & 3846 & 2984 & $\mathbf{2 3 0}$ \\
\hline Avg. & $\mathbf{1 3 2 5}$ & $\mathbf{4 3 9 1}$ & $\mathbf{2 6 7 2}$ & $\mathbf{4 4 5 . 0}$ \\
\hline Std. Dev. & $\mathbf{2 2 4 . 2}$ & $\mathbf{1 5 0 7 . 0}$ & $\mathbf{2 5 9 . 9}$ & $\mathbf{1 9 3 . 8}$ \\
\hline \% CV & $\mathbf{1 6 . 9}$ & $\mathbf{3 4 . 3}$ & $\mathbf{9 . 7}$ & \\
\hline
\end{tabular}

The samples that were contaminated and not cleaned had an average slope value of 255 and an average contamination level of $>100,000$ nanograms per square centimeter $\left(\mathrm{ng} / \mathrm{cm}^{2}\right)$. After wiping three times with IPA, the average slope was 2690 and the average contamination level 
was $511 \mathrm{ng} / \mathrm{cm}^{2}$. Two of the IPA cleaned samples were very clean; however, two of the samples evaluated exhibited fairly large amounts of contamination (greater than $1 \mu \mathrm{g} / \mathrm{cm}^{2}$ ). Cleaning with HFE-7100 was not as effective at removing the Krytox as cleaning with IPA. The average slope value after wiping three times with the HFE solvent was 1125 and the average contamination value was $6304 \mathrm{ng} / \mathrm{cm}^{2}$. Wiping six times with HFE-7100 was slightly more effective than wiping three times. The average slope was 1325 and the average contamination value was $4391 \mathrm{ng} / \mathrm{cm}^{2}$. Wiping three times with the HFE-7100/IPA azeotrope was the most effective for removing the Krytox grease. The average slope was 2672 and the average contamination value was $230 \mathrm{ng} / \mathrm{cm}^{2}$. Four of the five samples cleaned with the HFE-7100/IPA azeotrope were very clean; however, one sample did exhibit a large amount of contamination (greater than $1 \mu \mathrm{g} / \mathrm{cm}^{2}$ ). The HFE-7100/IPA azeotrope cleaned samples also showed the most consistency.

\section{Krytox 240-AD Fluorinated Grease on 304L Stainless Steel Disks}

The calibration of Krytox 240-AD fluorinated grease on 304L stainless steel disks is shown in Figure 3.
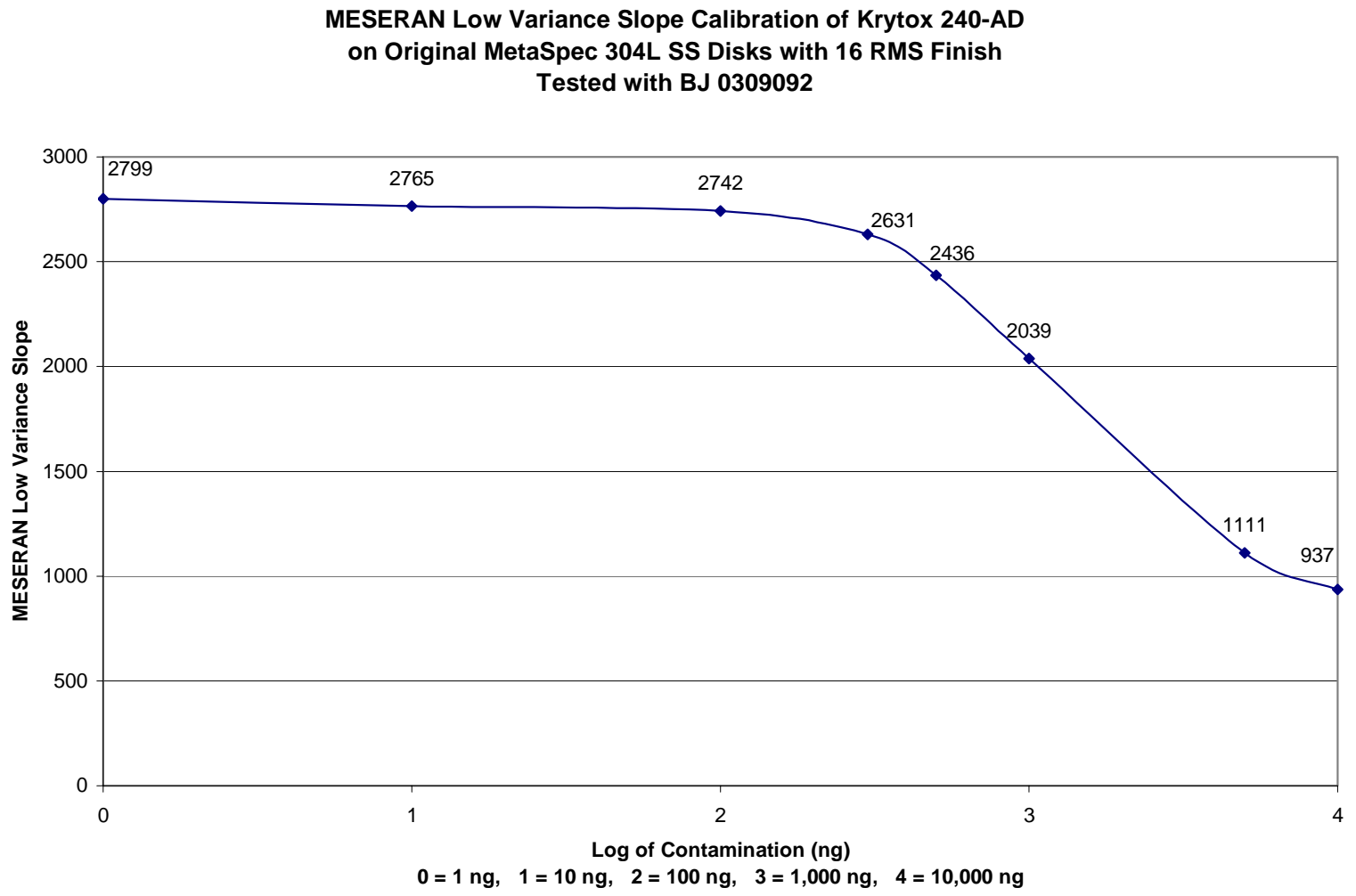

Figure 3. Calibration of Krytox 240-AD Fluorinated Grease on 304L Stainless Steel Disks 
The results of the cleaning evaluations performed to remove the Krytox 240-AD fluorinated grease from 304L stainless steel disks are shown in Table 4.

Table 4. MESERAN Results and Equivalent Contamination Amounts for Krytox 240AD Fluorinated Grease on 304L Stainless Steel Disks

\begin{tabular}{|c|c|c|c|c|c|c|}
\hline & \multicolumn{2}{|c|}{$\begin{array}{l}\text { Gross Contamination } \\
\text { (Not Cleaned) }\end{array}$} & \multicolumn{2}{|c|}{$\begin{array}{c}\text { Cleaned by Wiping } \\
\text { with IPA } \\
\text { (5 mL/Kaydry) }-3 \text { Times }\end{array}$} & \multicolumn{2}{|c|}{$\begin{array}{c}\text { Cleaned by Wiping } \\
\text { With HFE-7100 } \\
\text { (5 mL/Kaydry) - } 3 \text { Times }\end{array}$} \\
\hline Test & $\begin{array}{c}\text { Low } \\
\text { Variance } \\
\text { Slope }\end{array}$ & $\begin{array}{c}\text { Equivalent } \\
\text { Contamination } \\
\left(\mathrm{ng} / \mathrm{cm}^{2}\right)\end{array}$ & $\begin{array}{l}\text { Low } \\
\text { Variance } \\
\text { Slope }\end{array}$ & $\begin{array}{c}\text { Equivalent } \\
\text { Contamination } \\
\left(\mathrm{ng} / \mathrm{cm}^{2}\right)\end{array}$ & $\begin{array}{l}\text { Low } \\
\text { Variance } \\
\text { Slope }\end{array}$ & $\begin{array}{c}\text { Equivalent } \\
\text { Contamination } \\
\left(\mathrm{ng} / \mathrm{cm}^{2}\right)\end{array}$ \\
\hline 1 & 347 & Est. $>100,000$ & 3144 & $<1$ & 742 & $\begin{array}{c}>10000 \\
\text { (Est. 30000) }\end{array}$ \\
\hline 2 & 403 & Est. $>100,000$ & 2904 & $<1$ & 1280 & 3730 \\
\hline 3 & 291 & Est. $>100,000$ & 3400 & $<1$ & 1668 & 1903 \\
\hline 4 & 112 & Est. $>100,000$ & 2549 & 372 & 1434 & 2856 \\
\hline 5 & 453 & Est. $>100,000$ & 2877 & $<1$ & 1610 & 2104 \\
\hline Avg. & 321 & Est. $>\mathbf{1 0 0 , 0 0 0}$ & 2975 & 74 & 1347 & 8119 \\
\hline Std. Dev. & 131.7 & & 318.3 & 166.4 & 370.9 & 12253.2 \\
\hline$\% \mathrm{CV}$ & 41.0 & & 10.7 & 223.6 & 27.5 & 150.9 \\
\hline
\end{tabular}

Est. $=$ Values estimated outside of calibration curve

\begin{tabular}{|c|c|c|c|c|}
\hline \multirow[b]{2}{*}{ Test } & \multicolumn{2}{|c|}{$\begin{array}{c}\text { Cleaned by Wiping } \\
\text { With HFE-7100 } \\
\text { (5 mL/Kaydry) - } 6 \text { Times }\end{array}$} & \multicolumn{2}{|c|}{$\begin{array}{l}\text { Cleaned by Wiping With } \\
\text { HFE-7100/IPA Azeotrope } \\
\text { (5 mL/Kaydry) - } 3 \text { Times }\end{array}$} \\
\hline & $\begin{array}{l}\text { Low } \\
\text { Variance } \\
\text { Slope }\end{array}$ & $\begin{array}{c}\text { Equivalent } \\
\text { Contamination } \\
\left(\mathrm{ng} / \mathrm{cm}^{2}\right)\end{array}$ & $\begin{array}{c}\text { Low } \\
\text { Variance } \\
\text { Slope }\end{array}$ & $\begin{array}{c}\text { Equivalent } \\
\text { Contamination } \\
\left(\mathrm{ng} / \mathrm{cm}^{2}\right)\end{array}$ \\
\hline 1 & 1584 & 2201 & 3435 & $<1$ \\
\hline 2 & 1223 & 4117 & 3164 & $<1$ \\
\hline 3 & 1644 & 1984 & 2707 & 141 \\
\hline 4 & 1710 & 1769 & 2916 & $<1$ \\
\hline 5 & 1379 & 3141 & 2430 & 505 \\
\hline Avg. & 1508 & 2642 & 2930 & 129 \\
\hline Std. Dev. & 201.8 & 976.5 & 390.4 & 218.8 \\
\hline$\% \mathrm{CV}$ & 13.4 & 37.0 & 13.3 & 169.3 \\
\hline
\end{tabular}


The samples that were contaminated and not cleaned had an average slope value of 321 and an average contamination level of $>100,000 \mathrm{ng} / \mathrm{cm}^{2}$. After wiping three times with IPA, the average slope was 2975 and the average contamination level was $74 \mathrm{ng} / \mathrm{cm}^{2}$. Four of the IPA cleaned samples were very clean. Cleaning with HFE-7100 was not as effective at removing the Krytox as cleaning with IPA. The average slope value after wiping three times with the HFE solvent was 1347 and the average contamination value was $8119 \mathrm{ng} / \mathrm{cm}^{2}$. Wiping six times with HFE-7100 was slightly more effective than wiping three times. The average slope was 1508 and the average contamination value was $2642 \mathrm{ng} / \mathrm{cm}^{2}$. Wiping three times with the HFE-7100/IPA azeotrope approached the equivalency of wiping three times with IPA. The average slope was 2930 and the average contamination value was $129 \mathrm{ng} / \mathrm{cm}^{2}$. Three of the five samples cleaned with the HFE-7100/IPA azeotrope were very clean.

\section{Krytox 240-AD Fluorinated Grease on Passivated 304L Stainless Steel Disks}

The calibration of Krytox 240-AD fluorinated grease on passivated 304L stainless steel disks is shown in Figure 4.

MESERAN Low Variance Slope Calibration of Krytox 240-AD on Original MetaSpec Passivated 304L SS Disks with 16 RMS Finish Tested with BJ 0309092

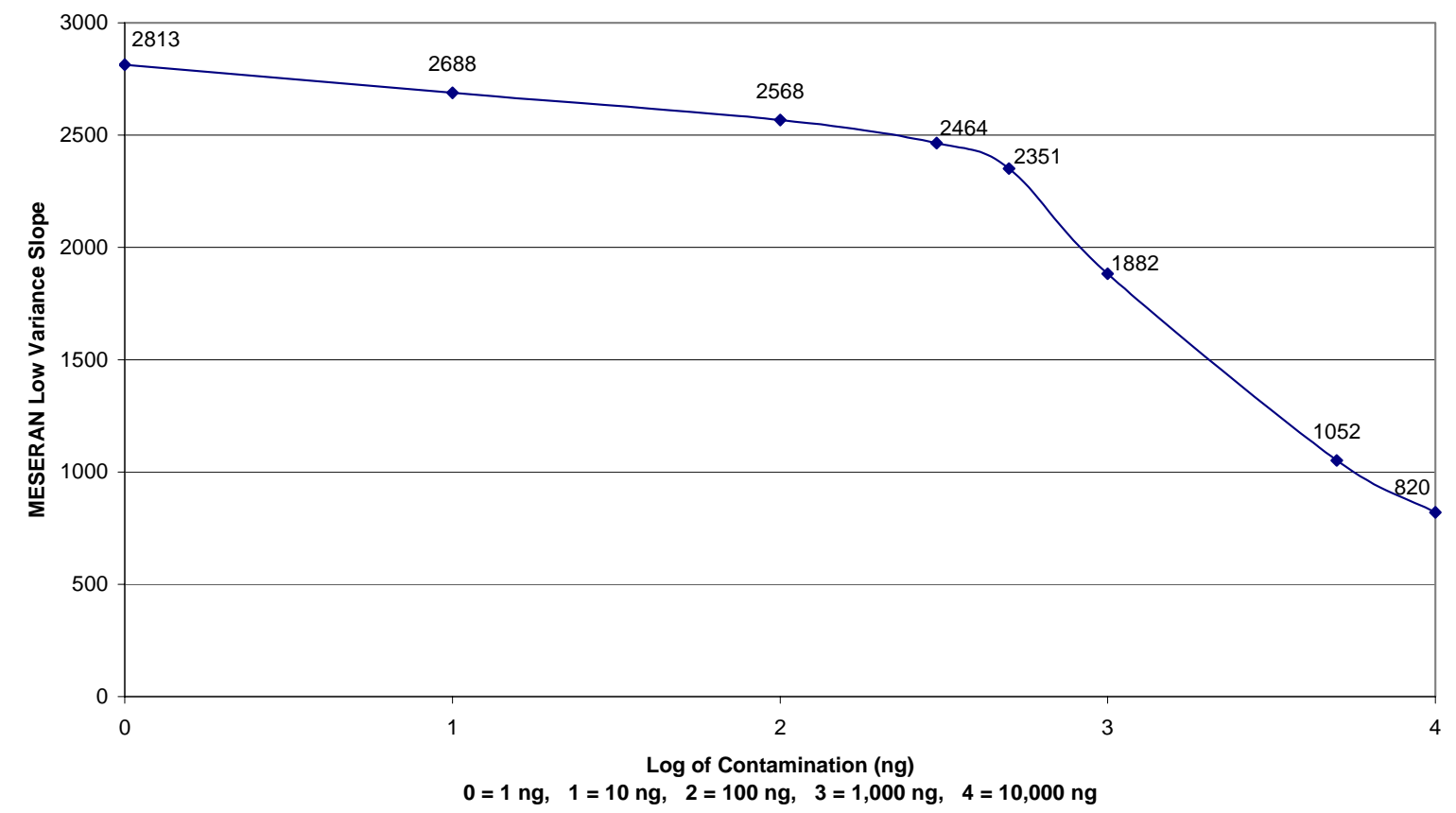

Figure 4. Calibration of Krytox 240-AD Fluorinated Grease on Passivated 304L Stainless Steel Disks 
The results of the cleaning evaluations performed to remove the Krytox 240-AD fluorinated grease from passivated 304L stainless steel disks are shown in Table 5.

Table 5. MESERAN Results and Equivalent Contamination Amounts for Krytox 240AD Fluorinated Grease on Passivated 304L Stainless Steel Disks

\begin{tabular}{|c|c|c|c|c|c|c|}
\hline & \multicolumn{2}{|c|}{$\begin{array}{l}\text { Gross Contamination } \\
\text { (Not Cleaned) }\end{array}$} & \multicolumn{2}{|c|}{$\begin{array}{c}\text { Cleaned by Wiping } \\
\text { with IPA } \\
\text { (5 mL/Kaydry) }-3 \text { Times }\end{array}$} & \multicolumn{2}{|c|}{$\begin{array}{c}\text { Cleaned by Wiping } \\
\text { With HFE-7100 } \\
\text { (5 mL/Kaydry) - } 3 \text { Times }\end{array}$} \\
\hline Test & $\begin{array}{c}\text { Low } \\
\text { Variance } \\
\text { Slope }\end{array}$ & $\begin{array}{c}\text { Equivalent } \\
\text { Contamination } \\
\left(\mathrm{ng} / \mathrm{cm}^{2}\right)\end{array}$ & $\begin{array}{l}\text { Low } \\
\text { Variance } \\
\text { Slope }\end{array}$ & $\begin{array}{c}\text { Equivalent } \\
\text { Contamination } \\
\left(\mathrm{ng} / \mathrm{cm}^{2}\right)\end{array}$ & $\begin{array}{l}\text { Low } \\
\text { Variance } \\
\text { Slope }\end{array}$ & $\begin{array}{c}\text { Equivalent } \\
\text { Contamination } \\
\left(\mathrm{ng} / \mathrm{cm}^{2}\right)\end{array}$ \\
\hline 1 & 358 & Est. $>100,000$ & 2805 & 1 & 1047 & 5075 \\
\hline 2 & 248 & Est. $>100,000$ & 2351 & 500 & 1047 & 5075 \\
\hline 3 & 326 & Est. $>100,000$ & 2878 & $<1$ & 1730 & 1343 \\
\hline 4 & 420 & Est. $>100,000$ & 2525 & 157 & 733 & $\begin{array}{c}>10000 \\
(\text { Est. } 14118)\end{array}$ \\
\hline 5 & 476 & Est. $>100,000$ & 2682 & 11 & 1585 & 1779 \\
\hline Avg. & 366 & Est. $>\mathbf{1 0 0 , 0 0 0}$ & 2648 & 134 & 1228 & 5478 \\
\hline Std. Dev. & 87.5 & & 213.3 & 215.2 & 415.3 & 5141.9 \\
\hline$\% \mathrm{CV}$ & 23.9 & & 8.1 & 160.8 & 33.8 & 93.9 \\
\hline
\end{tabular}

Est. $=$ Values estimated outside of calibration curve

\begin{tabular}{|c|c|c|c|c|}
\hline \multirow[b]{2}{*}{ Test } & \multicolumn{2}{|c|}{$\begin{array}{c}\text { Cleaned by Wiping } \\
\text { With HFE-7100 } \\
\text { (5 mL/Kaydry) - } 6 \text { Times }\end{array}$} & \multicolumn{2}{|c|}{$\begin{array}{l}\text { Cleaned by Wiping With } \\
\text { HFE-7100/IPA Azeotrope } \\
\text { (5 mL/Kaydry) - } 3 \text { Times }\end{array}$} \\
\hline & $\begin{array}{l}\text { Low } \\
\text { Variance } \\
\text { Slope }\end{array}$ & $\begin{array}{c}\text { Equivalent } \\
\text { Contamination } \\
\left(\mathrm{ng} / \mathrm{cm}^{2}\right)\end{array}$ & $\begin{array}{l}\text { Low } \\
\text { Variance } \\
\text { Slope }\end{array}$ & $\begin{array}{c}\text { Equivalent } \\
\text { Contamination } \\
\left(\mathrm{ng} / \mathrm{cm}^{2}\right)\end{array}$ \\
\hline 1 & 1616 & 1675 & 3166 & $<1$ \\
\hline 2 & 2060 & 769 & 3102 & $<1$ \\
\hline 3 & 1200 & 3753 & 2653 & 20 \\
\hline 4 & 1353 & 2789 & 2878 & $<1$ \\
\hline 5 & 1322 & 2962 & 2329 & 517 \\
\hline Avg. & 1510 & 2390 & 2826 & 107 \\
\hline Std. Dev. & 342.7 & 1170.8 & 343.3 & 229.1 \\
\hline$\% \mathrm{CV}$ & 22.7 & 49.0 & 12.1 & 213.3 \\
\hline
\end{tabular}


The samples that were contaminated and not cleaned had an average slope value of 366 and an average contamination level of $>100,000 \mathrm{ng} / \mathrm{cm}^{2}$. After wiping three times with IPA, the average slope was 2648 and the average contamination level was $134 \mathrm{ng} / \mathrm{cm}^{2}$. Three of the IPA cleaned samples were very clean. Cleaning with HFE-7100 was not as effective at removing the Krytox as cleaning with IPA. The average slope value after wiping three times with the HFE solvent was 1228 and the average contamination value was $5478 \mathrm{ng} / \mathrm{cm}^{2}$. One of the samples (test 4) showed a slope that was outside of the highest contamination level of the calibration curve (i.e., slope $<820$, contamination $>10000 \mathrm{ng} / \mathrm{cm}^{2}$ ). The data was extrapolated to estimate the contamination value as $14118 \mathrm{ng} / \mathrm{cm}^{2}$. Wiping six times with HFE-7100 was slightly more effective than wiping three times. The average slope was 1510 and the average contamination value was $2390 \mathrm{ng} / \mathrm{cm}^{2}$. Wiping three times with the HFE-7100/IPA azeotrope was slightly better than wiping three times with IPA. The average slope was 2826 and the average contamination value was $107 \mathrm{ng} / \mathrm{cm}^{2}$. Four of the five samples cleaned with the HFE-7100/IPA azeotrope were very clean.

\section{Krytox 240-AD Fluorinated Grease on 303 Stainless Steel Disks}

The calibration of Krytox 240-AD fluorinated grease on 303 stainless steel disks is shown in Figure 5.

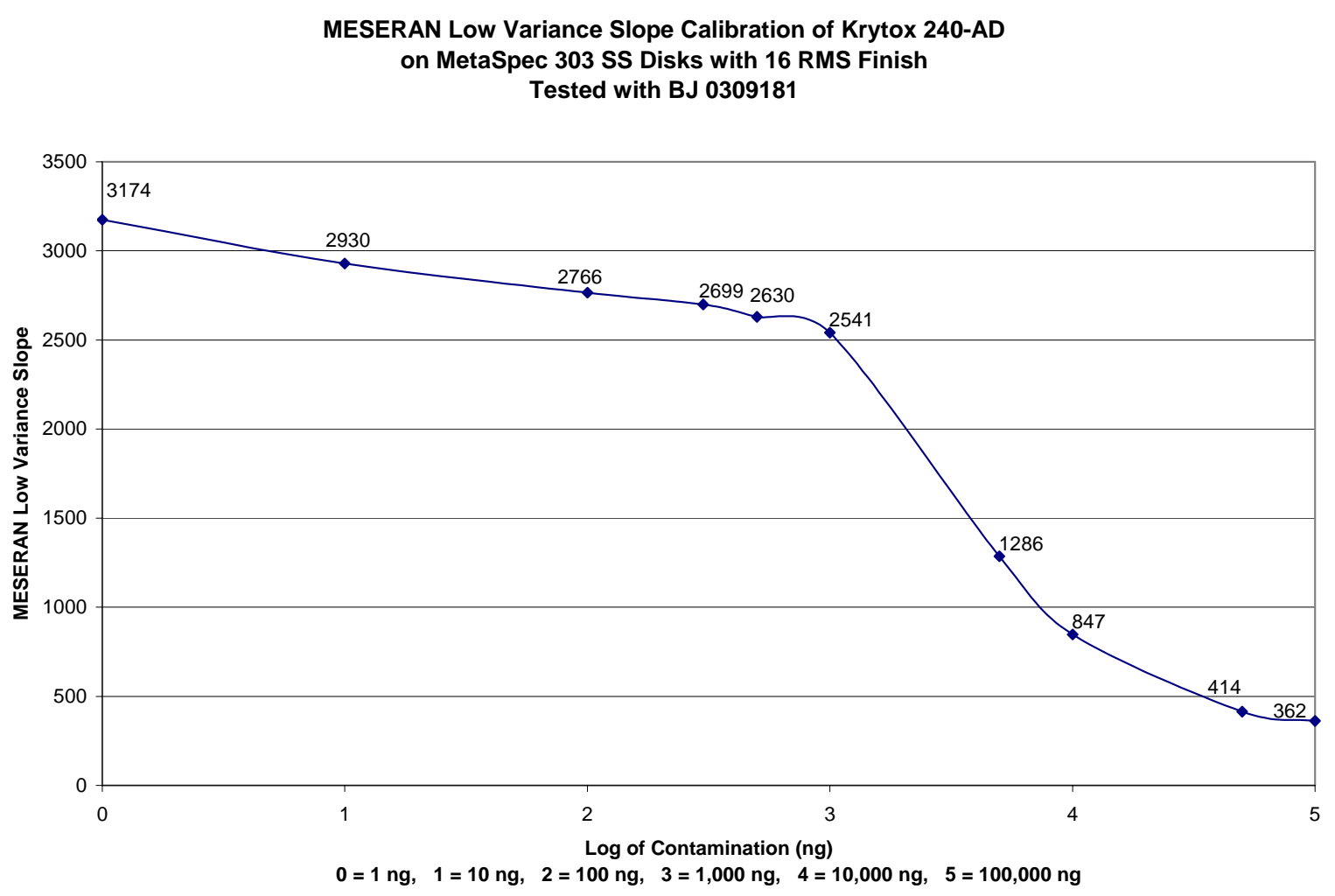

Figure 5. Calibration of Krytox 240-AD Fluorinated Grease on 303 Stainless Steel Disks 
The results of the cleaning evaluations performed to remove the Krytox 240-AD fluorinated grease from 303 stainless steel disks are shown in Table 6.

Table 6. MESERAN Results and Equivalent Contamination Amounts for Krytox 240AD Fluorinated Grease on 303 Stainless Steel Disks

\begin{tabular}{|c|c|c|c|c|c|c|}
\hline & \multicolumn{2}{|c|}{$\begin{array}{c}\text { Cleaned by Wiping } \\
\text { with IPA } \\
(5 \mathrm{~mL} / \text { Kaydry })-3 \text { Times }\end{array}$} & \multicolumn{2}{c|}{$\begin{array}{c}\text { Cleaned by Wiping } \\
\text { With HFE-7100 } \\
(5 \mathrm{~mL} / \text { Kaydry })-6 \text { Times }\end{array}$} & \multicolumn{2}{c|}{$\begin{array}{c}\text { Cleaned by Wiping With } \\
\text { HFE-7100/IPA Azeotrope } \\
(5 \mathrm{~mL} / \text { Kaydry })\end{array}$} \\
\hline Test & $\begin{array}{c}\text { Low Times } \\
\text { Variance } \\
\text { Slope }\end{array}$ & $\begin{array}{c}\text { Equivalent } \\
\text { Contamination } \\
\left(\mathrm{ng} / \mathrm{cm}^{2}\right)\end{array}$ & $\begin{array}{c}\text { Low } \\
\text { Variance } \\
\text { Slope }\end{array}$ & $\begin{array}{c}\text { Equivalent } \\
\text { Contamination } \\
\left(\mathrm{ng} / \mathrm{cm}^{2}\right)\end{array}$ & $\begin{array}{c}\text { Low } \\
\text { Variance } \\
\text { Slope }\end{array}$ & $\begin{array}{c}\text { Equivalent } \\
\text { Contamination } \\
\left(\mathrm{ng} / \mathrm{cm}^{2}\right)\end{array}$ \\
\hline 1 & 3044 & 3 & 3030 & 4 & 2888 & 18 \\
\hline 2 & 2848 & 32 & 3312 & $<1$ & 3102 & 2 \\
\hline 3 & 2622 & 532 & 1876 & 2346 & 3191 & $<1$ \\
\hline 4 & 2772 & 92 & 1780 & 2654 & 3146 & 1 \\
\hline 5 & 2449 & 1125 & 2595 & 657 & 2932 & 10 \\
\hline Avg. & $\mathbf{2 7 4 7}$ & $\mathbf{3 5 7}$ & $\mathbf{2 5 1 9}$ & $\mathbf{1 1 3 2}$ & $\mathbf{3 0 5 2}$ & $\mathbf{6}$ \\
\hline Std. Dev. & $\mathbf{2 2 5 . 5}$ & $\mathbf{4 8 0 . 0}$ & $\mathbf{6 8 1 . 0}$ & $\mathbf{1 2 8 1 . 6}$ & $\mathbf{1 3 4 . 1}$ & $\mathbf{7 . 5}$ \\
\hline \% CV & $\mathbf{8 . 2}$ & $\mathbf{1 3 4 . 5}$ & $\mathbf{2 7 . 0}$ & $\mathbf{1 1 3 . 2}$ & $\mathbf{4 . 4}$ & $\mathbf{1 1 7 . 2}$ \\
\hline
\end{tabular}

After wiping three times with IPA, the average slope was 2747 and the average contamination level was $357 \mathrm{ng} / \mathrm{cm}^{2}$. Three of the IPA cleaned samples were pretty clean $\left(<100 \mathrm{ng} / \mathrm{cm}^{2}\right)$; however, one was $532 \mathrm{ng} / \mathrm{cm}^{2}$ and another sample exhibited a larger amount of contamination (greater than $1 \mu \mathrm{g} / \mathrm{cm}^{2}$ ). Cleaning six times with HFE-7100 was not as effective at removing the Krytox as cleaning with IPA. The average slope value after wiping six times with the HFE solvent was 2519 and the average contamination value was $1132 \mathrm{ng} / \mathrm{cm}^{2}$. Two of the samples were very clean and two of the samples exhibited large amounts of contamination (greater than $1 \mu \mathrm{g} / \mathrm{cm}^{2}$ ). Wiping three times with the HFE-7100/IPA azeotrope was significantly better than wiping three times with IPA. The average slope was 3052 and the average contamination value was $6 \mathrm{ng} / \mathrm{cm}^{2}$. All five samples cleaned with the HFE-7100/IPA azeotrope were very clean.

\section{Krytox 240-AD Fluorinated Grease Conclusions}

A graphical representation of the MESERAN slope data for all of the Krytox 240-AD fluorinated grease cleaning evaluations for each substrate is shown in Figure 6. A graphical representation of the equivalent contamination amounts determined by MESERAN Analysis for all of the Krytox 240-AD fluorinated grease cleaning evaluations for each substrate is shown in Figure 7.

Wiping three times with the HFE-7100/IPA azeotrope is essentially equivalent to wiping three times with IPA. HFE-7100 is not as effective as either IPA or the HFE-7100/IPA azeotrope (even when six wipes are used). 


\section{Krytox 240- AD Fluorinated Grease Cleaning Evaluations}

MESERAN Slopes

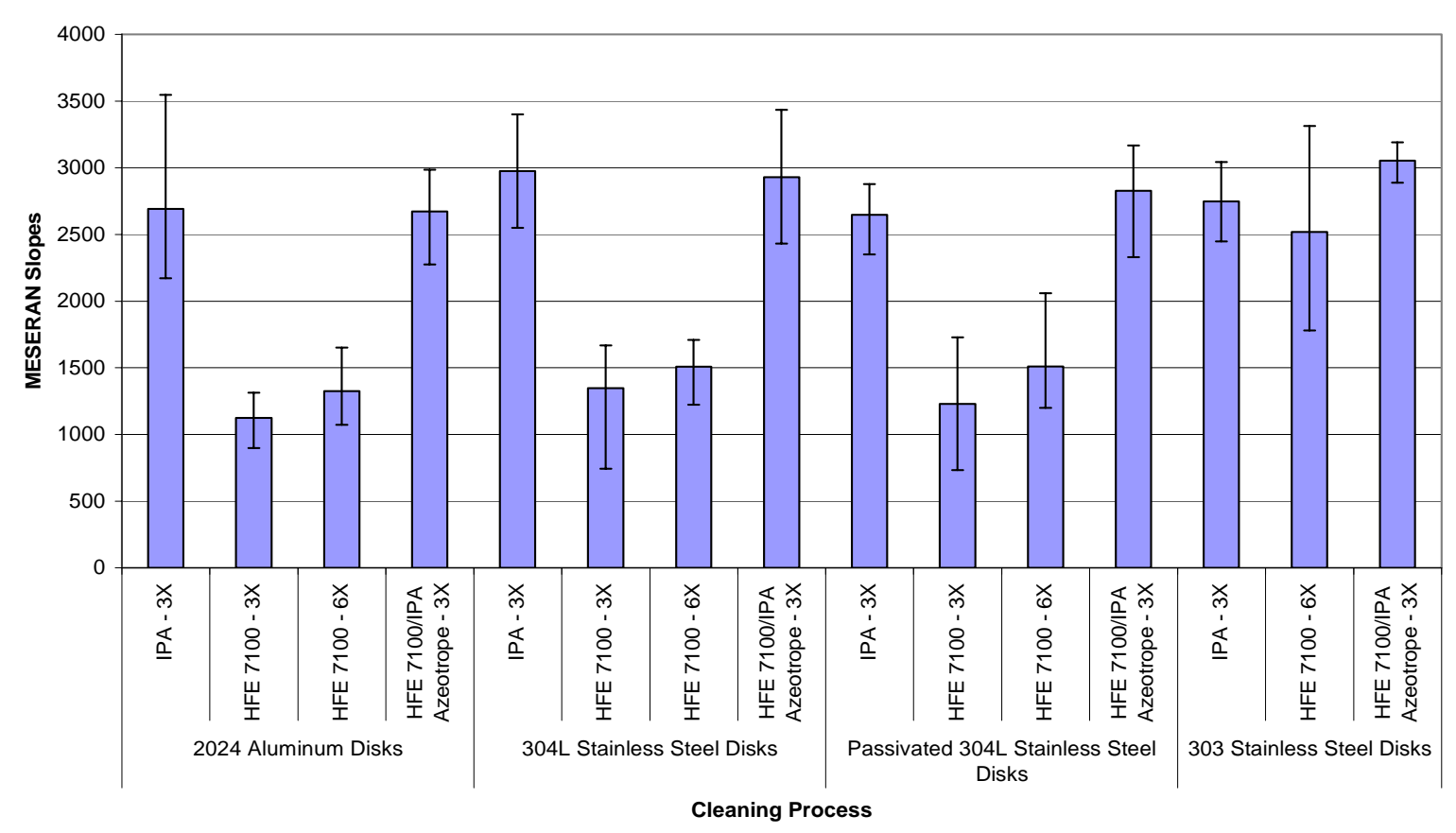

Figure 6. MESERAN Slope Data for Krytox 240-AD Fluorinated Grease Cleaning Evaluations

Krytox 240- AD Fluorinated Grease Cleaning Evaluations Equivalent Contamination Amounts Determined by MESERAN Analysis

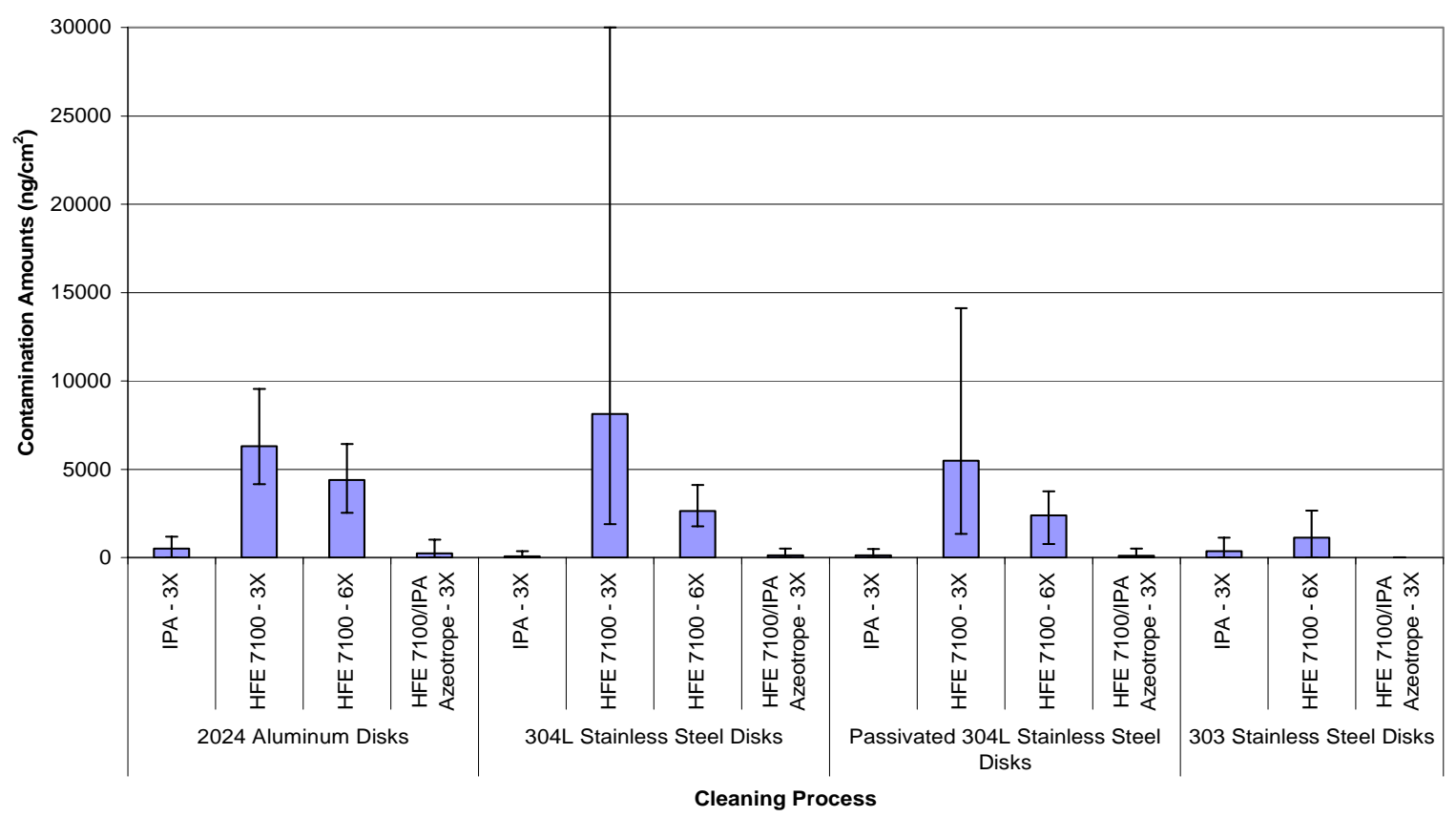

Figure 7. Equivalent Contamination Amounts Determined by MESERAN Analysis for Krytox 240-AD Fluorinated Grease Cleaning Evaluations 


\section{Dow Corning 4 (DC-4) Silicone Insulating Compound Cleaning Evaluations}

\section{DC-4 Silicone Insulating Compound on 2024 Aluminum Disks}

The calibration of DC-4 silicone insulating compound on 2024 aluminum disks is shown in Figure 8.

\section{MESERAN Low Variance Slope Calibration of DC-4 Silicone Insulating Compound on Original MetaSpec Bare AL (2024 T-351) Disks with 16 RMS Finish Tested with BH 0309091}

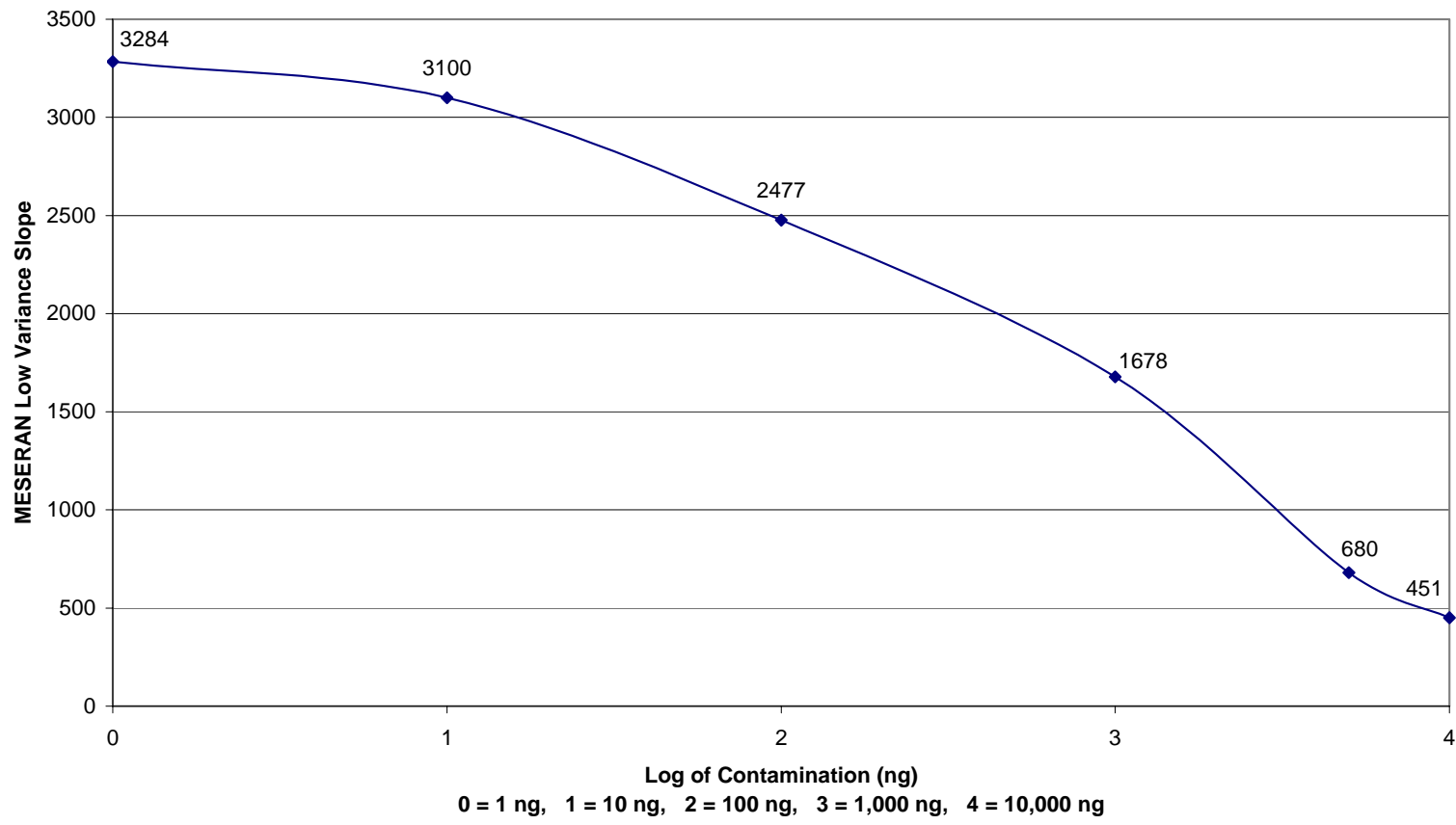

Figure 8. Calibration of DC-4 Silicone Insulating Compound on 2024 Aluminum Disks 
The results of the cleaning evaluations performed to remove the DC-4 silicone insulating compound from 2024 aluminum disks are shown in Table 7.

Table 7. MESERAN Results and Equivalent Contamination Amounts for DC-4 Silicone Insulating Compound on 2024 Aluminum Disks

\begin{tabular}{|c|c|c|c|c|c|c|}
\hline \multirow[b]{2}{*}{ Test } & \multicolumn{2}{|c|}{$\begin{array}{c}\text { Cleaned by Wiping } \\
\text { With HFE-7100 } \\
\text { Premoistened Polyester Wipers } \\
\text { 3 Times }\end{array}$} & \multicolumn{2}{|c|}{$\begin{array}{c}\text { Cleaned by Wiping } \\
\text { with IPA } \\
\text { (5 mL/Kaydry) }-3 \text { Times }\end{array}$} & \multicolumn{2}{|c|}{$\begin{array}{c}\text { Cleaned by Wiping } \\
\text { With HFE-7100 } \\
\text { (5 mL/Kaydry) - } 6 \text { Times }\end{array}$} \\
\hline & $\begin{array}{l}\text { Low } \\
\text { Variance } \\
\text { Slope }\end{array}$ & $\begin{array}{c}\text { Equivalent } \\
\text { Contamination } \\
\left(\mathrm{ng} / \mathrm{cm}^{2}\right)\end{array}$ & $\begin{array}{l}\text { Low } \\
\text { Variance } \\
\text { Slope }\end{array}$ & $\begin{array}{c}\text { Equivalent } \\
\text { Contamination } \\
\left(\mathrm{ng} / \mathrm{cm}^{2}\right)\end{array}$ & $\begin{array}{l}\text { Low } \\
\text { Variance } \\
\text { Slope }\end{array}$ & $\begin{array}{c}\text { Equivalent } \\
\text { Contamination } \\
\left(\mathrm{ng} / \mathrm{cm}^{2}\right)\end{array}$ \\
\hline 1 & 849 & 3807 & 2364 & 138 & 2401 & 124 \\
\hline 2 & 853 & 3782 & 3095 & 10 & 2731 & 39 \\
\hline 3 & 854 & 3776 & 3405 & $<1$ & 2149 & 257 \\
\hline 4 & 1159 & 2309 & 3050 & 12 & 2732 & 39 \\
\hline 5 & 1147 & 2354 & 3172 & 4 & 2939 & 18 \\
\hline Avg. & 972 & 3206 & 3017 & 33 & 2590 & 95 \\
\hline Std. Dev. & 164.9 & 798.2 & 389.9 & 59.0 & 313.1 & 99.1 \\
\hline$\% \mathrm{CV}$ & 17.0 & 24.9 & 12.9 & 179.9 & 12.1 & 103.9 \\
\hline
\end{tabular}

\begin{tabular}{|c|c|c|c|c|c|c|}
\hline \multirow[b]{2}{*}{ Test } & \multicolumn{2}{|c|}{$\begin{array}{c}\text { Cleaned by Wiping With HFE- } \\
\text { 7100/IPA Azeotrope } \\
\text { (5 mL/Kaydry) - } 3 \text { Times }\end{array}$} & \multicolumn{2}{|c|}{$\begin{array}{l}\text { Cleaned by Wiping With } \\
\text { HFE-7100/IPA Azeotrope } \\
\text { ( } 5 \text { mL/Kaydry) - } 6 \text { Times }\end{array}$} & \multicolumn{2}{|c|}{$\begin{array}{c}\text { Cleaned by Wiping With } \\
\text { HFE-7100/IPA Azeotrope } \\
\text { (5 mL/Kaydry) - } 6 \text { Times } \\
\text { Retests }\end{array}$} \\
\hline & $\begin{array}{c}\text { Low } \\
\text { Variance } \\
\text { Slope }\end{array}$ & $\begin{array}{c}\text { Equivalent } \\
\text { Contamination } \\
\left(\mathrm{ng} / \mathrm{cm}^{2}\right)\end{array}$ & $\begin{array}{c}\text { Low } \\
\text { Variance } \\
\text { Slope }\end{array}$ & $\begin{array}{c}\text { Equivalent } \\
\text { Contamination } \\
\left(\mathrm{ng} / \mathrm{cm}^{2}\right)\end{array}$ & $\begin{array}{l}\text { Low } \\
\text { Variance } \\
\text { Slope }\end{array}$ & $\begin{array}{c}\text { Equivalent } \\
\text { Contamination } \\
\left(\mathrm{ng} / \mathrm{cm}^{2}\right)\end{array}$ \\
\hline 1 & 1605 & 1124 & 2212 & 215 & 2436 & 113 \\
\hline 2 & 2312 & 161 & 2225 & 207 & 2025 & 368 \\
\hline 3 & 1958 & 446 & 1874 & 568 & 2117 & 282 \\
\hline 4 & 1422 & 1510 & 2174 & 239 & 2081 & 313 \\
\hline 5 & 2157 & 251 & 2262 & 186 & 1581 & 1169 \\
\hline 6 & 1299 & 1842 & & & & \\
\hline Avg. & 1792 & 889 & 2149 & 283 & 2048 & 449 \\
\hline Std. Dev. & 411.4 & 704.6 & 157.1 & 160.5 & 306.2 & 413.6 \\
\hline$\% \mathrm{CV}$ & 23.0 & 79.3 & 7.3 & 56.8 & 15.0 & 92.2 \\
\hline
\end{tabular}


The samples that were cleaned by wiping three times with HFE-7100 saturated premoistened polyester wipers remained significantly contaminated. The average slope was 972 and the average contamination level was $3206 \mathrm{ng} / \mathrm{cm}^{2}$. Additional wipes with the HFE-7100 saturated premoistened polyester wipers (data not shown) did not improve the cleanliness levels. Additional tests were run by wiping a "clean - not contaminated" aluminum disk three times with the HFE-7100 saturated premoistened polyester wipers. This resulted in a slope of 1534 and a contamination level of $1261 \mathrm{ng} / \mathrm{cm}^{2}$. This result indicates that wiping clean substrates with the HFE-7100 saturated premoistened polyester wipers leaves a significant amount of contamination. The contamination is either because the HFE-7100 used to saturate the polyester wipers is not very clean in terms of nonvolatile residue or the HFE-7100 is extracting something from the polyester wipers or the bags they are stored in. After wiping three times with IPA, the average slope was 3017 and the average contamination level was $33 \mathrm{ng} / \mathrm{cm}^{2}$. Four of the five IPA cleaned samples were very clean. Because the HFE-7100 saturated premoistened polyester wipers did not do an adequate job of removing the DC-4 silicone (and left a residue on even clean substrates), it was decided to evaluate HFE-7100 in the same manner as IPA ( $5 \mathrm{~mL} /$ Kaydry). The average slope value for wiping six times with HFE-7100 was 2590 and the average contamination level was $95 \mathrm{ng} / \mathrm{cm}^{2}$. Three of the samples were very clean. Wiping three times with the HFE-7100/IPA azeotrope was not as good as wiping three times with IPA or six times with HFE-7100. The average slope was 1792 and the average contamination value was $889 \mathrm{ng} / \mathrm{cm}^{2}$. Three of the six samples cleaned three times with the HFE-7100/IPA azeotrope showed significant contamination amounts. Wiping six times with the HFE-7100/IPA azeotrope was an improvement over wiping three times. The average slope increased to 2149 and the average contamination level decreased to $283 \mathrm{ng} / \mathrm{cm}^{2}$. This still was not as effective as wiping three times with IPA or six times with HFE-7100. Evaluation of six wipes with the HFE7100/IPA azeotrope was repeated. The average slope obtained for these tests was 2048 and the average contamination amount was $449 \mathrm{ng} / \mathrm{cm}^{2}$. The first four tests fell in line with the original tests of the HFE-7100/IPA azeotrope; however, the fifth test exhibited a significant amount of contamination which increased the average contamination for this group of tests. The average contamination amount for the first four tests of the repeat evaluations was $269 \mathrm{ng} / \mathrm{cm}^{2}$ which compares favorably with the $283 \mathrm{ng} / \mathrm{cm}^{2}$ average of the initial tests. The HFE-7100/IPA azeotrope (6 wipes) was not as effective as the IPA (three wipes) or the HFE-7100 (6 wipes). 


\section{DC-4 Silicone Insulating Compound on 304L Stainless Steel Disks}

The calibration of DC-4 silicone insulating compound on 304L stainless steel disks is shown in Figure 9.

MESERAN Low Variance Slope Calibration of DC-4 Silicone Insulating Compound on Original MetaSpec 304L SS Disks with 16 RMS Finish Tested with BH 0309091

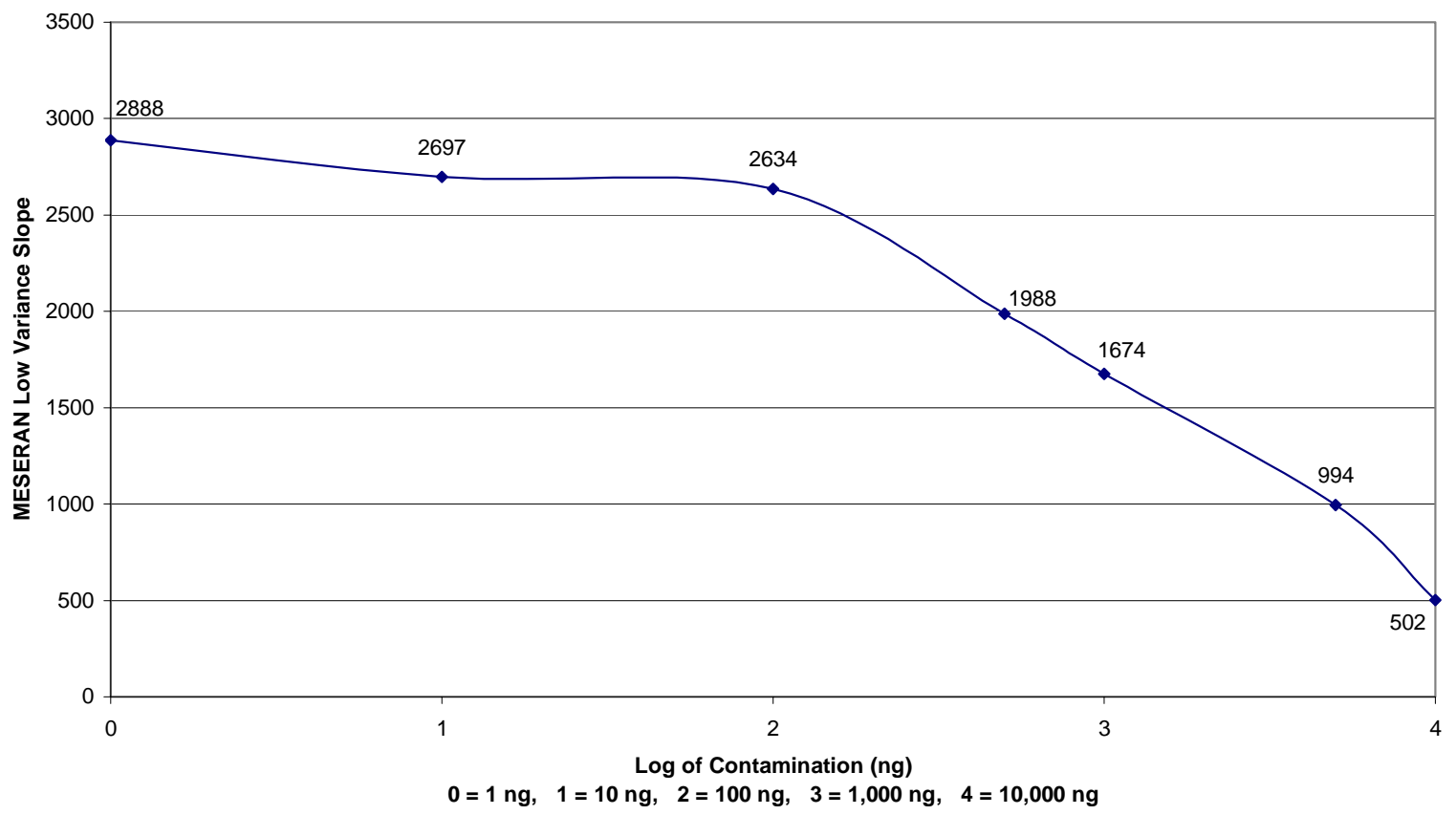

Figure 9. Calibration of DC-4 Silicone Insulating Compound on 304L Stainless Steel Disks 
The results of the cleaning evaluations performed to remove the DC-4 silicone insulating compound from 304L stainless steel disks are shown in Table 8.

Table 8. MESERAN Results and Equivalent Contamination Amounts for DC-4 Silicone Insulating Compound on 304L Stainless Steel Disks

\begin{tabular}{|c|c|c|c|c|}
\hline \multirow[b]{2}{*}{ Test } & \multicolumn{2}{|c|}{$\begin{array}{c}\text { Cleaned by Wiping } \\
\text { With HFE-7100 } \\
\text { Premoistened Polyester Wipers } \\
3 \text { Times }\end{array}$} & \multicolumn{2}{|c|}{$\begin{array}{c}\text { Cleaned by Wiping } \\
\text { with IPA } \\
\text { (5 mL/Kaydry) - } 3 \text { Times }\end{array}$} \\
\hline & $\begin{array}{l}\text { Low } \\
\text { Variance } \\
\text { Slope }\end{array}$ & $\begin{array}{c}\text { Equivalent } \\
\text { Contamination } \\
\left(\mathrm{ng} / \mathrm{cm}^{2}\right)\end{array}$ & $\begin{array}{l}\text { Low } \\
\text { Variance } \\
\text { Slope }\end{array}$ & $\begin{array}{c}\text { Equivalent } \\
\text { Contamination } \\
\left(\mathrm{ng} / \mathrm{cm}^{2}\right)\end{array}$ \\
\hline 1 & 1178 & 3237 & 3630 & $<1$ \\
\hline 2 & 1114 & 3766 & 3292 & $<1$ \\
\hline 3 & 1431 & 1779 & 2992 & $<1$ \\
\hline 4 & 960 & 5247 & 4079 & $<1$ \\
\hline 5 & 1133 & 3600 & 3109 & $<1$ \\
\hline Avg. & 1163 & 3526 & 3420 & $<1$ \\
\hline Std. Dev. & 170.7 & 1241.0 & 440.1 & \\
\hline$\% \mathrm{CV}$ & 14.7 & 35.2 & 12.9 & \\
\hline
\end{tabular}

\begin{tabular}{|c|c|c|c|c|}
\hline & \multicolumn{2}{|c|}{$\begin{array}{c}\text { Cleaned by Wiping With HFE- } \\
7100 / \text { IPA Azeotrope } \\
(5 \mathrm{~mL} / \text { Kaydry })-3 \text { Times }\end{array}$} & \multicolumn{2}{c|}{$\begin{array}{c}\text { Cleaned by Wiping With } \\
\text { HFE-7100/IPA Azeotrope } \\
(5 \mathrm{~mL} / \text { Kaydry })-6 \text { Times }\end{array}$} \\
\hline Test & $\begin{array}{c}\text { Low } \\
\text { Variance } \\
\text { Slope }\end{array}$ & $\begin{array}{c}\text { Equivalent } \\
\text { Contamination } \\
\left(\mathrm{ng} / \mathrm{cm}^{2}\right)\end{array}$ & $\begin{array}{c}\text { Low } \\
\text { Variance } \\
\text { Slope }\end{array}$ & $\begin{array}{c}\text { Equivalent } \\
\text { Contamination } \\
\left(\mathrm{ng} / \mathrm{cm}^{2}\right)\end{array}$ \\
\hline 1 & 2360 & 198 & 2787 & 3 \\
\hline 2 & 2327 & 215 & 2587 & 112 \\
\hline 3 & 2680 & 19 & 2076 & 402 \\
\hline 4 & 2529 & 130 & 2419 & 171 \\
\hline 5 & 1802 & 754 & 2467 & 152 \\
\hline Avg. & $\mathbf{2 3 4 0}$ & $\mathbf{2 6 3}$ & $\mathbf{2 4 6 7}$ & $\mathbf{1 6 8}$ \\
\hline Std. Dev. & $\mathbf{3 3 2 . 2}$ & $\mathbf{2 8 5 . 2}$ & $\mathbf{2 6 0 . 8}$ & $\mathbf{1 4 5 . 8}$ \\
\hline \% CV & $\mathbf{1 4 . 2}$ & $\mathbf{1 0 8 . 4}$ & $\mathbf{1 0 . 6}$ & $\mathbf{8 6 . 8}$ \\
\hline
\end{tabular}

The samples that were cleaned by wiping three times with HFE-7100 saturated premoistened polyester wipers remained significantly contaminated. The average slope was 1163 and the average contamination level was $3526 \mathrm{ng} / \mathrm{cm}^{2}$. After wiping three times with IPA, the average 
slope was 3420 and the average contamination level was $<1 \mathrm{ng} / \mathrm{cm}^{2}$. All five IPA cleaned samples were very clean. Wiping three times with the HFE-7100/IPA azeotrope was not as good as wiping three times with IPA. The average slope was 2340 and the average contamination value was $263 \mathrm{ng} / \mathrm{cm}^{2}$. One of the five samples cleaned three times with the HFE-7100/IPA azeotrope was very clean and one showed a significant contamination amount. Wiping six times with the HFE-7100/IPA azeotrope was a slight improvement over wiping three times. The average slope increased to 2467 and the average contamination level decreased to $168 \mathrm{ng} / \mathrm{cm}^{2}$. This still was not as effective as wiping three times with IPA.

\section{DC-4 Silicone Insulating Compound on Passivated 304L Stainless Steel Disks}

The calibration of DC-4 silicone insulating compound on passivated 304L stainless steel disks is shown in Figure 10.
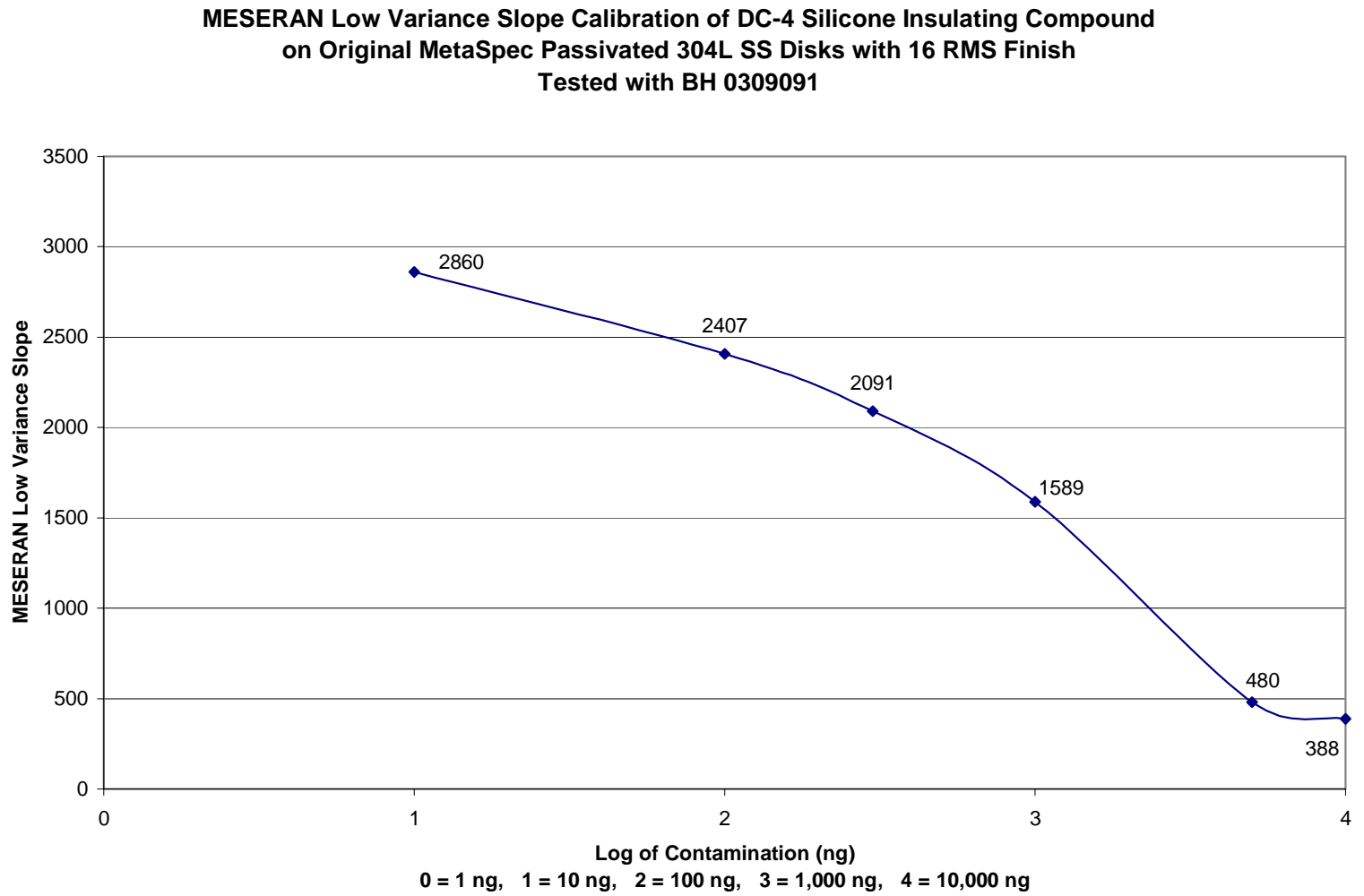

Figure 10. Calibration of DC-4 Silicone Insulating Compound on Passivated 304L Stainless Steel Disks

As can be seen from Figure 10, the calibration was only conducted down to $10 \mathrm{ng}$. Any slopes obtained on samples tested and compared to this calibration that are higher than 2860 are reported as $<10 \mathrm{ng}$. Estimates can be made by extrapolating the curve and estimating a value for $1 \mathrm{ng}$. Any estimates shown will be indicated as such. 
The results of the cleaning evaluations performed to remove the DC-4 silicone insulating compound from passivated 304L stainless steel disks are shown in Table 9.

Table 9. MESERAN Results and Equivalent Contamination Amounts for DC-4 Silicone Insulating Compound on Passivated 304L Stainless Steel Disks

\begin{tabular}{|c|c|c|c|c|}
\hline & \multicolumn{2}{|c|}{$\begin{array}{c}\text { Cleaned by Wiping } \\
\text { With HFE-7100 } \\
\text { Premoistened Polyester Wipers } \\
\text { 3 Times }\end{array}$} & \multicolumn{2}{c|}{$\begin{array}{c}\text { Cleaned by Wiping } \\
\text { with IPA } \\
\text { (5 mL/Kaydry) - 3 Times }\end{array}$} \\
\hline Test & $\begin{array}{c}\text { Low } \\
\text { Variance } \\
\text { Slope }\end{array}$ & $\begin{array}{c}\text { Equivalent } \\
\text { Contamination } \\
\left(\mathrm{ng} / \mathrm{cm}^{2}\right)\end{array}$ & $\begin{array}{c}\text { Low } \\
\text { Variance } \\
\text { Slope }\end{array}$ & $\begin{array}{c}\text { Equivalent } \\
\text { Contamination } \\
\left(\mathrm{ng} / \mathrm{cm}^{2}\right)\end{array}$ \\
\hline 1 & 1189 & 1787 & 2905 & $<10($ Est. 6) \\
\hline 3 & 1022 & 2277 & 2666 & 27 \\
\hline 4 & 1043 & 2209 & 2307 & 142 \\
\hline 5 & 1189 & 1787 & 2448 & 81 \\
\hline Avg. & $\mathbf{1 1 0 3}$ & $\mathbf{2 0 3 4}$ & $\mathbf{2 5 5 7}$ & $\mathbf{6 7}$ \\
\hline Std. Dev. & $\mathbf{8 0 . 3}$ & $\mathbf{2 3 3 . 2}$ & $\mathbf{2 3 3 . 1}$ & $\mathbf{5 3 . 1}$ \\
\hline \% CV & $\mathbf{7 . 3}$ & $\mathbf{1 1 . 5}$ & $\mathbf{9 . 1}$ & $\mathbf{7 9 . 4}$ \\
\hline
\end{tabular}

Est. = Value estimated outside of calibration curve

\begin{tabular}{|c|c|c|c|c|}
\hline & \multicolumn{2}{|c|}{$\begin{array}{c}\text { Cleaned by Wiping With HFE- } \\
\text { 7100/IPA Azeotrope } \\
(5 \mathrm{~mL} / \text { Kaydry })-3 \text { Times }\end{array}$} & \multicolumn{2}{c|}{$\begin{array}{c}\text { Cleaned by Wiping With } \\
\text { HFE-7100/IPA Azeotrope }\end{array}$} \\
\hline Test & $\begin{array}{c}\text { Low } \\
\text { Variance } \\
\text { Slope }\end{array}$ & $\begin{array}{c}\text { Equivalent } \\
\text { Contamination } \\
\left(\mathrm{ng} / \mathrm{cm}^{2}\right)\end{array}$ & $\begin{array}{c}\text { Low } \\
\text { Variance } \\
\text { Slope }\end{array}$ & $\begin{array}{c}\text { Equivalent } \\
\text { Contamination } \\
\left(\mathrm{ng} / \mathrm{cm}^{2}\right)\end{array}$ \\
\hline 1 & 2421 & 93 & 2335 & 128 \\
\hline 2 & 1975 & 396 & 2028 & 349 \\
\hline 3 & 1963 & 408 & 2401 & 102 \\
\hline 4 & 2008 & 366 & 1702 & 763 \\
\hline 5 & 1842 & 545 & 1927 & 445 \\
\hline Avg. & $\mathbf{2 0 4 2}$ & $\mathbf{3 6 2}$ & $\mathbf{2 0 7 9}$ & $\mathbf{3 5 7}$ \\
\hline Std. Dev. & $\mathbf{2 2 1 . 1}$ & $\mathbf{1 6 5 . 2}$ & $\mathbf{2 9 0 . 3}$ & $\mathbf{2 6 9 . 0}$ \\
\hline \% CV & $\mathbf{1 0 . 8}$ & $\mathbf{4 5 . 7}$ & $\mathbf{1 4 . 0}$ & $\mathbf{7 5 . 3}$ \\
\hline
\end{tabular}


The samples that were cleaned by wiping three times with HFE-7100 saturated premoistened polyester wipers remained significantly contaminated. The average slope was 1103 and the average contamination level was $2034 \mathrm{ng} / \mathrm{cm}^{2}$. After wiping three times with IPA, the average slope was 2557 and the average contamination level was $67 \mathrm{ng} / \mathrm{cm}^{2}$. Wiping three times with the HFE-7100/IPA azeotrope was not as good as wiping three times with IPA. The average slope was 2042 and the average contamination value was $362 \mathrm{ng} / \mathrm{cm}^{2}$. Wiping six times with the HFE7100/IPA azeotrope did not show any improvement over wiping three times. The average slope was 2079 and the average contamination level was $357 \mathrm{ng} / \mathrm{cm}^{2}$. Even with increased wipes, the HFE-7100/IPA azeotrope was not as effective at removing the DC-4 silicone from the passivated 304L stainless steel as the IPA.

\section{DC-4 Silicone Insulating Compound on 303 Stainless Steel Disks}

The calibration of DC-4 silicone insulating compound on 303 stainless steel disks is shown in Figure 11.
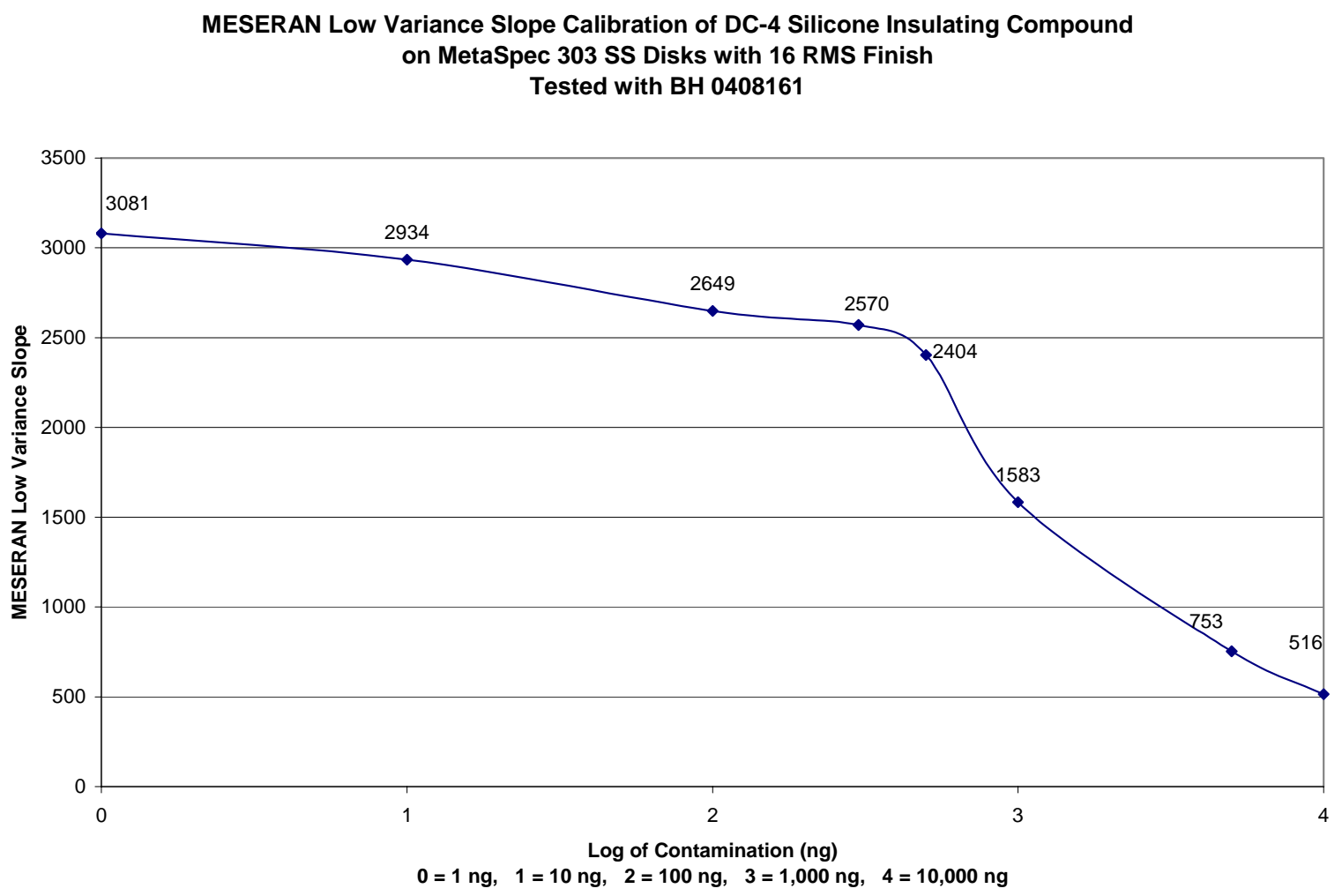

Figure 11. Calibration of DC-4 Silicone Insulating Compound on 303 Stainless Steel Disks 
The results of the cleaning evaluations performed to remove the DC-4 silicone insulating compound from 303 stainless steel disks are shown in Table 10.

Table 10. MESERAN Results and Equivalent Contamination Amounts for DC-4 Silicone Insulating Compound on 303 Stainless Steel Disks

\begin{tabular}{|c|c|c|c|c|c|c|}
\hline \multirow[b]{2}{*}{ Test } & \multicolumn{2}{|c|}{$\begin{array}{c}\text { Cleaned by Wiping } \\
\text { With HFE-7100 } \\
\text { Premoistened Polyester Wipers } \\
3 \text { Times }\end{array}$} & \multicolumn{2}{|c|}{$\begin{array}{c}\text { Cleaned by Wiping } \\
\text { with IPA } \\
\text { (5 mL/Kaydry) }-3 \text { Times } \\
\text { (Initial Tests) }\end{array}$} & \multicolumn{2}{|c|}{$\begin{array}{c}\text { Cleaned by Wiping } \\
\text { With HFE-7100 } \\
\text { (5 mL/Kaydry) - } 6 \text { Times } \\
\text { (Initial Tests) }\end{array}$} \\
\hline & $\begin{array}{c}\text { Low } \\
\text { Variance } \\
\text { Slope }\end{array}$ & $\begin{array}{c}\text { Equivalent } \\
\text { Contamination } \\
\left(\mathrm{ng} / \mathrm{cm}^{2}\right)\end{array}$ & $\begin{array}{c}\text { Low } \\
\text { Variance } \\
\text { Slope }\end{array}$ & $\begin{array}{c}\text { Equivalent } \\
\text { Contamination } \\
\left(\mathrm{ng} / \mathrm{cm}^{2}\right)\end{array}$ & $\begin{array}{c}\text { Low } \\
\text { Variance } \\
\text { Slope }\end{array}$ & $\begin{array}{c}\text { Equivalent } \\
\text { Contamination } \\
\left(\mathrm{ng} / \mathrm{cm}^{2}\right)\end{array}$ \\
\hline 1 & 944 & 3452 & 2761 & 40 & 3112 & $<1$ \\
\hline 2 & 1041 & 2860 & 2936 & 10 & 2539 & 330 \\
\hline 3 & 1168 & 2236 & 3440 & $<1$ & 2799 & 30 \\
\hline 4 & 900 & 3760 & 3246 & $<1$ & 2164 & 612 \\
\hline 5 & 1280 & 1800 & 2842 & 21 & 3209 & $<1$ \\
\hline Avg. & 1067 & 2822 & 3045 & 14 & 2765 & 195 \\
\hline Std. Dev. & 157.5 & 816.4 & 287.3 & 16.8 & 427.5 & 271.6 \\
\hline$\% \mathrm{CV}$ & 14.8 & 28.9 & 9.4 & 118.5 & 15.5 & 139.6 \\
\hline
\end{tabular}

\begin{tabular}{|c|c|c|c|c|}
\hline & \multicolumn{2}{|c|}{$\begin{array}{c}\text { Cleaned by Wiping With HFE- } \\
7100 / \text { IPA Azeotrope } \\
(5 \mathrm{~mL} / \text { Kaydry })-3 \text { Times }\end{array}$} & \multicolumn{2}{c|}{$\begin{array}{c}\text { Cleaned by Wiping With } \\
\text { HFE-7100/IPA Azeotrope } \\
(5 \mathrm{~mL} / \text { Kaydry })-6 \text { Times }\end{array}$} \\
\hline Test & $\begin{array}{c}\text { Low } \\
\text { Variance } \\
\text { Slope }\end{array}$ & $\begin{array}{c}\text { Equivalent } \\
\text { Contamination } \\
\left(\mathrm{ng} / \mathrm{cm}^{2}\right)\end{array}$ & $\begin{array}{c}\text { Low } \\
\text { Variance } \\
\text { Slope }\end{array}$ & $\begin{array}{c}\text { Equivalent } \\
\text { Contamination } \\
\left(\mathrm{ng} / \mathrm{cm}^{2}\right)\end{array}$ \\
\hline 1 & 2325 & 534 & 2106 & 643 \\
\hline 2 & 1765 & 858 & 2430 & 462 \\
\hline 3 & 1853 & 796 & 1569 & 1028 \\
\hline 4 & 1577 & 1012 & 1679 & 922 \\
\hline 5 & 1479 & 1223 & 2517 & 353 \\
\hline Avg. & $\mathbf{1 8 0 0}$ & $\mathbf{8 8 5}$ & $\mathbf{2 0 6 0}$ & $\mathbf{6 8 1}$ \\
\hline Std. Dev. & $\mathbf{3 2 8 . 8}$ & $\mathbf{2 5 6 . 0}$ & $\mathbf{4 2 8 . 4}$ & $\mathbf{2 8 9 . 5}$ \\
\hline \% CV & $\mathbf{1 8 . 3}$ & $\mathbf{2 8 . 9}$ & $\mathbf{2 0 . 8}$ & $\mathbf{4 2 . 5}$ \\
\hline
\end{tabular}


Table 10 (continued). MESERAN Results and Equivalent Contamination Amounts for DC-4 Silicone Insulating Compound on 303 Stainless Steel Disks

\begin{tabular}{|c|c|c|c|c|c|c|}
\hline & \multicolumn{2}{|c|}{$\begin{array}{c}\text { Cleaned by Wiping } \\
\text { With HFE-7100DL } \\
(5 \text { mL/Kaydry) - 6 Times } \\
\text { (Retests) }\end{array}$} & \multicolumn{2}{c|}{$\begin{array}{c}\text { Cleaned by Wiping } \\
\text { with IPA } \\
(5 \text { mL/Kaydry) - 3 Times } \\
\text { (Retests) }\end{array}$} & \multicolumn{2}{|c|}{$\begin{array}{c}\text { Samples Not Contaminated } \\
\text { Cleaned by Wiping } \\
\text { With HFE-7100DL } \\
(5 \text { mL/Kaydry) - 3 Times }\end{array}$} \\
\hline Test & $\begin{array}{c}\text { Low } \\
\text { Variance } \\
\text { Slope }\end{array}$ & $\begin{array}{c}\text { Equivalent } \\
\text { Contamination } \\
\left(\mathrm{ng} / \mathrm{cm}^{2}\right)\end{array}$ & $\begin{array}{c}\text { Low } \\
\text { Variance } \\
\text { Slope }\end{array}$ & $\begin{array}{c}\text { Equivalent } \\
\text { Contamination } \\
\left(\mathrm{ng} / \mathrm{cm}^{2}\right)\end{array}$ & $\begin{array}{c}\text { Low } \\
\text { Variance } \\
\text { Slope }\end{array}$ & $\begin{array}{c}\text { Equivalent } \\
\text { Contamination } \\
\left(\mathrm{ng} / \mathrm{cm}^{2}\right)\end{array}$ \\
\hline 1 & 1847 & 800 & 2689 & 72 & 2922 & 11 \\
\hline 2 & 1803 & 830 & 2547 & 322 & 2265 & 562 \\
\hline 3 & 1680 & 921 & 2753 & 43 & 3114 & $<1$ \\
\hline 4 & 1490 & 1198 & 3154 & $<1$ & 2745 & 46 \\
\hline Avg. & 1177 & 2197 & 2894 & 14 & 2683 & 76 \\
\hline Std. Dev. & $\mathbf{1 5 9 9}$ & $\mathbf{1 1 8 9}$ & $\mathbf{2 8 0 7}$ & $\mathbf{9 0}$ & $\mathbf{2 7 4 6}$ & $\mathbf{1 3 9}$ \\
\hline \% CV & $\mathbf{2 7 3 . 7}$ & $\mathbf{5 8 4 . 9}$ & $\mathbf{2 3 0 . 4}$ & $\mathbf{1 3 2 . 3}$ & $\mathbf{3 1 6 . 9}$ & $\mathbf{2 3 8 . 3}$ \\
\hline
\end{tabular}

The samples that were cleaned by wiping three times with HFE-7100 saturated premoistened polyester wipers remained significantly contaminated. The average slope was 1067 and the average contamination level was $2822 \mathrm{ng} / \mathrm{cm}^{2}$. After wiping three times with IPA in the initial tests performed, the average slope was 3045 and the average contamination level was $14 \mathrm{ng} / \mathrm{cm}^{2}$. All of the samples cleaned with IPA in the initial group exhibited low contamination levels. The IPA cleaning tests were performed again at a later date and the average slope obtained for the retests was 2807 and the average contamination level was $90 \mathrm{ng} / \mathrm{cm}^{2}$. One of the samples exhibited more contamination than the other four samples, which increased the average contamination level for the retest group. The initial tests performed by wiping six times with HFE-7100 (5 mL/Kaydry) yielded an average slope of 2765 and an average contamination level of $195 \mathrm{ng} / \mathrm{cm}^{2}$. Three of the samples evaluated exhibited very low contamination levels and the other two samples exhibited higher contamination levels. All of these samples still looked somewhat contaminated. These tests were performed again at a later date using the new bottle of HFE-7100DL, and the average slope was 1599 and the average contamination level was 1189 $\mathrm{ng} / \mathrm{cm}^{2}$. All of the samples tested exhibited high levels of contamination. Samples that had not been intentionally contaminated with DC-4 silicone were cleaned by wiping three times with the HFE-7100DL to make sure that the solvent was not contaminated. The average slope was 2746 and the average contamination amount was $139 \mathrm{ng} / \mathrm{cm}^{2}$. Four of the five samples tested pretty clean; however, one sample exhibited a larger amount of contamination. It is postulated that this sample must not have been properly precleaned prior to these tests and the HFE-7100DL was unable to completely remove whatever contamination had previously been on the sample. It does not appear that the HFE-7100DL has a large nonvolatile residue issue. There is no clear-cut 
answer as to why the initial tests on HFE-7100 yielded much cleaner surfaces than the subsequent retests. The evaluations conducted on the HFE-7100/IPA azeotrope indicate that it does not remove the DC-4 silicone as well as IPA. Wiping three times with the HFE-7100/IPA azeotrope yielded an average slope of 1800 and an average contamination level of $885 \mathrm{ng} / \mathrm{cm}^{2}$. Wiping six times with the HFE-7100/IPA azeotrope slightly improved the results. The average slope increased to 2060 and the average contamination level decreased to $681 \mathrm{ng} / \mathrm{cm}^{2}$. All of the samples tested with three and six wipes with the HFE-7100/IPA azeotrope showed significant contamination amounts. Even with increased wipes, the HFE-7100/IPA azeotrope was not as effective at removing the DC-4 silicone from the 303 stainless steel as the IPA.

\section{DC-4 Silicone Insulating Compound Conclusions}

A graphical representation of the MESERAN slope data for all of the DC-4 silicone insulating compound cleaning evaluations for each substrate is shown in Figure 12. A graphical representation of the equivalent contamination amounts determined by MESERAN Analysis for all of the DC-4 silicone insulating compound cleaning evaluations for each substrate is shown in Figure 13.

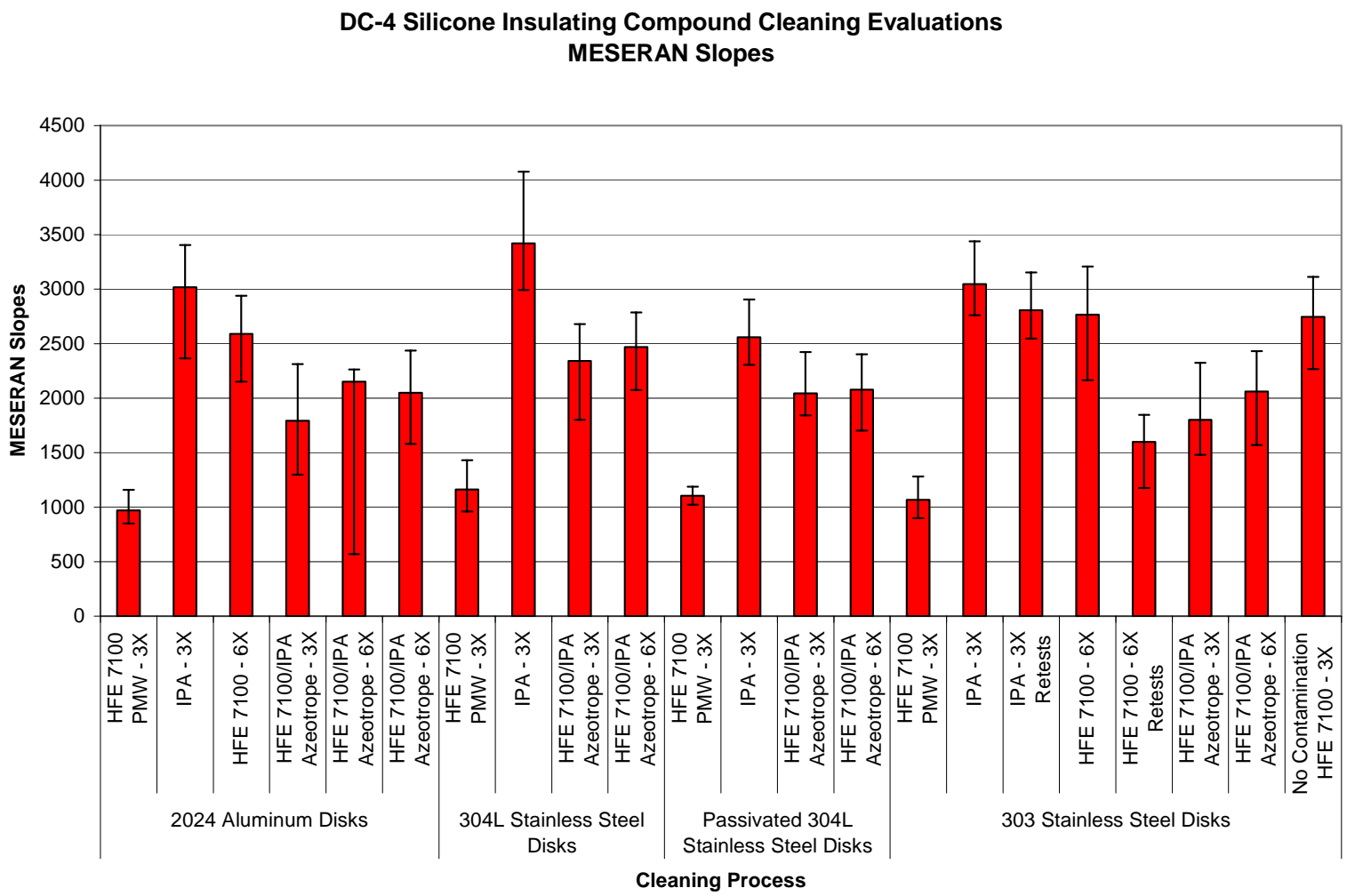

Figure 12. MESERAN Slope Data for DC-4 Silicone Insulating Compound Cleaning Evaluations 
DC-4 Silicone Insulating Compound Cleaning Evaluations

Equivalent Contamination Amounts Determined by MESERAN Analysis

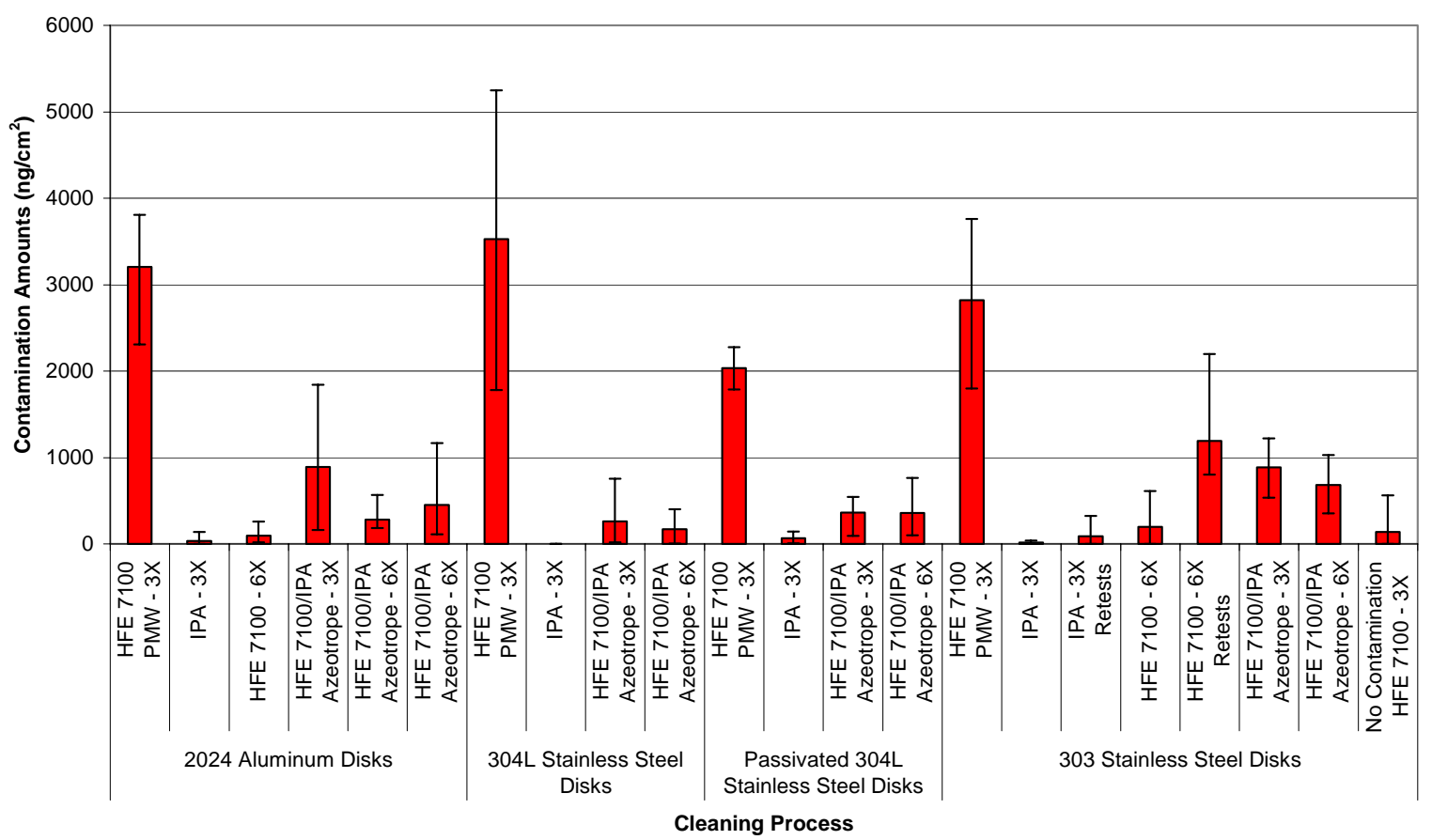

Figure 13.Equivalent Contamination Amounts Determined by MESERAN Analysis for DC-4 Silicone Insulating Compound Cleaning Evaluations

IPA is the most effective solvent evaluated for removing DC-4 silicone. In initial evaluations, wiping six times with HFE-7100 approaches the same cleanliness achieved with wiping three times with IPA; however the results could not be repeated when the HFE-7100 evaluations were performed again. The HFE-7100/IPA azeotrope was not as effective as IPA, even when six wipes were used.

DC-4 silicone was the hardest contaminant for the HFE-7100/IPA azeotrope to remove. Wiping six times with HFE-7100/IPA azeotrope did not remove the DC-4 silicone as well as IPA.

Wiping six times with HFE-7100/IPA azeotrope was able to clean the DC-4 silicone from all of the substrates to a level below $1 \mu \mathrm{g} / \mathrm{cm}^{2}$ (the cleanliness level called out by most aerospace companies for metal cleaning operations). However, it was unable to clean it to submonolayer levels. It must be determined whether the cleanliness level achieved is good enough or if additional wipes are necessary. 


\section{$\underline{\text { Dust Sebum Emulsion Cleaning Evaluations }}$}

\section{Dust Sebum Emulsion on 2024 Aluminum Disks}

The calibration of dust sebum emulsion on 2024 aluminum disks is shown in Figure 14.
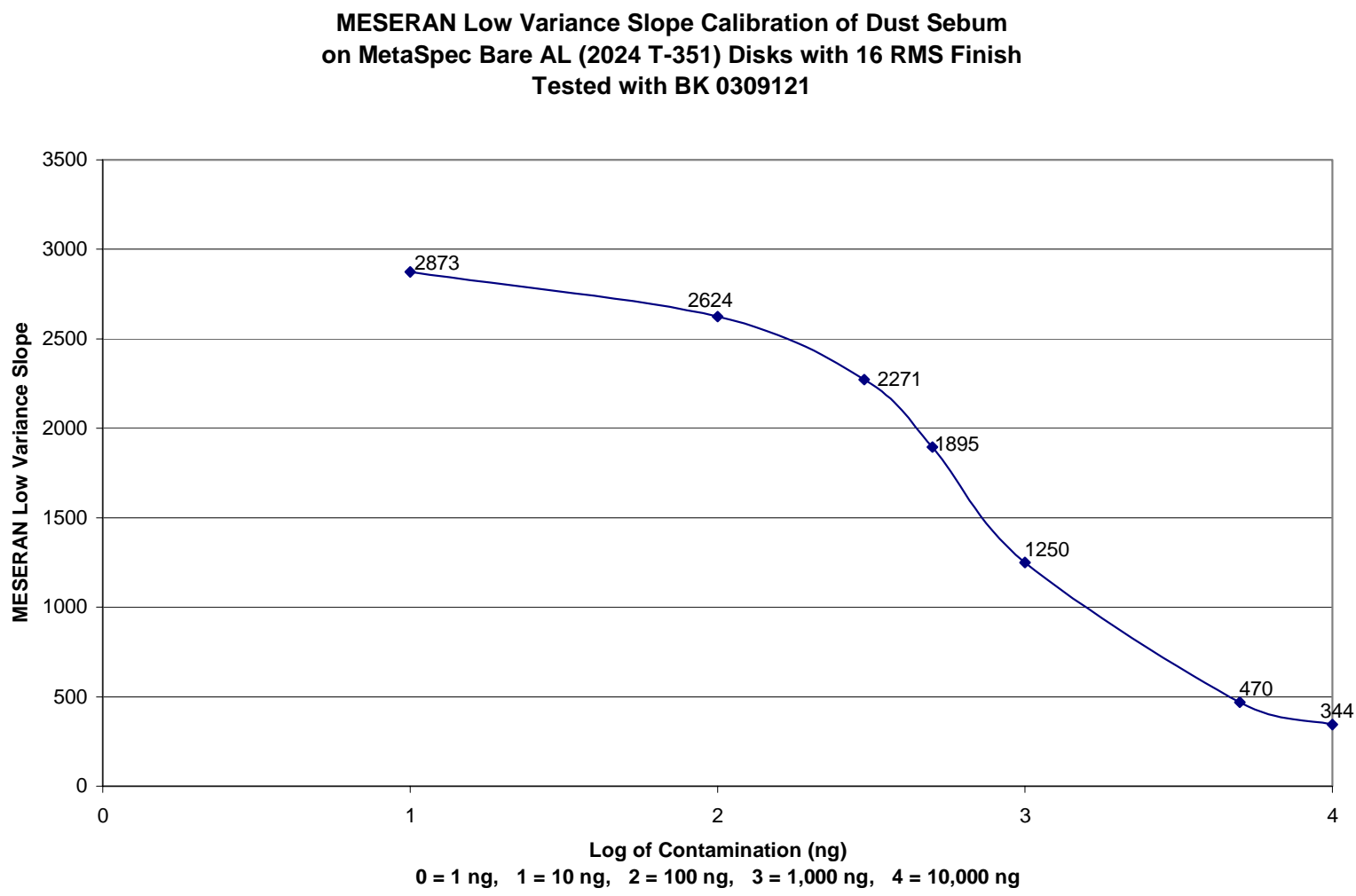

Figure 14. Calibration of Dust Sebum Emulsion on 2024 Aluminum Disks

As can be seen from Figure 14, the calibration was only conducted down to 10 ng. Any slopes obtained on samples tested and compared to this calibration that are higher than 2873 are reported as <10 ng. Any slopes obtained that are lower than 344 are reported as >10,000 ng. Estimates can be made by extrapolating the curve and estimating a value for $1 \mathrm{ng}$ and a value for something higher than 10,000 ng. Any estimates shown will be indicated as such. 
The results of the cleaning evaluations performed to remove the dust sebum emulsion from 2024 aluminum disks are shown in Table 11.

Table 11. MESERAN Results and Equivalent Contamination Amounts for Dust Sebum Emulsion on 2024 Aluminum Disks

\begin{tabular}{|c|c|c|c|c|c|c|}
\hline \multirow[b]{2}{*}{ Test } & \multicolumn{2}{|c|}{$\begin{array}{c}\text { Cleaned by Wiping } \\
\text { With HFE-7100 } \\
\text { Premoistened Polyester Wipers } \\
3 \text { Times }\end{array}$} & \multicolumn{2}{|c|}{$\begin{array}{c}\text { Cleaned by Wiping } \\
\text { with IPA } \\
\text { (5 mL/Kaydry) - } 3 \text { Times }\end{array}$} & \multicolumn{2}{|c|}{$\begin{array}{c}\text { Cleaned by Wiping } \\
\text { With HFE-7100 } \\
\text { (5 mL/Kaydry) }-6 \text { Times }\end{array}$} \\
\hline & $\begin{array}{l}\text { Low } \\
\text { Variance } \\
\text { Slope }\end{array}$ & $\begin{array}{c}\text { Equivalent } \\
\text { Contamination } \\
\left(\mathrm{ng} / \mathrm{cm}^{2}\right)\end{array}$ & $\begin{array}{l}\text { Low } \\
\text { Variance } \\
\text { Slope }\end{array}$ & $\begin{array}{c}\text { Equivalent } \\
\text { Contamination } \\
\left(\mathrm{ng} / \mathrm{cm}^{2}\right)\end{array}$ & $\begin{array}{l}\text { Low } \\
\text { Variance } \\
\text { Slope }\end{array}$ & $\begin{array}{c}\text { Equivalent } \\
\text { Contamination } \\
\left(\mathrm{ng} / \mathrm{cm}^{2}\right)\end{array}$ \\
\hline 1 & 297 & $\begin{array}{c}>10000 \\
\text { (Est. 17737) }\end{array}$ & 2953 & $<10$ (Est. 4) & 2357 & 230 \\
\hline 2 & 338 & $\begin{array}{c}>10000 \\
\text { (Est. 10759) }\end{array}$ & 2539 & 130 & 1517 & 751 \\
\hline 3 & 553 & 4213 & 1922 & 482 & 1459 & 799 \\
\hline 4 & 528 & 4436 & 2862 & 11 & 1221 & 1062 \\
\hline 5 & 656 & 3406 & 3037 & $<10$ (Est. 1) & 1427 & 827 \\
\hline Avg. & 474 & 8110 & 2663 & 126 & 1596 & 733 \\
\hline Std. Dev. & 151.7 & 6134.0 & 455.0 & 206.4 & 439.7 & 306.2 \\
\hline$\% \mathrm{CV}$ & 32.0 & 75.6 & 17.1 & 164.3 & 27.5 & 41.7 \\
\hline
\end{tabular}

Est. = Values estimated outside of calibration curve

\begin{tabular}{|c|c|c|c|c|}
\hline & \multicolumn{2}{|c|}{$\begin{array}{c}\text { Cleaned by Wiping With HFE- } \\
7100 / \text { IPA Azeotrope } \\
(5 \mathrm{~mL} / \text { Kaydry })-3 \text { Times }\end{array}$} & \multicolumn{2}{c|}{$\begin{array}{c}\text { Cleaned by Wiping With } \\
\text { HFE-7100/IPA Azeotrope } \\
(5 \mathrm{~mL} / \text { Kaydry })-6 \text { Times }\end{array}$} \\
\hline Test & $\begin{array}{c}\text { Low } \\
\text { Variance } \\
\text { Slope } \\
\text { Contamination } \\
\left(\mathrm{ng} / \mathrm{cm}^{2}\right)\end{array}$ & $\begin{array}{c}\text { Low } \\
\text { Variance } \\
\text { Slope }\end{array}$ & $\begin{array}{c}\text { Equivalent } \\
\text { Contamination } \\
\left(\mathrm{ng} / \mathrm{cm}^{2}\right)\end{array}$ \\
\hline 1 & 2399 & 201 & 2935 & $<10($ Est. 5) \\
\hline 2 & 2810 & 18 & 3202 & $<10($ Est. $<1)$ \\
\hline 3 & 2526 & 136 & 2372 & 219 \\
\hline 4 & 2123 & 367 & 2273 & 298 \\
\hline 5 & 2633 & 92 & 2831 & 15 \\
\hline Avg. & $\mathbf{2 4 9 8}$ & $\mathbf{1 6 3}$ & $\mathbf{2 7 2 3}$ & $\mathbf{1 0 7}$ \\
\hline Std. Dev. & $\mathbf{2 5 8 . 3}$ & $\mathbf{1 3 2 . 1}$ & $\mathbf{3 9 1 . 1}$ & $\mathbf{1 4 0 . 9}$ \\
\hline \% CV & $\mathbf{1 0 . 3}$ & $\mathbf{8 1 . 2}$ & $\mathbf{1 4 . 4}$ & $\mathbf{1 3 1 . 2}$ \\
\hline
\end{tabular}

Est. $=$ Values estimated outside of calibration curve

The samples that were cleaned by wiping three times with HFE-7100 saturated premoistened polyester wipers remained significantly contaminated. The average slope was 474 and the 
average contamination level was $8110 \mathrm{ng} / \mathrm{cm}^{2}$. All of the samples showed significant amounts of contamination. Two of the samples exhibited slopes lower than the bottom range of the calibration (i.e., lower than 344 which correlate to $>10,000 \mathrm{ng} / \mathrm{cm}^{2}$ ). Their contamination amounts were estimated by extrapolating the curve beyond 10,000 ng based upon likely values seen in other calibrations. The samples cleaned by wiping three times with IPA had an average slope of 2663 and an average contamination level of $126 \mathrm{ng} / \mathrm{cm}^{2}$. Three of the five samples were very clean and one sample had significantly more contamination than the other samples. The samples cleaned by wiping six times with HFE-7100 (5 mL/Kaydry) yielded an average slope of 1596 and an average contamination level of $733 \mathrm{ng} / \mathrm{cm}^{2}$. Wiping three times with the HFE-7100/IPA azeotrope approached the equivalency of wiping three times with IPA. The average slope was 2498 and the average contamination value was $163 \mathrm{ng} / \mathrm{cm}^{2}$. Wiping six times with the HFE-7100/IPA azeotrope increased the average slope to 2723 and decreased the average contamination level to $107 \mathrm{ng} / \mathrm{cm}^{2}$. Three of the five samples wiped six times with the HFE7100/IPA azeotrope were very clean. Wiping six times with the HFE-7100/IPA azeotrope was slightly better than wiping three times with IPA.

\section{Dust Sebum Emulsion on 304L Stainless Steel Disks}

The calibration of dust sebum emulsion on 304L stainless steel disks is shown in Figure 15.
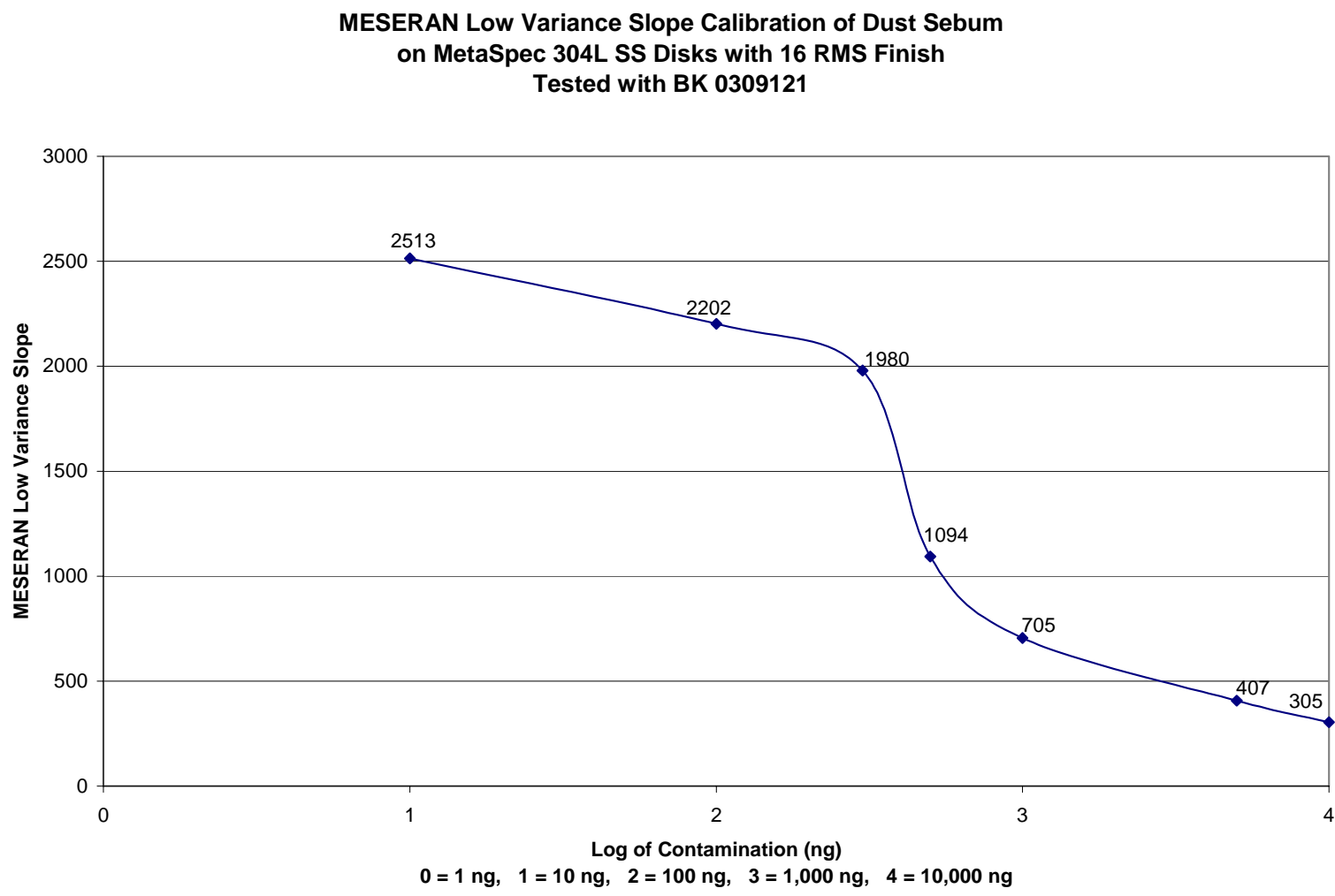

Figure 15. Calibration of Dust Sebum Emulsion on 304L Stainless Steel Disks

As can be seen from Figure 15, the calibration was only conducted down to $10 \mathrm{ng}$. Any slopes obtained on samples tested and compared to this calibration that are higher than 2513 are 
reported as $<10 \mathrm{ng}$. Estimates can be made by extrapolating the curve and estimating a value for 1 ng. Any estimates shown will be indicated as such.

The results of the cleaning evaluations performed to remove the dust sebum emulsion from 304L stainless steel disks are shown in Table 12.

Table 12. MESERAN Results and Equivalent Contamination Amounts for Dust Sebum Emulsion on 304L Stainless Steel Disks

\begin{tabular}{|c|c|c|c|c|c|c|}
\hline \multirow[b]{2}{*}{ Test } & \multicolumn{2}{|c|}{$\begin{array}{c}\text { Cleaned by Wiping } \\
\text { With HFE-7100 } \\
\text { Premoistened Polyester Wipers } \\
3 \text { Times }\end{array}$} & \multicolumn{2}{|c|}{$\begin{array}{c}\text { Cleaned by Wiping } \\
\text { with IPA } \\
\text { (5 mL/Kaydry) - } 3 \text { Times }\end{array}$} & \multicolumn{2}{|c|}{$\begin{array}{c}\text { Cleaned by Wiping } \\
\text { With HFE-7100 } \\
\text { (5 mL/Kaydry) - } 6 \text { Times }\end{array}$} \\
\hline & $\begin{array}{l}\text { Low } \\
\text { Variance } \\
\text { Slope }\end{array}$ & $\begin{array}{c}\text { Equivalent } \\
\text { Contamination } \\
\left(\mathrm{ng} / \mathrm{cm}^{2}\right)\end{array}$ & $\begin{array}{l}\text { Low } \\
\text { Variance } \\
\text { Slope }\end{array}$ & $\begin{array}{c}\text { Equivalent } \\
\text { Contamination } \\
\left(\mathrm{ng} / \mathrm{cm}^{2}\right)\end{array}$ & $\begin{array}{l}\text { Low } \\
\text { Variance } \\
\text { Slope }\end{array}$ & $\begin{array}{c}\text { Equivalent } \\
\text { Contamination } \\
\left(\mathrm{ng} / \mathrm{cm}^{2}\right)\end{array}$ \\
\hline 1 & 1154 & 483 & 2844 & $<10$ (Est. <1) & 2861 & $<10$ (Est. $<1)$ \\
\hline 2 & 1374 & 425 & 2930 & $<10$ (Est. <1) & 2354 & 32 \\
\hline 3 & 767 & 895 & 3027 & $<10$ (Est. <1) & 3060 & $<10($ Est. $<1)$ \\
\hline 4 & 1024 & 566 & 3205 & $<10$ (Est. $<1)$ & 2713 & $<10($ Est. $<1)$ \\
\hline 5 & 360 & 6881 & 3222 & $<10$ (Est. <1) & 2770 & $<10($ Est. $<1)$ \\
\hline Avg. & 936 & 1850 & 3046 & $<\mathbf{1 0}$ (Est. $<1)$ & 2752 & 7 \\
\hline Std. Dev. & 389.7 & 2818.3 & 166.5 & & 258.4 & 14.3 \\
\hline$\% \mathrm{CV}$ & 41.6 & 152.3 & 5.5 & & 9.4 & 207.5 \\
\hline
\end{tabular}

Est. $=$ Values estimated outside of calibration curve

\begin{tabular}{|c|c|c|c|c|}
\hline & \multicolumn{2}{|c|}{$\begin{array}{c}\text { Cleaned by Wiping With HFE- } \\
7100 / \text { IPA Azeotrope } \\
(5 \mathrm{~mL} / \text { Kaydry })-3 \text { Times }\end{array}$} & \multicolumn{2}{|c|}{$\begin{array}{c}\text { Cleaned by Wiping With } \\
\text { HFE-7100/IPA Azeotrope } \\
(5 \mathrm{~mL} / \text { Kaydry })-6 \text { Times }\end{array}$} \\
\hline Test & $\begin{array}{c}\text { Low } \\
\text { Variance } \\
\text { Slope }\end{array}$ & $\begin{array}{c}\text { Equivalent } \\
\text { Contamination } \\
\left(\mathrm{ng} / \mathrm{cm}^{2}\right)\end{array}$ & $\begin{array}{c}\text { Low } \\
\text { Variance } \\
\text { Slope }\end{array}$ & $\begin{array}{c}\text { Equivalent } \\
\text { Contamination } \\
\left(\mathrm{ng} / \mathrm{cm}^{2}\right)\end{array}$ \\
\hline 1 & 2720 & $<10($ Est. $<1)$ & 2508 & 10 \\
\hline 2 & 3103 & $<10($ Est. $<1)$ & 3019 & $<10($ Est. $<1)$ \\
\hline 3 & 2814 & $<10($ Est. $<1)$ & 2968 & $<10($ Est. $<1)$ \\
\hline 4 & 2185 & 109 & 2839 & $<10($ Est. $<1)$ \\
\hline 5 & 2576 & $<10($ Est. 5$)$ & 3059 & $<10($ Est. $<1)$ \\
\hline Avg. & $\mathbf{2 6 8 0}$ & $\mathbf{2 3}$ & $\mathbf{2 8 7 9}$ & $\mathbf{2}$ \\
\hline Std. Dev. & $\mathbf{3 3 7 . 0}$ & $\mathbf{4 8 . 0}$ & $\mathbf{2 2 3 . 1}$ & $\mathbf{4 . 6}$ \\
\hline \% CV & $\mathbf{1 2 . 6}$ & $\mathbf{2 0 9 . 2}$ & $\mathbf{7 . 8}$ & $\mathbf{2 2 3 . 6}$ \\
\hline
\end{tabular}

Est. $=$ Values estimated outside of calibration curve 
The samples that were cleaned by wiping three times with HFE-7100 saturated premoistened polyester wipers remained significantly contaminated. The average slope was 936 and the average contamination level was $1850 \mathrm{ng} / \mathrm{cm}^{2}$. All of the samples showed significant amounts of contamination, especially sample five. The samples cleaned by wiping three times with IPA had an average slope of 3046 and an average contamination level of $<1 \mathrm{ng} / \mathrm{cm}^{2}$. All of the samples were very clean. The samples cleaned by wiping six times with HFE-7100 (5 mL/Kaydry) yielded an average slope of 2752 and an average contamination level of $7 \mathrm{ng} / \mathrm{cm}^{2}$. All of the samples were very clean. Wiping three times with the HFE-7100/IPA azeotrope approached the equivalency of wiping three times with IPA and three times with HFE-7100. The average slope was 2680 and the average contamination value was $23 \mathrm{ng} / \mathrm{cm}^{2}$. Four of the five samples were extremely clean while one sample exhibited a little more contamination. Wiping six times with the HFE-7100/IPA azeotrope increased the average slope to 2879 and decreased the average contamination level to $2 \mathrm{ng} / \mathrm{cm}^{2}$. All of the samples were very clean. Both the HFE-7100 and the HFE-7100/IPA azeotrope appear to be able to clean the 304L stainless steel disks to similar levels as the IPA.

\section{Dust Sebum Emulsion on Passivated 304L Stainless Steel Disks}

The calibration of dust sebum emulsion on passivated 304L stainless steel disks is shown in Figure 16.
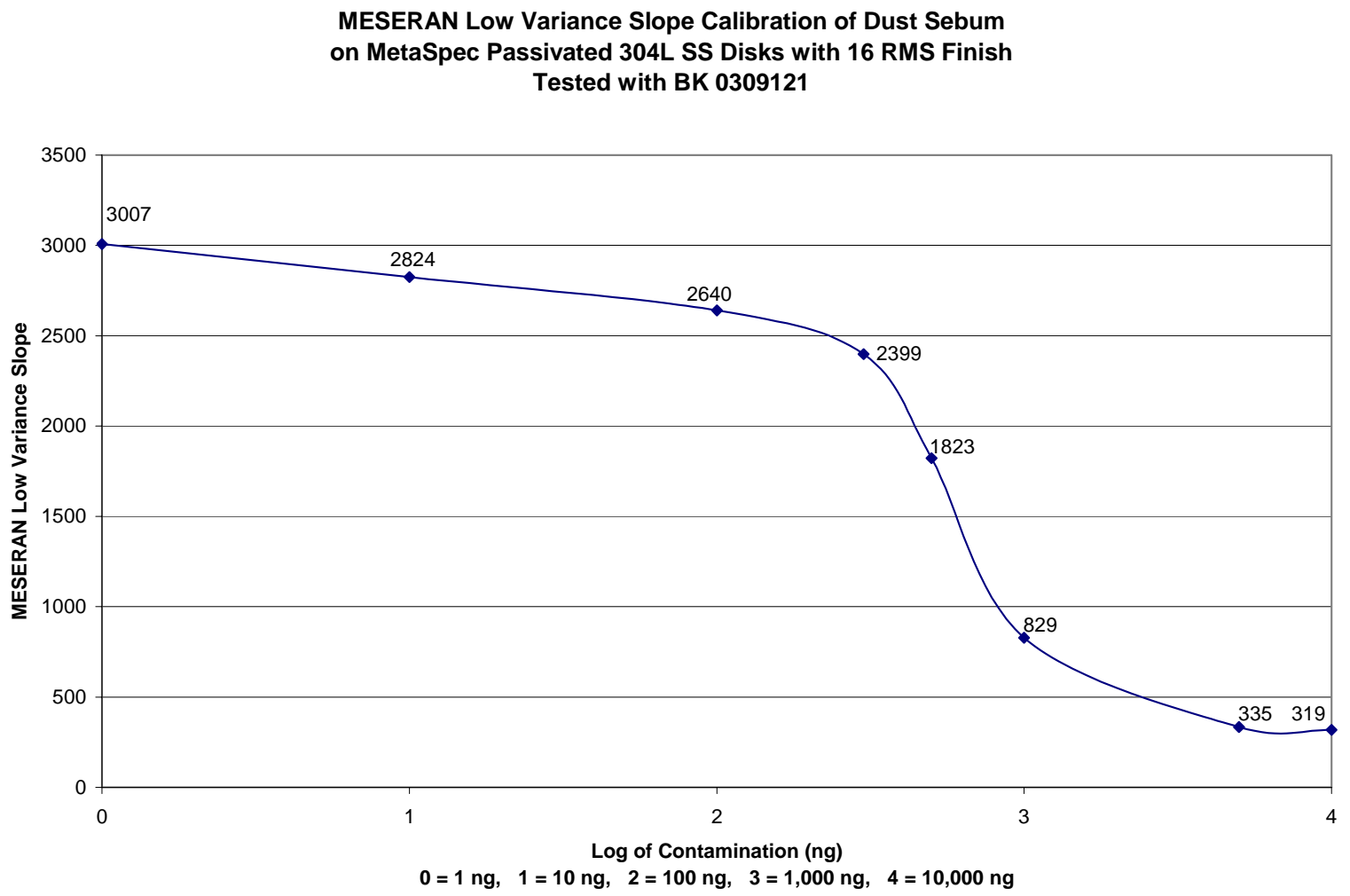

Figure 16. Calibration of Dust Sebum Emulsion on Passivated 304L Stainless Steel Disks 
The results of the cleaning evaluations performed to remove the dust sebum emulsion from passivated 304L stainless steel disks are shown in Table 13.

Table 13. MESERAN Results and Equivalent Contamination Amounts for Dust Sebum Emulsion on Passivated 304L Stainless Steel Disks

\begin{tabular}{|c|c|c|c|c|}
\hline & \multicolumn{2}{|c|}{$\begin{array}{c}\text { Cleaned by Wiping } \\
\text { With HFE-7100 } \\
\text { Tremoistened Polyester Wipers } \\
\text { 3 Times }\end{array}$} & \multicolumn{2}{c|}{$\begin{array}{c}\text { Cleaned by Wiping } \\
\text { with IPA } \\
\text { (5 mL/Kaydry) - 3 Times }\end{array}$} \\
\hline Test & $\begin{array}{c}\text { Low } \\
\text { Variance } \\
\text { Slope }\end{array}$ & $\begin{array}{c}\text { Equivalent } \\
\text { Contamination } \\
\left(\mathrm{ng} / \mathrm{cm}^{2}\right)\end{array}$ & $\begin{array}{c}\text { Low } \\
\text { Variance } \\
\text { Slope }\end{array}$ & $\begin{array}{c}\text { Equivalent } \\
\text { Contamination } \\
\left(\mathrm{ng} / \mathrm{cm}^{2}\right)\end{array}$ \\
\hline 1 & 1060 & 851 & 1741 & 529 \\
\hline 2 & 691 & 1568 & 3085 & $<1$ \\
\hline 3 & 604 & 2081 & 2448 & 240 \\
\hline 4 & 914 & 942 & 2588 & 127 \\
\hline 5 & 1775 & 517 & 2011 & 423 \\
\hline Avg. & $\mathbf{1 0 0 9}$ & $\mathbf{1 1 9 2}$ & $\mathbf{2 3 7 5}$ & $\mathbf{2 6 4}$ \\
\hline Std. Dev. & $\mathbf{4 6 4 . 6}$ & $\mathbf{6 2 5 . 7}$ & $\mathbf{5 2 1 . 8}$ & $\mathbf{2 1 4 . 5}$ \\
\hline \% CV & $\mathbf{4 6 . 1}$ & $\mathbf{5 2 . 5}$ & $\mathbf{2 2 . 0}$ & $\mathbf{8 1 . 2}$ \\
\hline
\end{tabular}

\begin{tabular}{|c|c|c|c|c|}
\hline & \multicolumn{2}{|c|}{$\begin{array}{c}\text { Cleaned by Wiping } \\
\text { With HFE-7100 } \\
(5 \mathrm{~mL} / \text { Kaydry }-6 \text { Times }\end{array}$} & $\begin{array}{c}\text { Cleaned by Wiping With } \\
\text { HFE-7100/IPA Azeotrope } \\
(5 \mathrm{~mL} / \text { Kaydry) - 3 Times }\end{array}$ \\
\hline Test & $\begin{array}{c}\text { Low } \\
\text { Variance } \\
\text { Slope } \\
\text { Contamination } \\
\left(\mathrm{ng} / \mathrm{cm}^{2}\right)\end{array}$ & $\begin{array}{c}\text { Low } \\
\text { Variance } \\
\text { Slope }\end{array}$ & $\begin{array}{c}\text { Equivalent } \\
\text { Contamination } \\
\left(\mathrm{ng} / \mathrm{cm}^{2}\right)\end{array}$ \\
\hline 1 & 2517 & 175 & 3707 & $<1$ \\
\hline 2 & 2798 & 14 & 2532 & 164 \\
\hline 3 & 2778 & 18 & 2954 & $<1$ \\
\hline 4 & 2851 & 7 & 3392 & $<1$ \\
\hline 5 & 2399 & 300 & 3283 & $\mathbf{3 3}$ \\
\hline Avg. & $\mathbf{2 6 6 9}$ & $\mathbf{1 0 3}$ & $\mathbf{3 1 7 4}$ & $\mathbf{7 3 . 1}$ \\
\hline Std. Dev. & $\mathbf{1 9 8 . 5}$ & $\mathbf{1 3 0 . 7}$ & $\mathbf{4 4 8 . 3}$ & $\mathbf{2 2 0 . 3}$ \\
\hline \% CV & $\mathbf{7 . 4}$ & $\mathbf{1 2 7 . 2}$ & $\mathbf{1 4 . 1}$ & \\
\hline
\end{tabular}


The samples that were cleaned by wiping three times with HFE-7100 saturated premoistened polyester wipers remained significantly contaminated. The average slope was 1009 and the average contamination level was $1192 \mathrm{ng} / \mathrm{cm}^{2}$. All of the samples showed significant amounts of contamination, especially samples two and three. The samples cleaned by wiping three times with IPA had an average slope of 2375 and an average contamination level of $264 \mathrm{ng} / \mathrm{cm}^{2}$. Only one of the samples was extremely clean. The samples cleaned by wiping six times with HFE7100 (5 mL/Kaydry) yielded an average slope of 2669 and an average contamination level of $103 \mathrm{ng} / \mathrm{cm}^{2}$. Three of the samples were very clean and the other two samples had more contamination. Wiping three times with the HFE-7100/IPA azeotrope yielded an average slope of 3174 and the average contamination value of $33 \mathrm{ng} / \mathrm{cm}^{2}$. Four of the five samples were extremely clean while one sample exhibited a little more contamination. Both the HFE-7100 (six wipes) and the HFE-7100/IPA azeotrope (three wipes) appear to be able to consistently clean the passivated 304L stainless steel disks to lower levels than the IPA.

\section{Dust Sebum Emulsion on 303 Stainless Steel Disks}

The calibration of dust sebum emulsion on 303 stainless steel disks is shown in Figure 17.
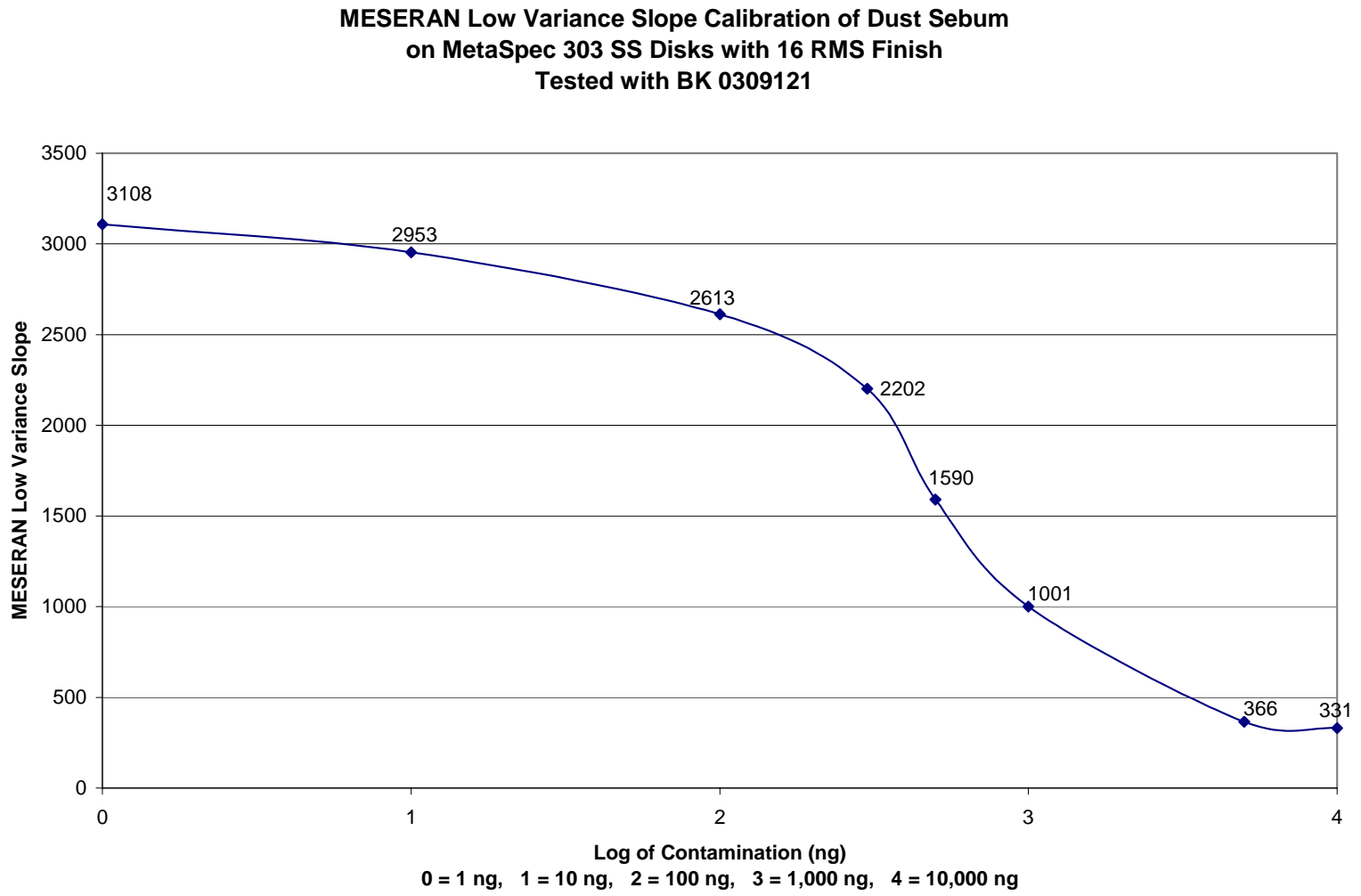

Figure 17. Calibration of Dust Sebum Emulsion on 303 Stainless Steel Disks 
The results of the cleaning evaluations performed to remove the dust sebum emulsion from 303 stainless steel disks are shown in Table 14.

Table 14. MESERAN Results and Equivalent Contamination Amounts for Dust Sebum Emulsion on 303 Stainless Steel Disks

\begin{tabular}{|c|c|c|c|c|}
\hline & \multicolumn{2}{|c|}{$\begin{array}{c}\text { Cleaned by Wiping } \\
\text { With HFE-7100 } \\
\text { Premoistened Polyester Wipers } \\
\text { 3 Times }\end{array}$} & \multicolumn{2}{c|}{$\begin{array}{c}\text { Cleaned by Wiping } \\
\text { with IPA } \\
\text { (5 mL/Kaydry) - 3 Times }\end{array}$} \\
\hline Test & $\begin{array}{c}\text { Low } \\
\text { Variance } \\
\text { Slope }\end{array}$ & $\begin{array}{c}\text { Equivalent } \\
\text { Contamination } \\
\left(\mathrm{ng} / \mathrm{cm}^{2}\right)\end{array}$ & $\begin{array}{c}\text { Low } \\
\text { Variance } \\
\text { Slope }\end{array}$ & $\begin{array}{c}\text { Equivalent } \\
\text { Contamination } \\
\left(\mathrm{ng} / \mathrm{cm}^{2}\right)\end{array}$ \\
\hline 1 & 483 & 3717 & 2856 & 19 \\
\hline 2 & 1886 & 391 & 2655 & 75 \\
\hline 3 & 642 & 2484 & 3033 & 3 \\
\hline 4 & 1691 & 460 & 3121 & $<1$ \\
\hline 5 & 768 & 1805 & 2881 & 16 \\
\hline Avg. & $\mathbf{1 0 9 4}$ & $\mathbf{1 7 7 1}$ & $\mathbf{2 9 0 9}$ & $\mathbf{2 3}$ \\
\hline Std. Dev. & $\mathbf{6 4 5 . 7}$ & $\mathbf{1 4 0 7 . 3}$ & $\mathbf{1 7 9 . 2}$ & $\mathbf{3 0 . 3}$ \\
\hline \% CV & $\mathbf{5 9 . 0}$ & $\mathbf{7 9 . 5}$ & $\mathbf{6 . 2}$ & $\mathbf{1 3 1 . 9}$ \\
\hline
\end{tabular}

\begin{tabular}{|c|c|c|c|c|}
\hline & \multicolumn{2}{|c|}{$\begin{array}{c}\text { Cleaned by Wiping } \\
\text { With HFE-7100 } \\
(5 \mathrm{~mL} / \text { Kaydry }-6 \text { Times }\end{array}$} & $\begin{array}{c}\text { Cleaned by Wiping With } \\
\text { HFE-7100/IPA Azeotrope } \\
(5 \mathrm{~mL} / \text { Kaydry) - 3 Times }\end{array}$ \\
\hline Test & $\begin{array}{c}\text { Low } \\
\text { Variance } \\
\text { Slope } \\
\text { Contamination } \\
\left(\mathrm{ng} / \mathrm{cm}^{2}\right)\end{array}$ & $\begin{array}{c}\text { Low } \\
\text { Variance } \\
\text { Slope }\end{array}$ & $\begin{array}{c}\text { Equivalent } \\
\text { Contamination } \\
\left(\mathrm{ng} / \mathrm{cm}^{2}\right)\end{array}$ \\
\hline 1 & 2323 & 217 & 2605 & 102 \\
\hline 2 & 2652 & 77 & 2924 & 12 \\
\hline 3 & 2581 & 109 & 3071 & 2 \\
\hline 4 & 2484 & 141 & 3262 & 111 \\
\hline 5 & 2604 & 102 & 2575 & $\mathbf{4 5}$ \\
\hline Avg. & $\mathbf{2 5 2 9}$ & $\mathbf{1 2 9}$ & $\mathbf{2 8 8 7}$ & $\mathbf{5 6 . 0}$ \\
\hline Std. Dev. & $\mathbf{1 3 0 . 3}$ & $\mathbf{5 4 . 2}$ & $\mathbf{2 9 6 . 9}$ & $\mathbf{1 2 3 . 5}$ \\
\hline \% CV & $\mathbf{5 . 2}$ & $\mathbf{4 1 . 9}$ & $\mathbf{1 0 . 3}$ & \\
\hline
\end{tabular}

The samples that were cleaned by wiping three times with HFE-7100 saturated premoistened polyester wipers remained significantly contaminated. The average slope was 1094 and the average contamination level was $1771 \mathrm{ng} / \mathrm{cm}^{2}$. Three of the five samples showed significant amounts of contamination. The samples cleaned by wiping three times with IPA had an average slope of 2909 and an average contamination level of $23 \mathrm{ng} / \mathrm{cm}^{2}$. Four of the five samples were 
very clean. The samples cleaned by wiping six times with HFE-7100 (5 mL/Kaydry) yielded an average slope of 2529 and an average contamination level of $129 \mathrm{ng} / \mathrm{cm}^{2}$. These samples visually appeared to have islands of contamination present. It is speculated that the majority of the visual contamination was inorganic material (dust) from the dust sebum emulsion (i.e., MESERAN testing only detects organic contamination - this would explain why the slopes are relatively high even though visual contamination is present). Wiping three times with the HFE7100/IPA azeotrope yielded an average slope of 2887 and the average contamination value of 45 $\mathrm{ng} / \mathrm{cm}^{2}$. Three of the five samples were extremely clean while the other two samples exhibited a little more contamination. All of the samples cleaned with the HFE-7100/IPA azeotrope appeared to be visually clean. The HFE-7100/IPA azeotrope approaches the cleanliness achieved with the IPA.

\section{Dust Sebum Emulsion Conclusions}

A graphical representation of the MESERAN slope data for all of the dust sebum emulsion evaluations for each substrate is shown in Figure 18. A graphical representation of the equivalent contamination amounts determined by MESERAN Analysis for all of the dust sebum emulsion cleaning evaluations for each substrate is shown in Figure 19.

Dust Sebum Emulsion Cleaning Evaluations MESERAN Slopes

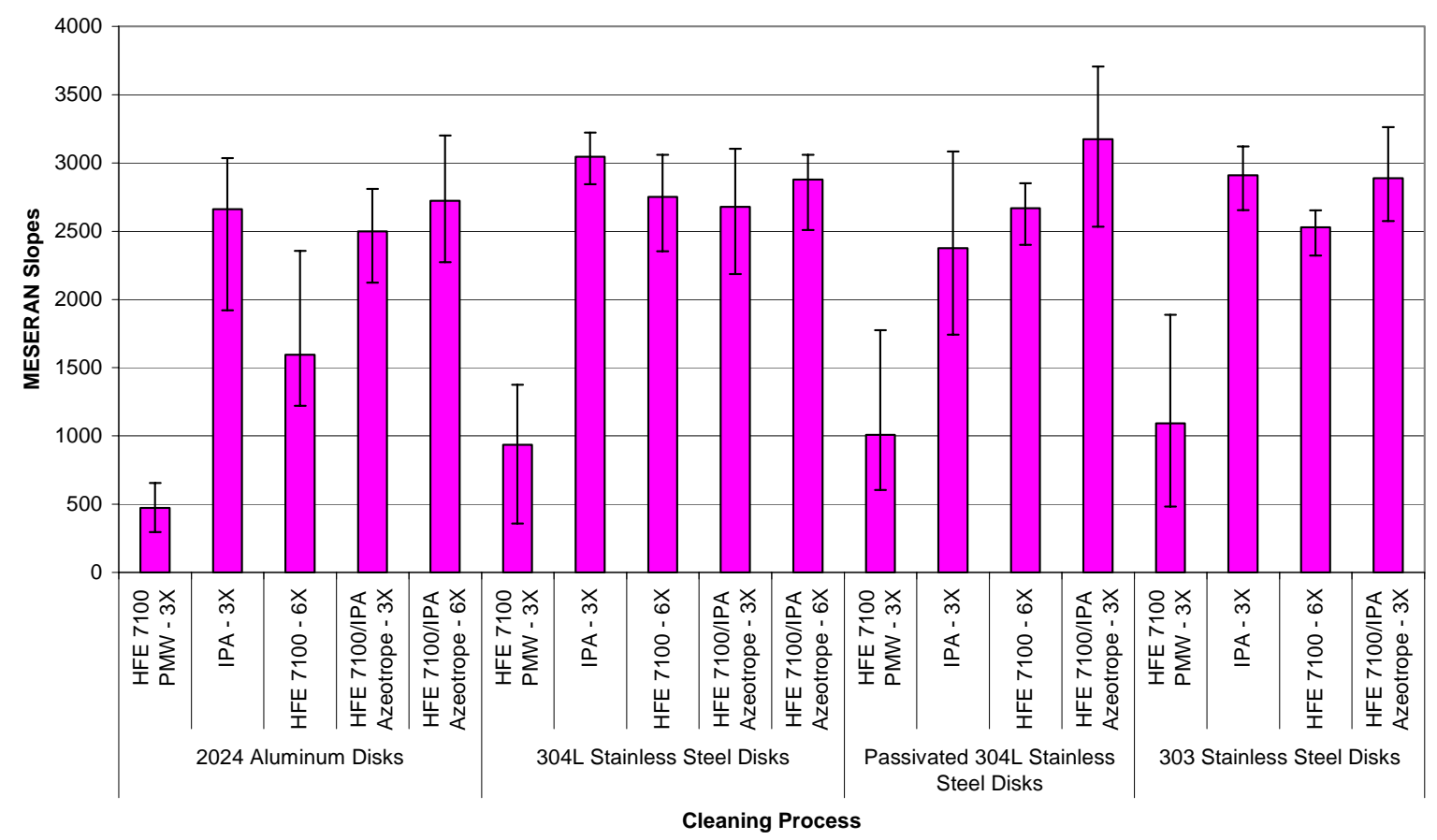

Figure 18. MESERAN Slope Data for Dust Sebum Emulsion Cleaning Evaluations 
Dust Sebum Emulsion Cleaning Evaluations

Equivalent Contamination Amounts Determined by MESERAN Analysis

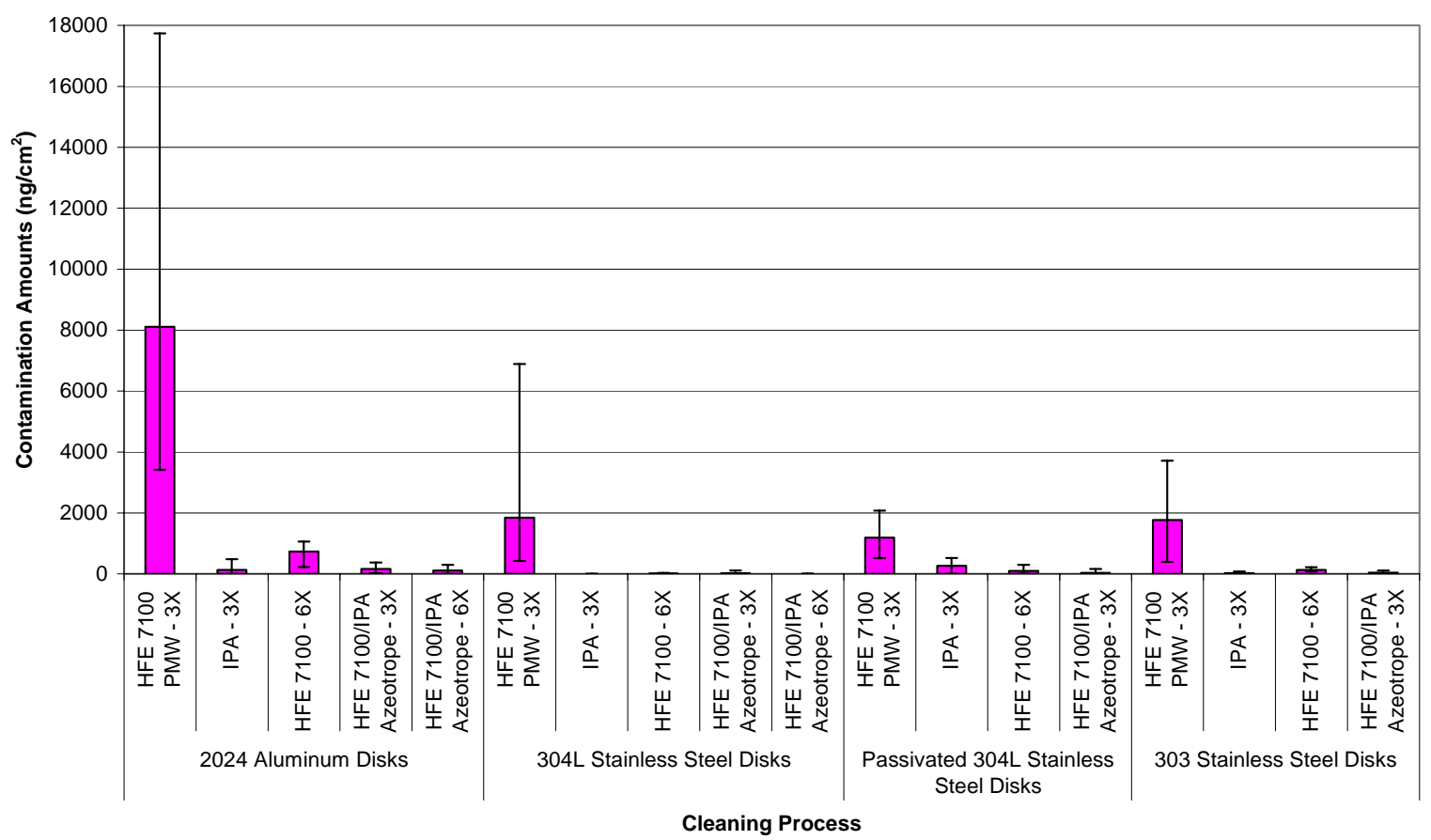

Figure 19. Equivalent Contamination Amounts Determined by MESERAN Analysis for Dust Sebum Emulsion Cleaning Evaluations

Regardless of the substrate, wiping six times with HFE-7100/IPA azeotrope approaches the same cleanliness achieved with wiping three times with IPA. For some substrates, wiping three times with HFE-7100/IPA azeotrope is roughly equivalent to wiping three times with IPA. For some substrates, wiping six times with HFE-7100 approaches the same cleanliness achieved with wiping three times with IPA. Wiping six times with HFE-7100/IPA azeotrope is more effective than wiping six times with HFE-7100.

\section{Conclusions}

For the two alternative solvents evaluated, the HFE-7100/IPA azeotrope is much more effective than HFE-7100 for removing the three contaminants from the four substrates evaluated.

MESERAN data indicates that the HFE-7100/IPA azeotrope was able to remove all three of the contaminants from all of the substrates to a level below $1 \mu \mathrm{g} / \mathrm{cm}^{2}$ (the cleanliness level called out by most aerospace companies for metal cleaning operations). In some cases, the HFE-7100/IPA azeotrope was even able to remove the contaminants below $100 \mathrm{ng} / \mathrm{cm}^{2}$ (the cleanliness level LLNL calls out for some of their NIF cleaning operations). However, no defined cleanliness levels are called out for the product being wipe cleaned at BWXT Pantex Plant. Therefore, these evaluations centered on determining if either HFE-7100 or HFE-7100/IPA azeotrope could clean as well as or better than the baseline solvent (IPA). 
Generally, for Krytox 240-AD and dust sebum emulsion, wiping six times with HFE-7100/IPA azeotrope approached the same cleanliness achieved with wiping three times with IPA. For some substrates, wiping three times with HFE-7100/IPA azeotrope was roughly equivalent to wiping three times with IPA. However, for other substrates, wiping six times was necessary.

For Krytox 240-AD, three wipes with HFE-7100/IPA azeotrope was equivalent to three wipes with IPA.

For dust sebum emulsion, wiping six times with HFE-7100/IPA azeotrope approaches the same cleanliness achieved with wiping three times with IPA.

IPA is the most effective solvent evaluated for removing DC-4 silicone. In initial evaluations, wiping six times with HFE-7100 approaches the same cleanliness achieved with wiping three times with IPA; however, the results could not be repeated when the HFE-7100 evaluations were performed again. The HFE-7100/IPA azeotrope was not as effective as IPA even when six wipes were used.

DC-4 silicone was the hardest contaminant for the HFE-7100/IPA azeotrope to remove. Wiping six times with HFE-7100/IPA azeotrope did not remove the DC-4 silicone as well as IPA. Wiping six times with HFE-7100/IPA azeotrope was able to clean the DC-4 silicone from all of the substrates to a level below $1 \mu \mathrm{g} / \mathrm{cm}^{2}$. However, it was unable to clean it to submonolayer levels. It must be determined whether the cleanliness level achieved is good enough or if additional wipes are necessary.

HFE-7100 Premoistened Wipers were not effective in removing contamination. In addition, they appeared to leave large amounts of contamination on the samples. Either the HFE-7100 in the premoistened wipers is not very clean or the HFE-7100 is extracting something from the wipers or the bags they are stored in.

Wipe cleaning is an operator-dependent process and can lead to variability in cleaning results. Even when the same operator cleans all of the samples, significant variability will exist. Generally, wipe cleaning is good for removing gross amounts of contamination, but will not consistently remove low levels of contamination unless the contaminants being cleaned are soluble in the solvent used for wiping.

\section{Acknowledgements}

The author greatly appreciates the assistance of Eddie Lopez, SNL/NM; Jan Birkbeck, BWXT Pantex Plant; and Chad Woodburn, Tom Hand, and George Bohnert, KCP, for their support in completing this work. 


\section{References}

1. National Nuclear Security Administration Supplemental Directive 452.2B, Change 1, 3/22/02, Safety of Nuclear Explosive Operations, Albuquerque General Nuclear Explosive Safety Rule \#5, Section 4.2.e(2).(f). $\underline{5}$

2. HFE-7100 Hydrofluoroether, Product Information Sheet \# 98-0212-2430-2, October, 2000, 3M Specialty Materials, 3M Center, St. Paul, MN 55144-1000.

3. HFE-71IPA Hydrofluoroether Azeotrope, Product Information Sheet \# 98-0212-2549-9, September, 2001, 3M Specialty Materials, 3M Center, St. Paul, MN 55144-1000.

4. Krytox 240 Series, DuPont Performance Lubricants, Deep Water, NJ, 08023.

5. DC-4 Electrical Insulating Compound, Dow Corning Corporation, Midland, MI, 486860994.

6. Dust sebum emulsion, Scientific Services S/D Inc., 42 Main Street, P. O. Box 778, Sparrow Bush, N.Y., 12780.

7. J. L. Anderson, “Quantitative Detection of Surface Contaminants,” Journal of the American Association of Contamination Control, II, 6:9, (1963).

8. J. L. Anderson, et. al. "Measurement and Evaluation of Surfaces and Surface Phenomena by Evaporative Rate Analyses,” Journal of Paint Technology, Vol. 40, No. 523, 320-327, (August, 1968).

9. J. L. Anderson, “Evaporative Rate Analysis: Its First Decade.” A chapter in Characterization of Metal and Polymer Surfaces. L. H. Lee, Editor, 2, Academic Press, Inc., New York, 409-427, (1977). This paper summarizes all known references prior to 1975.

10. L. C. Jackson, "Solubility Parameters and Evaporative Rate Analyses in Organic Residue Characterization,” (Topical Report), UNCLASSIFIED, Bendix-Kansas City Division: BDX-613-1099, March 1974. (Available from NTIS)

11. L. C. Jackson, "Contaminant Removal Based on Solubility Parameter and Evaporative Rate Analysis Technologies,” (Topical Report), UNCLASSIFIED, Bendix-Kansas City Division: BDX-613-1128, August 1974. (Available from NTIS)

12. L. C. Jackson, “How to Select a Substrate Cleaning Solvent,” Adhesives Age, 22-31, (December, 1974).

13. L. C. Jackson, "Solvent Cleaning Process Efficiency,” Adhesives Age, 19, 31-34, (July, 1976).

14. L. C. Jackson, “Removal of Silicone Grease and Oil Contaminants,” Adhesives Age, $\underline{28}$ (4), 29-32, (1977).

15. L. C. Jackson, “Contaminant Cleaning for Critical Electrical Assembly Areas,” (Final Report), UNCLASSIFIED, Bendix-Kansas City Division: BDX-613-1695, February 1978. (Available from NTIS)

16. M. G. Benkovich, “Solvent Substitution for Electronic Products,” International Journal of Environmentally Conscious Manufacturing, 1, No. 1, 27-32 (1992).

17. M. G. Benkovich and J. L. Anderson, "Measurement of Organic Residues on Surfaces to a Low Fraction of a Monolayer,” Precision Cleaning, 16-28, (May 1996). This paper includes many of the more current references to MESERAN technology.

18. M. G. Benkovich and J. L. Anderson, "Quantification of MicroOrganic Residues to Low Nanogram Levels,” Precision Cleaning '96 Proceedings, 115-122, (1996). 
19. J. L. Anderson, R. F. Russell, and M. G. Benkovich, "Quantitative Measurement of Extremely Low Levels of Non-Volatile Residues (NVR) on Surfaces and in Liquids," Precision Cleaning '97 Proceedings, 96-108, (1997).

20. J. L. Anderson, R. F. Russell, and M. G. Benkovich, "Solvent NVR: A Problem and a Solution,” CleanTech '98 Proceedings, 331-340, (1998).

21. M. G. Benkovich and J. L. Anderson, "A New Method Using MESERAN Technique for Measuring Surface Contamination After Solvent Extraction,” Surface Contamination and Cleaning, K. L. Mittal, Editor, 1, VSP BV, The Netherlands, 47-73, (2003).

22. MESERAN Analyzer Literature, ERA Systems Inc., The MESERAN Company, Chattanooga, TN.

23. IEST-STD-CC1246D Product Cleanliness Levels and Contamination Control Program, Institute of Environmental Sciences and Technology, (2002). 


\section{Appendix}

Detailed Information on MESERAN Analysis for Organic Contamination Detection 


\section{Appendix \\ Detailed Information on MESERAN Analysis for Organic Contamination Detection}

\section{Background}

The principle of the MESERAN technique was discovered by John L. Anderson, President of ERA Systems, Inc., The MESERAN Company, in 1960. This analytical technique is used in a number of industrial and governmental facilities (within the United States and abroad) for research and development purposes as well as for quality and production control. The characterization of the surface being analyzed is carried out by depositing a chemical detector onto the test surface and observing the rate at which the chemical detector disappears from the surface. The MESERAN technique is routinely used for quantifying organic contamination on surfaces and the crosslink density (or degree of cure) in polymers. In addition, the MESERAN technique can be used for quantifying chemically active sites on surfaces.

The Kansas City Plant (KCP) has been using MESERAN Analyzers for approximately 30 years to detect and quantify organic contamination on parts and evaluate various cleaning processes for removing organic contamination. KCP has used MESERAN Analyzers extensively to evaluate the ability of alternate solvents and processes for removing specific organic contaminants to eliminate the use of chlorinated and fluorinated solvents.

\section{Principle of MESERAN Technique}

The standard microcomputer-based MESERAN technology involves deposition, using a "clean" precision microsyringe, onto a flat or concave surface of $18 \mu \mathrm{L}$ of a test solution consisting of a low boiling solvent or solvent combination (for these evaluations - cyclopentane) and a highboiling-but-volatile Carbon-14 labeled compound (in a ratio of approximately 60,000:1). Figure 1 shows the application of test solution. For example, the amount of tridecane-C14 radiochemical per single test $(<0.06 \mu \mathrm{Ci})$ corresponds to approximately $6 \mathrm{E} 14\left(6 \times 10^{14}\right)$ molecules which equates to one nanomole, the equivalent of approximately one molecular layer over one square centimeter. Metered air or nitrogen gas is permitted to flow across the surface and between the surface and a Geiger Müller detector positioned directly above the surface. The evaporation of the low boiling solvent and then the radiochemical is observed as a function of time by recording the detected emissions per second arising from the radiochemical molecules remaining on, or retained by, the surface--the vapor-phase, already-evaporated molecules having been swept out from under the detector by the metered gas (see Figure 2) 


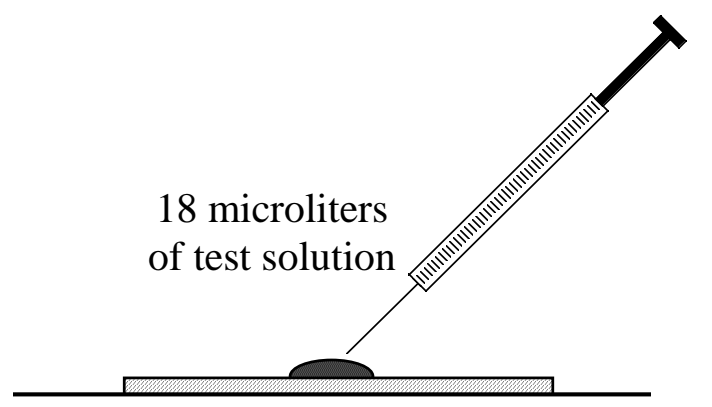

Figure 1. Application of Test Solution
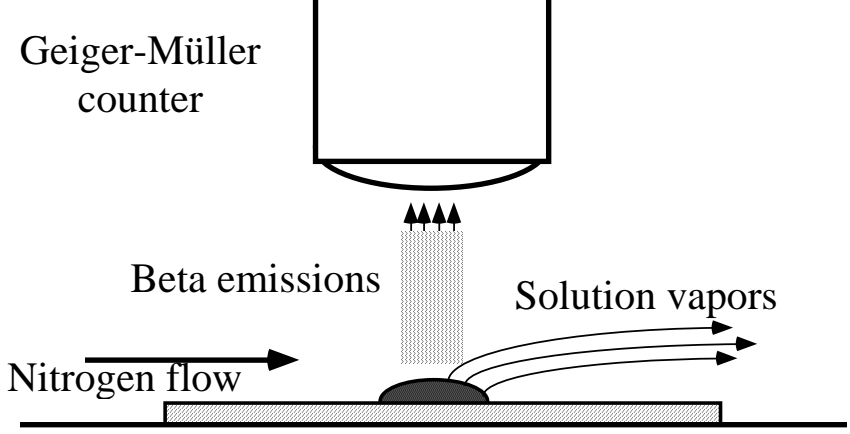

Figure 2. Measurement of Emissions

Each test takes less than 3 minutes and the amount of radiochemical employed is EXEMPT from U S Nuclear Regulatory Commission and/or 'Agreement State' licensing regulations due to the very low level of C-14 involved.

For the measurement of microorganic residues, the MESERAN method may be used:

(1) Directly on a flat or concave surface and any microorganic residue thereon which is chemically compatible with the particular radiochemical employed, or

(2) Indirectly using an extracting solvent followed by depositing and evaporating an aliquot amount onto a "clean" reference surface. Subsequent deposition and evaporation of the radiochemical solution permits measurement of the amount of deposited residue by comparing the results with previously obtained standards similarly deposited from volumetric dilutions.

For non-polar and/or hydrocarbon type residues, tridecane-C14 in cyclopentane (designated BK) is employed. For more polar residues, tetrabromoethane-C14 in cyclopentane (designated AK) is used. In order to provide a high number of detected emissions for the minimal amount of radiochemical deposited, the tridecane-C14 has a specific activity of approximately 57 $\mu \mathrm{Ci} / \mu$ mole (one tridecane atom is essentially pure C14 isotope) while the tetrabromoethane has both carbon atoms labeled (approximately $114 \mu \mathrm{Ci} / \mu$ mole). Approximately $200 \mathrm{ng}$ of radiochemical are deposited in each test with similar levels of radioactivity.

The MESERAN method assumes that the particular radiochemical employed is chemically compatible with the residue, that the test solution droplet covers all of the residue, and that the test solution solvent substantially dissolves the residue within the time period of the solvent evaporation. Attention to the avoidance of inadvertent contamination and the maintenance of reasonably constant temperature and pressure are required for optimal reproducibility from test to test. 


\section{Mechanism of the MESERAN Technique for Quantifying Organic Residues}

When a homogeneous chemical is permitted to evaporate, the classical mechanism of the process (normally measured by monitoring the already evaporated portion) follows first order kinetics, i.e., the plot of log concentration vs. time is a straight line. This mechanism applies to pure materials as well as to solutions of chemicals in which the components are chemically compatible and in which the second component is non-volatile under the conditions of the process. In the presence of the second component, the rate of evaporation is slowed.

In the MESERAN technology, however, the amount of radiochemical retained by the surface as a function of time is measured by counting the emissions arising from the radiochemical molecules remaining on the surface. In this discussion, the temperature and pressure are assumed constant and the concentration of already evaporated molecules in the adjacent gaseous phase approaches zero due to the flowing air or nitrogen referred to above. The molecular weight of each evaporating molecule and the intermolecular forces among the near-neighbor molecules are thus the primary factors in determining the tendency of each molecule to remain in solution or conversely to escape from the liquid portion of the air/liquid (or semisolid) interface. In the MESERAN technology, which employs only a monolayer equivalent of the radiochemical, the observed rate of evaporation is thus a function of the residual concentration of the nonevaporated molecules of the Carbon-14 radiochemical. Figure 3 illustrates the typical evaporation of the radiochemical solution from a clean surface. The A-B line represents the evaporation of the low boiling solvent (e.g., cyclopentane). The rationale for the initial increase in counts/second is that the C-14 soft beta emissions are partially absorbed by the solvent molecules. B represents the point at which substantially all of the low boiling solvent has evaporated and the maximal amount of residual radiation reaches the GM detector. The B-C line represents the evaporation of the radiochemical from the surface under the conditions of the test. $\mathrm{C}$ represents a level where the GM detector can no longer adequately differentiate the residual radiation from background.

A solution of the high-boiling-but-volatile tridecane-C14 in higher boiling hydrocarbons (i.e., contamination) follows a similar but slower path than does the evaporation of the labeled tridecane itself since the non-volatile "residue" molecules occupy increasing portions of the liquid (or semi-solid) interface. The rate at which the solvent evaporates is slowed somewhat and the rate at which the radiochemical evaporates is slowed considerably with the observed rate of evaporation being a function of the amount of residue on the surface. The observed rate of evaporation of the radiochemical (the slope expressed as a positive integer) thus is an inverse measure of the amount of non-evaporating residue. The lower the slope, the more the residue and vice versa. Figure 4 illustrates typical evaporations of the radiochemical solution with increasing amounts of residue. ABC is repeated from Figure 3 and illustrates a typical evaporation of the radiochemical solution with no interactions from residue (i.e., a clean substrate). $A * B * C *$ illustrates a typical evaporation of the radiochemical solution with some contamination present. $\mathrm{A}^{* *} \mathrm{~B}^{* *} \mathrm{C} * *$ illustrates a typical evaporation of the radiochemical solution with a larger amount of contamination present. 


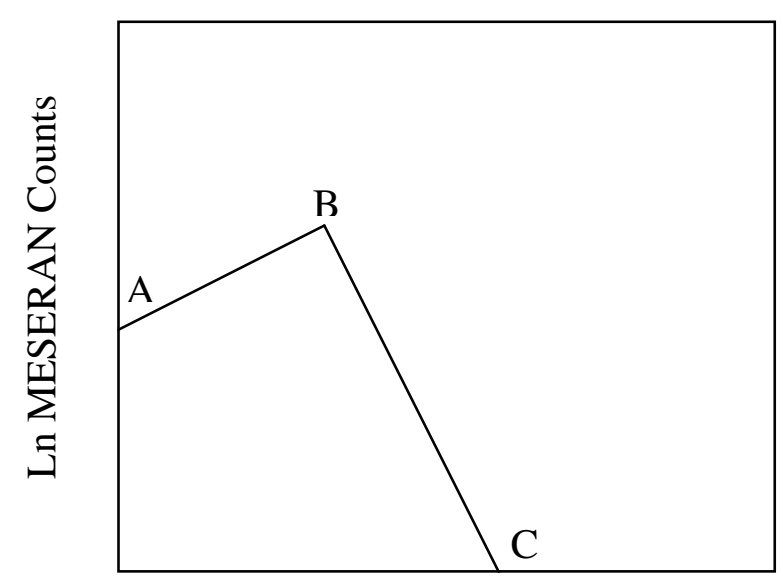

Time (sec)

Figure 3. Typical Evaporation of Radiochemical Solution from a Clean Surface

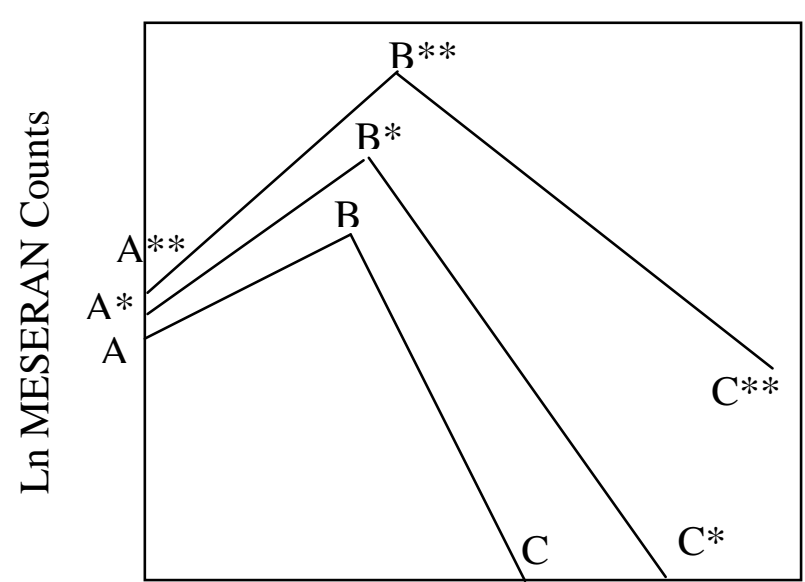

Time (sec)

Figure 4. Typical Evaporations of Radiochemical Solution with Increasing Amounts of Residue

\section{Methods of Analyzing MESERAN Data}

\section{Historical Method (Total Counts)}

Historically, KCP only used the Total Counts method of analysis for analyzing MESERAN data. This involved summing the radioactive counts detected by the GM detector for a period of 112 seconds. The Total Counts method has been used for approximately 30 years at KCP by testing a surface with the MESERAN Analyzer and comparing the results to those obtained from known clean standards for that particular surface. The total counts of the clean standard are subtracted from the total counts obtained on the surface being tested to give a net total counts representing the contamination amount. Lower total counts represent low levels of organic residue and high total counts represent high levels of organic contamination. This result can be compared to previously performed calibrations of contamination to obtain a quantitative result for the contamination amount.

In many cases, quantitative contamination data are not needed. For instance, if one is performing process control work to determine if the cleaning process is performing as designed, quantitative data on the actual amount of contamination may not be necessary. Often times, as long as the parts being cleaned are less than a certain level of contamination, they are clean enough. Therefore, one only has to establish the MESERAN total counts that correspond to that level of contamination and relate the tests as being in compliance or not. KCP has used this technique for years to control cleanliness and compare the abilities of different cleaners and cleaning processes to remove various contaminants. KCP related net total counts MESERAN data to electrical and catastrophic adhesive failures. They noted that electrical failures on products occurred when the net total counts exceeded 100 and adhesive failures occurred when net total counts exceeded 200. As long as the MESERAN net total counts were below these levels, no cleaning related failures occurred. 
The 112 second test time period was used because the original MESERAN units in the 1960s and 1970s operated by recording counts in 14 second increments and KCP used to total of eight of the 14 second increments for their test time. These units also only recorded every $8^{\text {th }}$ count that was detected due to the counting mechanism used at the time. When microcomputers became available in the 1980s, automatic MESERAN units were manufactured and equipped with computer interfaces. These units recorded counts every $1 / 2$ second and the test time could be set to any length desired; however, to make everything equivalent to historical data, the program was written for KCP to base the calculations on 112 seconds with only every $8^{\text {th }}$ count reported.

\section{Newly Developed Method (Slope of Radiochemical Evaporation)}

A new Slope Method of analyzing the MESERAN data has recently been developed and improved. The Slope Method is the slope of the evaporation of radiochemical (the post-peak portion of the curve shown in Figure 3 as the B-C line). Even though this method of analysis was known as a viable method since the 1960s and 1970s, it was not a practical method to use until microcomputers became widely available so the data could be manipulated easily. Some initial slope calculations were available with the automatic MESERAN units in the mid-to-late 1980s and early 1990s; however, KCP found them of limited use at the time. This project further developed the slope technology to its current state.

Based upon raw data minus background, Figure 5 illustrates three typical experimentally derived curves of natural logarithm (Ln or ln) counts per second minus background vs. time in seconds. Figure 5 is similar to Figure 4 except raw data from actual tests are shown.

In Figure 5, the upper curve represents a high level of organic residue, the middle curve represents a medium level of organic residue, and the lower curve represents a low level of organic residue. The scatter, particularly at the lower values, is due to the inherent randomness of radiation (the Poisson distribution in which the square root of each count total is the best estimate of one standard deviation). In an effort to reduce the effect of the randomness of radiation, the data (ln (counts - background) are "smoothed" from six seconds through 115 seconds (for 120 second length tests) and replotted. The smoothing is accomplished by summing the ln (counts - background) at the sixth second with the previous five seconds and the subsequent five seconds and dividing this number by 10. A divisor of 10 is used instead of 11 because it is statistically sound to take the number of items being smoothed and subtract one from it because a degree of freedom is lost. This process is carried out through the $115^{\text {th }}$ second and the subsequent data are replotted as smoothed (ln (counts - background)) versus time. Figure 6 represents the same data as in Figure 5 except that the data in Figure 6 are logarithmically smoothed to increase the reliability of the individual points. The plotted smoothed curve is then analyzed via linear regression to determine the slope of the post-peak line (down to near background) which best fits the data representing the evaporative process. The determined slope is multiplied by $-10,000$ to convert it to a positive integer; this becomes the reported MESERAN slope value with units of smoothed (ln (counts - background))/sec $\mathrm{x}(-10,0000)$. 


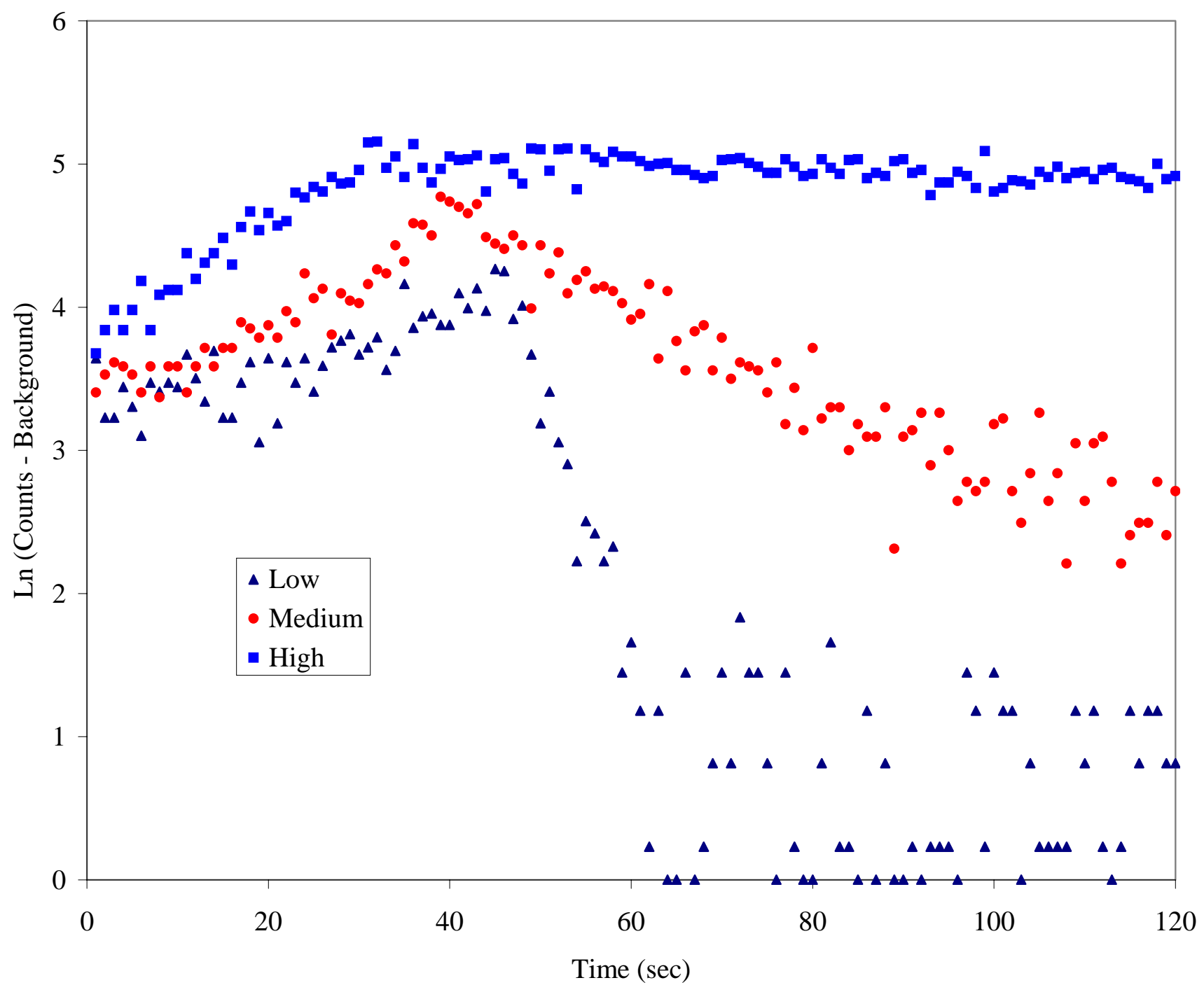

Figure 5. Plot of Raw Data Showing Low, Medium, and High Levels of Organic Contamination

\section{Comparison of Methods}

The Slope Method is more sensitive than the Total Counts Method, especially at low levels of contamination. For measuring microorganic residues, the Total Counts Method of analysis (i.e., the area under each overall curve based on actual counts) is valid from somewhat less than $200 \mathrm{ng}$ to approximately $100,000 \mathrm{ng}(100 \mu \mathrm{g})$. Higher total counts are indicative of higher organic residue levels and vice versa. The Slope Method of data analysis, normally based on statistically smoothed data and based on the log count vs. time relationship, increases the sensitivity of the lower limit markedly (to less than $1 \mathrm{ng}$ ) since the total counts method (the total area under each curve) approaches statistical insignificance somewhat below 200 ng. Expressed as a positive integer, the higher (or steeper) the slope, the cleaner the surface and conversely, the lower (or more flat) the slope, the higher the residue. 


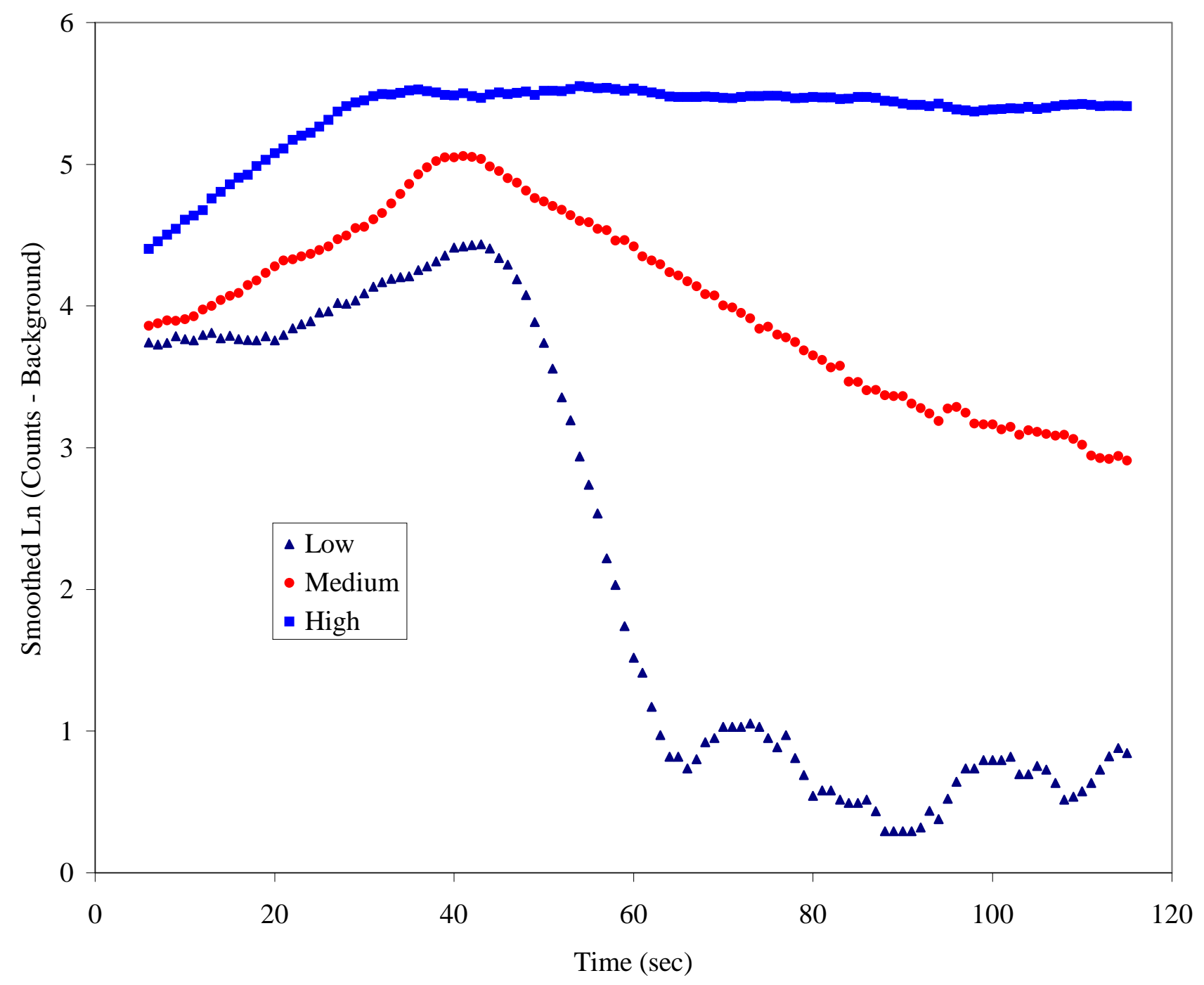

Figure 6. Logarithm Plot of Smoothed Data Showing Low, Medium, and High Levels of Organic Contamination

Both the Total Counts and Slope Methods of analysis can be used qualitatively or quantitatively. Qualitative measurements can be made by comparing the results obtained on the surface being tested to the results obtained from known clean standards for that particular surface.

Quantitative measurements can be made by comparing the data to previously performed calibrations of contamination to obtain a result for the contamination amount. 


\section{Formulation of Calibration Solutions}

Calibrations of various contaminants (oils, greases, mold releases, rosin fluxes, etc) typically encountered in KCP production operations have been performed to develop calibration curves for these contaminants on substrates of interest. MESERAN total counts and slope results obtained can now be compared to the calibration curves to determine quantitative amounts of contamination detected.

The volumetric dilution process for making calibration solutions is shown in Figure 7.

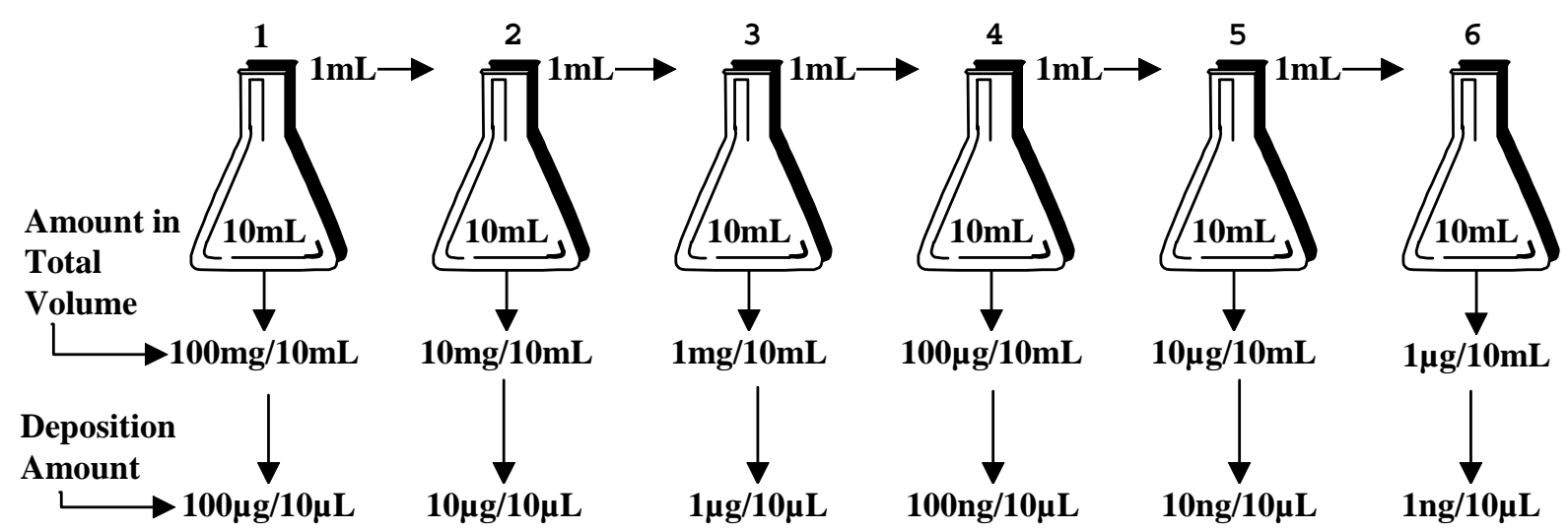

Figure 7. Calibration Solution Formulation

Volumetric dilutions were used to make contamination solutions for depositing known amounts of the organic contaminant on reference substrates (e.g., aluminum panels, stainless steel disks, glass cones, etc.). These calibrations were performed in the following manner. A master calibration solution was prepared in a 10-mL volumetric flask by dissolving $100 \mathrm{mg}$ of the organic contaminant in $10 \mathrm{~mL}$ of solvent (e.g., cyclopentane, methylene chloride, or hexane that has been double distilled in an all-glass still with no grease in the joints - NVOR of these solvents are approximately $10 \mathrm{ppb}$ ). The master calibration solution was thoroughly mixed and $1 \mathrm{~mL}$ of this solution was placed in another $10-\mathrm{mL}$ volumetric flask. The second volumetric flask was then diluted with the double distilled solvent until the solution level was at $10 \mathrm{~mL}$ and this solution was thoroughly mixed. Subsequent dilutions were carried out in a similar fashion. Ten microliters $(\mu \mathrm{L})$ of each calibration solution were deposited on the precleaned substrates and allowed to evaporate. This resulted in the following amounts of contamination on the substrates: $1 \mathrm{ng}, 10 \mathrm{ng}, 100 \mathrm{ng}, 1 \mu \mathrm{g}, 10 \mu \mathrm{g}$, and $100 \mu \mathrm{g}$. In some cases, intermediate levels were obtained by depositing $3 \mu \mathrm{L}$ and $5 \mu \mathrm{L}$ of the calibration solutions. 